\title{
A Design Guide and Specification for Small Explosive Containment Structures
}

\author{
Kirk A. Marchand \\ P. A. Cox \\ Michael A. Polcyn \\ Southwest Research Institute \\ P.O. Drawer 28510 \\ San Antonio, Texas 78228-0510 \\ Sandia Contract AG-8266
}

\begin{abstract}
The design of structural containments for testing small explosive devices requires the designer to consider the various aspects of the explosive loading, i.e., shock and gas or quasistatic pressure. Additionally, if the explosive charge has the potential of producing damaging fragments, provisions must be made to arrest the fragments. This may require that the explosive be packed in a fragment attenuating material, which also will affect the loads predicted for containment response. Material also may be added just to attenuate shock, in the absence of fragments.

Three charge weights are used in the design. The actual charge is used to determine a design fragment. Blast loads are determined for a "design charge," defined as $125 \%$ of the operational charge in the explosive device. No yielding is permitted at the design charge weight. Blast loads are also determined for an over-charge, defined as $200 \%$ of the operational charge in the explosive device. Yielding, but no failure, is permitted at this over-charge.

This guide emphasizes the calculation of loads and fragments for which the containment must be designed. The designer has the option of using simplified or complex design-analysis methods. Examples in the guide use readily available single degree-of -freedom (sdof) methods, plus static methods for equivalent dynamic loads. These are the common methods for blast resistant design. Some discussion of more complex methods is included. Generally, the designer who chooses more complex methods must be fully knowledgeable in their use and limitations. Finally, newly fabricated containments initially must be proof tested to $125 \%$ of the operational load and then inspected at regular intervals. This specification provides guidance for design, proof testing, and inspection of small explosive containment structures.
\end{abstract}





\section{DISCLAIMER}

This report was prepared as an account of work sponsored by an agency of the United States Government. Neither the United States Government nor any agency thereof, nor any of their employees, make any warranty, express or implied, or assumes any legal liability or responsibility for the accuracy, completeness, or usefulness of any information, apparatus, product, or process disciosed, or represents that its use would not infringe privately owned rights. Reference herein to any specific commercial product, process, or service by trade name, trademark, manufacturer, or otherwise does not necessarily constitute or imply its endorsement, recommendation, or favoring by the United States Government or any agency thereof. The views and opinions of authors expressed herein do not necessarily state or reflect those of the United States Government or any agency thereof. 


\section{DISCLAIMER}

\section{Portions of this document may be illegible in electronic image products. Images are produced from the best available original document.}




\section{Contents}

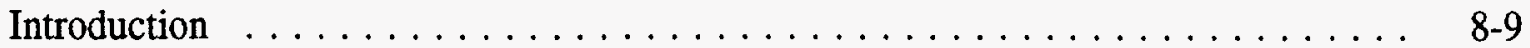

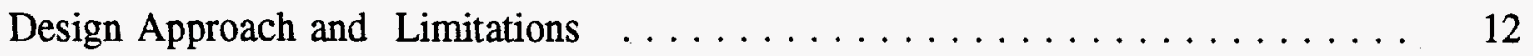

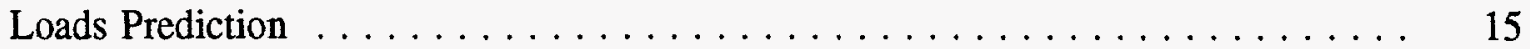

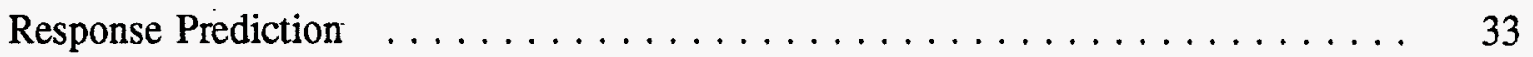

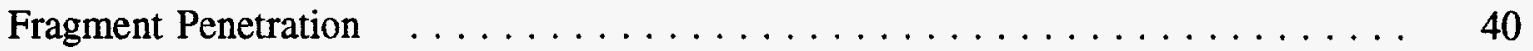

Design Details $\ldots \ldots \ldots \ldots \ldots \ldots \ldots \ldots \ldots \ldots \ldots \ldots \ldots \ldots \ldots$

Inspection and Testing Recommendations $\ldots \ldots \ldots \ldots \ldots \ldots \ldots \ldots \ldots, 51$

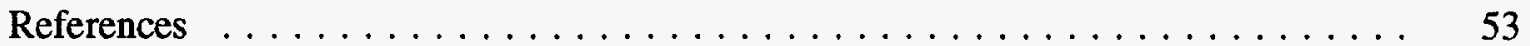

Appendix A - Example Loads Calculations $\ldots \ldots \ldots \ldots \ldots \ldots \ldots \ldots \ldots$ A-1

Appendix B - Response Calculations: Summary . . . . . . . . . . . . B-1

Response Calculations: Design Charge Weight ......... B-3

Response Predictions: $200 \%$ Overcharge $\ldots \ldots \ldots \ldots \ldots \ldots$ B-20

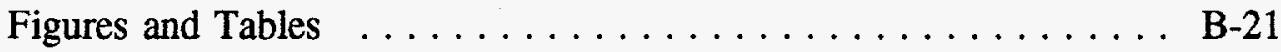

Appendix C - Transformation Factors for Beams and Plates $\ldots \ldots \ldots \ldots \ldots$ C-1

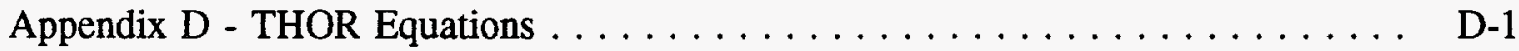

\section{Figures}

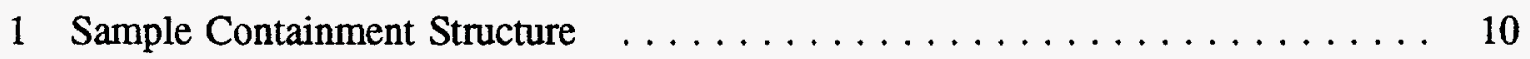

2 Positive Phase Shock Parameters for TNT in Air $\ldots \ldots \ldots \ldots \ldots \ldots \ldots$

3 Inverse of Scaled Standoff versus Scaled Strain $(t=$ vessel thickness, $r=$ vessel radius) for Air and Vermicalite Filled Spherical Vessels . . . . . . 26

4 Gas Pressure as a Function of Loading Density $\ldots \ldots \ldots \ldots \ldots \ldots \ldots 27$

5 Gurney Equation for Different Cases $\ldots \ldots \ldots \ldots \ldots \ldots \ldots \ldots \ldots \ldots$

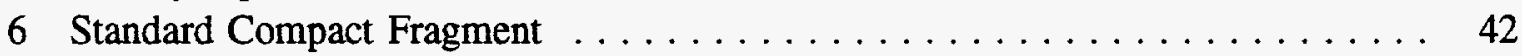

7 Idealized Locking Stress-Strain Behavior $\ldots \ldots \ldots \ldots \ldots \ldots \ldots \ldots \ldots . \ldots 4$

\section{Tables}

1 Averaged Free-Air Equivalent Weights . . . . . . . . . . . . . 16

2 Equivalency Factors (For Complete Combustion) Based on Confined Explosion Gas Pressures ................................ 17

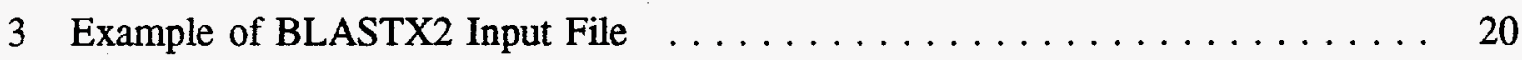

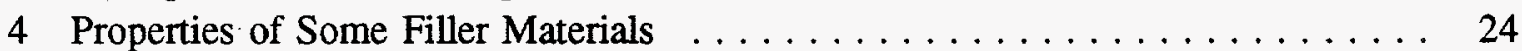

5 Gurney Constant for Various Explosives $\ldots \ldots \ldots \ldots \ldots \ldots \ldots \ldots \ldots$

6 Mott Scaling Constants for Mild Steel Casings and Various Explosives ..... 32

7 "Lockup" Parameters for Selected Filler Materials . . . . . . . . . . . . . . . 43

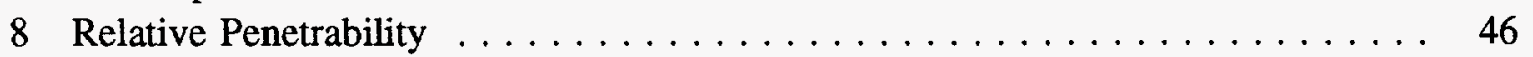




\section{GLOSSARY}

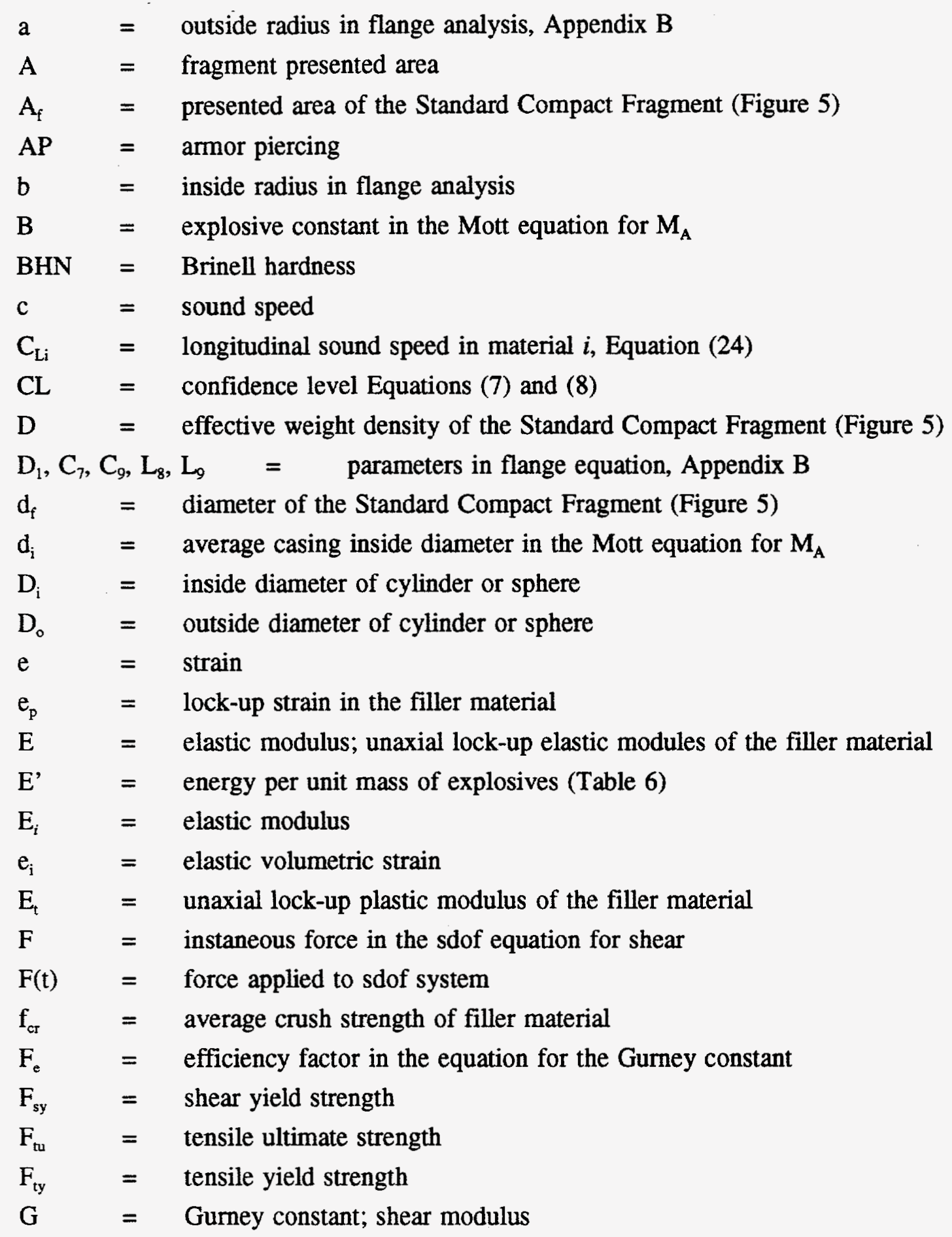




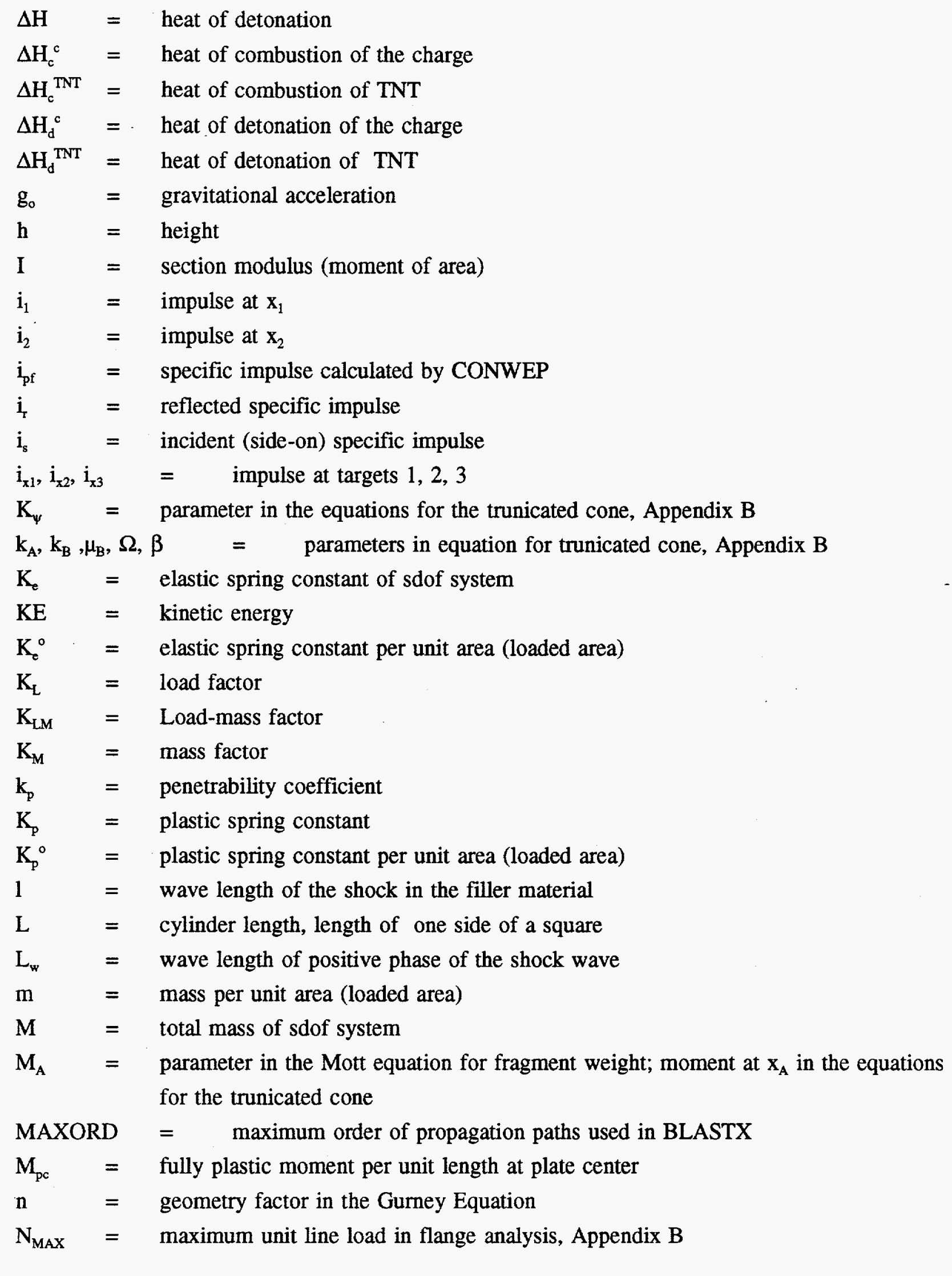




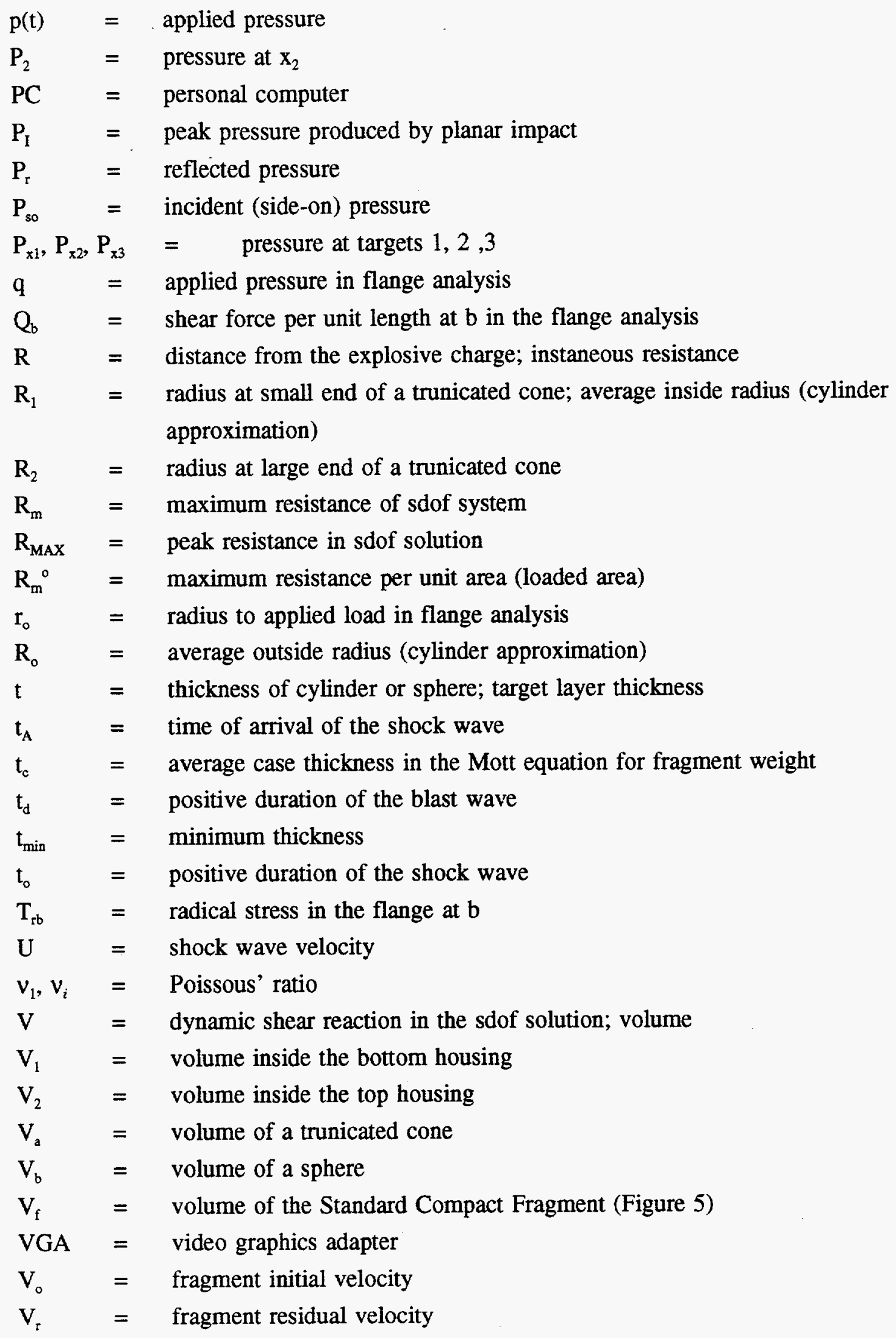




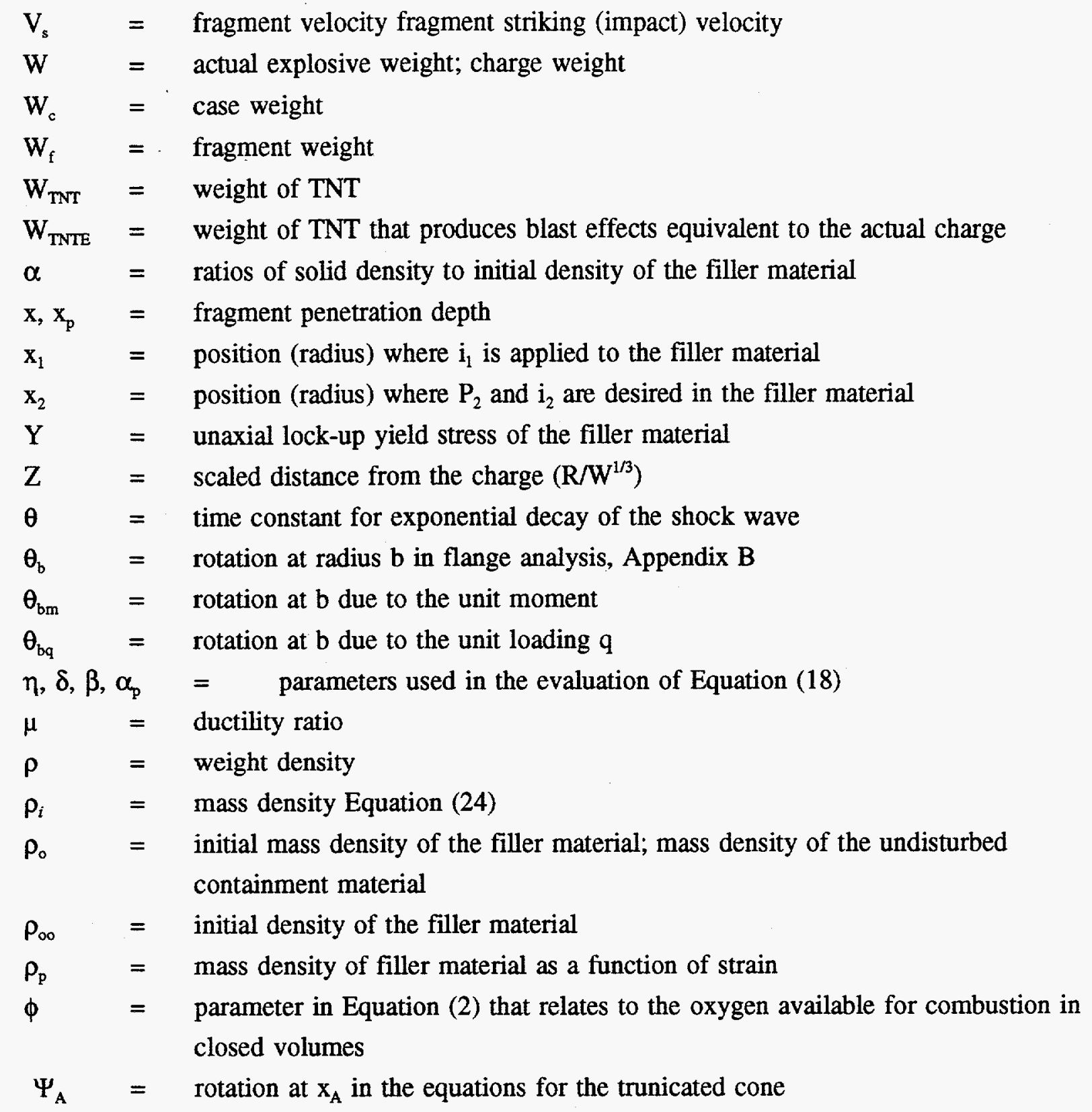





\section{A Design Guide and Specification for Small Explosive Containment Structures}

\section{Introduction}

Weapon systems components include small explosive devices that are used for a variety of purposes including triggering, power supply, cutting and separating. These weapon system components must be routinely tested in parallel with their companion components for functional compliance. The small explosive devices may consist of charge weights ranging from milligrams to ounces of explosives, but generally do not approach pounds of material. Functional testing is often performed at high acceleration levels in a centrifuge. Thus, the containment weight and size can be constrained by the performance capabilities and geometry of the centrifuge. During testing, the products of the explosion, including shock waves, gas pressures and fragments must all be arrested by a containment so that peripheral damage to the parallel component undergoing testing or the centrifuge does not occur.

Figure 1 shows a sample containment designed for the testing of the device that contains the equivalent of 3.5 grams of TNT. The containment is configured with a primary chamber where the device is positioned and functioned, and with a secondary chamber designed to provide volume for expansion of explosive gas products. The primary chamber is filled with vermiculite for shock and fragment attenuation. Between the chambers is a rupture disk which restrains the vermiculite early in the explosive event. The containment also makes use of a Spirolox retaining ring for cover attachment. Bolts or other fasteners that can be a weak point in a containment structure are eliminated by this design. Appendices A and B present a complete example analysis of the sample containment.

This document provides guidance for the proper design, testing and inspection of containment structures for small explosive devices. Emphasis is placed on determining the loads on the structure caused by the detonation of the explosive. Loads are determined for a design charge of $125 \%$ and an over-charge of $200 \%$ of the operational charge in the explosive device. Load calculations are sometimes complicated by unusual geometry of the containments and the explosive devices and by the use of materials in the containment to attenuate shock or arrest fragments.

Although the emphasis is on loads, methods of analysis for use in design are also addressed. Analysis methods used in this guide are based on sdof equivalent systems. This method defines a sdof model (equivalent system) for a distributed structural element, such as the wall of a containment structure. Its usefulness lies in its simplicity. The methods for transforming many types of structural elements into sdof systems are readily available, and it is easy to solve for the response of a sdof system. More complex methods can be used. Methods available are many and varied, and the designer who chooses to use such methods must be fully versed in their use and limitations. Loads 


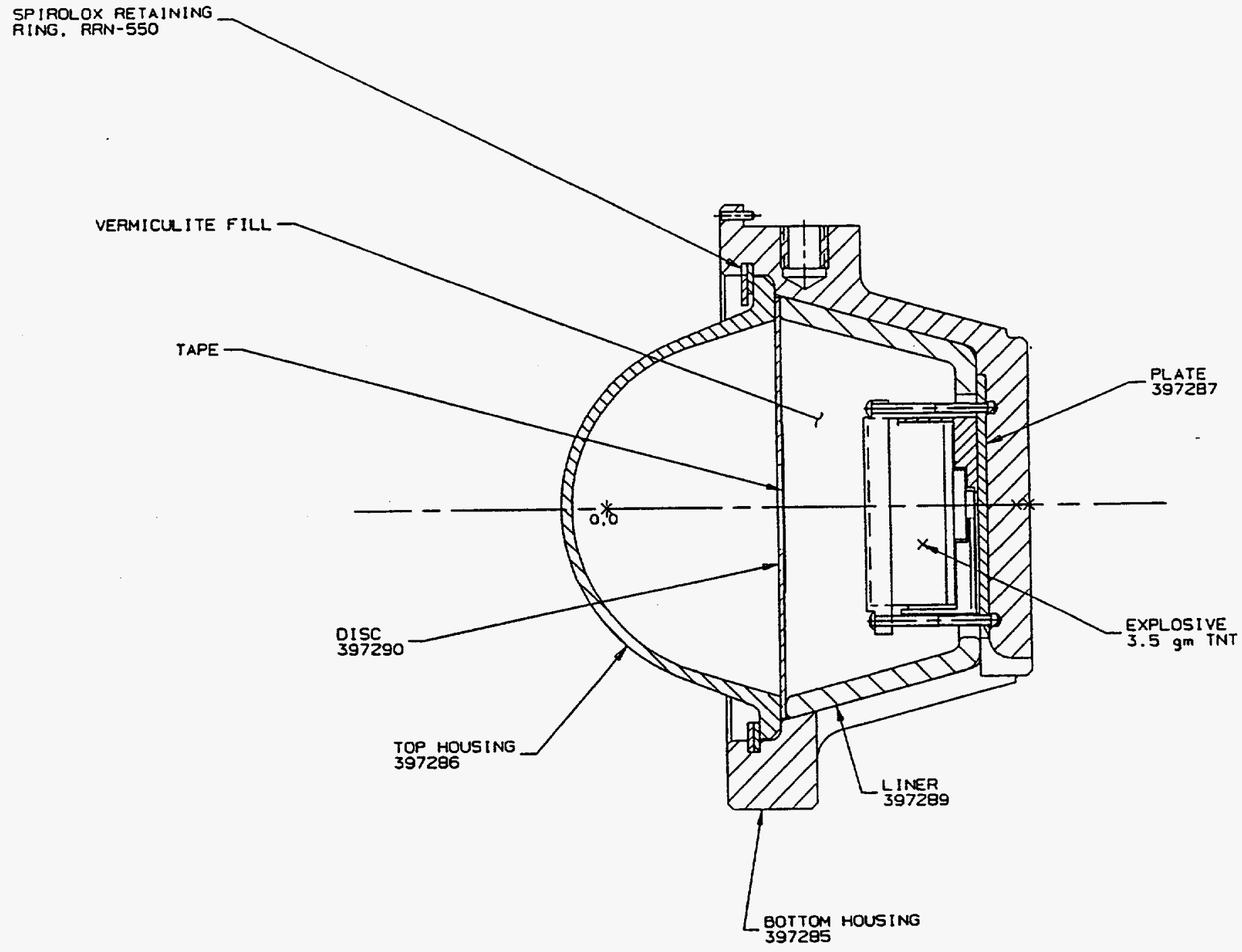

Figure 1. Sample Containment Structure 
developed in the guide apply equally to either method. The containment is designed not to yield at the design charge weight. It is also checked for the $200 \%$ over-charge weight, for which yielding, but no failure, is permitted.

Once the containment has been designed it must be built and tested. Testing is done at the design charge weight and the containment must not yield. Guidance is given for testing, and criteria are given for post test inspection, to determine whether or not the containment passed the test. After the containment is put in service, it is important to know how many times it can be used before it is scrapped. This is tied to inspection and a methodology is given for determining useful life. 


\section{Design Approach and Limitations}

This section will describe qualitatively the approach used to 1) predict shock loads in a containment, 2) predict shock attenuation in "filler" materials, 3) predict fragments from the device and their penetration, 4) predict gas pressures, 5) predict structural response, 6) analyze details such as connections and fasteners, and 7) inspect the containment for compliance to the proof test and for damage during subsequent usage.

Three different charge weights are used in the design. Fragments are determined for the actual charge in the explosive device. For purposes of determining the blast loads, a "design charge" is defined as $125 \%$ of the actual charge. A proof test of the containment is required at the design charge weight and no yielding is permitted. Blast loads are also defined for an over-charge equal to $200 \%$ of the actual charge. Yielding, up to three times the yield strain, but no failure, is permitted at this over-charge. This must be shown by analysis as no tests are required for the over-charge.

Although discouraged, fragment impact with the wall of the containment is permitted if penetration depth is less than $25 \%$ of the wall thickness and the wall of the containment is checked for spallation. Impact loads are combined with shock and gas pressure loads where appropriate. Fragment impact damage will prevent reuse of the containment.

Structural response predictions in this guide are based upon sdof methods, and quantitative information is provided only for these methods. In this qualitative discussion, more complex methods also are described. If the designer chooses to use the more complex methods, it is expected that the preliminary design will be performed with the simpler methods and final design calculations with the more complex methods.

\section{Shock Loads in Air}

Shocks in the containment (in air) are created by the very rapid release of energy from the explosive charge in the device. Confinement of the explosive products by the device itself is ignored; however, the fragments of the device can contribute to the total loads on the containment. Geometry of the charge also can be important, affecting the magnitude of the pressure and impulse close to the device. Clearly, the explosion of an irregular charge inside an irregular containment structure makes shock load predictions difficult. Thus, one cannot simply turn to blast curves for explosions in "free air," and make the appropriate adjustments. Fortunately, the development of BLASTX2 ${ }^{[1]}$ by the U.S. Army Waterways Experiment Station, Vicksburg, MS, makes the prediction of loads for such complicated geometry tractable on a PC. Otherwise, one would have to rely upon hydrocodes ${ }^{1}$ for the predictions.

BLASTX2 computes shocks inside structures using free air data from Kingery and Bulmash ${ }^{[2]}$, ray tracing and image charges to represent reflections, and the Lamb shock addition rules to combine multiple shocks (as explained in Appendix B of Ref. 1). The program treats forty-one different

1 Computer codes written to solve for the large strain, higher rate behavior of materials, usually solids, to include hydrodynamic effects and shock wave propagation. 
explosives, spherical charges, and fairly general geometry. The basic geometry is that of a parallelepiped; however, provision is made for wall segments with which one can approximate cylinders and other irregular geometries. BLASTX3, when released, will have provisions for even more general shapes. The provision for multiple charges permits simulation of other than spherical charge geometry by subdividing a charge into several smaller spaced charges. Blast loads in secondary chambers, e.g., expansion chambers, can be predicted by BLASTX2 using predicted pressure and impulse values at the opening between the compartments. Details for the use of BLASTX2 are given in the next section and its use is demonstrated in Appendix A for an example problem.

\section{Shock Attenuation in Filler Materials}

The addition of filler materials can attenuate or enhance the shock loads on the containment. In close to the charge, shock loads are enhanced; further away they are attenuated. The procedure presented in the guide assumes that reflections can occur, even in a filler material, and uses a modification of a procedure presented by Hayes ${ }^{[3]}$ to attenuate the shock wave. Data for shock attenuation in filler materials (crushable materials) is very limited and the methodology in the guide, while not validated, could be improved by additional research in this area.

\section{Fragments}

To determine fragments from the exploding device, the guide assumes that the explosive is in contact with the fragmenting wall. If it is not, predicted velocities will be too high. Equations developed by Gurney ${ }^{[4]}$ and Mott ${ }^{[5]}$ are used. A worst case (wc) fragment is defined that must be arrested by the containment. The actual charge weight in the explosive device is used for these calculations. Equations are given to determine penetration of fragments in filler materials and metals. They are used to design a means of arresting the wc fragment without damage to the containment boundary that would jeopardize its ability to resist the blast loads without failure.

\section{Gas Pressure}

Gas pressure in a closed volume is caused by heating and the generation of gaseous products from the explosion. Most of the increase comes from heating and much of the heating is produced by shock reflections. When filler material is present, it reduces the shock reflections, thus reducing heating; it may absorb heat, thus reducing peak temperature; and it also reduces the volume, which can increase pressure. The first two effects oppose the latter, but whether or not the effects are completely offsetting is not known. The effects of fillers on gas pressure has not been quantified, and this needs to be done. Lacking definitative data on which to derive a method that accounts for filler materials, good judgement dictated that the effect of the filler on the gas pressure be ignored. Thus, gas pressures are predicted using BLASTX2, which has provisions for computing gas pressure when fillers are not present. [Accounting for a reduction in volume, while ignoring the other effects, seemed too conservative. Conservatism has been introduced into the guide by the use of a design charge that is $125 \%$ of the actual charge and a requirement that the containment be checked for failure with a $200 \%$ over-charge.] 


\section{Structural Analysis}

Structural analysis methods presented in this guide utilize single degree of freedom (sdof) equivalent systems. This method defines a sdof system to represent a structural element (a distributed system such as a wall or plate). The underlying assumption for the method is a deformed shape for the structural element. Methods described in this guide utilize the static deformed shape for the structural element, under the same distribution of load as provided by the blast pressures. This assumption works well except for very intense shock loads. For this case shear reactions can be underestimated. These "flaws" in the methodology have not detracted from its usefulness and it has been used extensively in blast resistant design for the military and others and the methods for transforming many types of structural elements to sdof systems already have been defined. The use of these methods does not preclude the use of more complex methods. More complex methods suitable for these types of analyses include finite element methods that provide nonlinear, transient solutions, and hydrocodes. Lagrangian and arbitrarily Lagrangian-Eulerian hydrocodes are preferred for these types of analyses. Even when the more complex methods are chosen, sdof methods are useful for initial design.

\section{Connections and Fasteners}

Fasteners are difficult to analyze for dynamic loads using sdof methods. Most often, the loads on the fasteners are reaction loads, and reactions can be underestimated in sdof models. The tendency of sdof methods to underestimate reaction loads is somewhat offset by the fact that flexibility in thefasteners, which will act to reduce the reaction loads, is ignored. To add fastener flexibility requires a multi-degree-of-freedom (mdof) model (at least two dof) and is left to the category of "more complex methods." The approach taken in the guide is to design for the maximum predicted reaction, applied as a static load. This permits the use of static equations, as found in books by Roark ${ }^{[6]}$ and others, to predict fastener stresses and design supporting structure such as flanges. Also, the guide emphasizes the use of alternatives to bolted connections. These include snap rings and threaded connections. These connections are simpler to use and reduce error when the containment is closed for testing. Unfortunately, they are limited to cylindrical type joints and so provisions for bolted connections are included in the guide.

\section{Inspection}

Inspections are required by the guide for proof testing and before the containment is used for each operational test or test series. Inspections for proof testing are performed to confirm that the containment is not damaged by the proof test. Inspections before each use of the containment (after it is placed in service) are performed to verify that no damage has been done that renders the containment unfit for service. 


\section{Loads Prediction}

This section addresses in more detail the calculation of loads on the containment structure. It is divided into five sections:

TNT Equivalent Explosive Weight

Shock Loads

Shock Attenuation by Fillers

Gas Pressures

Design Fragment

\section{TNT Equivalent Explosive Weight}

The defacto standard for the presentation of blast data, whether for shocks, gas pressure, or fragmentation, is TNT. Thus, when working with an explosive other than TNT, one must be able to define the explosive as an equivalent weight of TNT, $\mathrm{W}_{\mathrm{TNTE}}$. This has been done for many explosives using experimental data. When data are not available, estimates are made using the heats of detonation, $\Delta \mathrm{H}_{\mathrm{d}}$, and heats of combustion, $\Delta \mathrm{H}_{\mathrm{c}}$, of the explosives. TNT equivalency is expressed as the weight of TNT divided by the weight of another explosive that produces the same effect, whether measured in terms of peak shock pressure, shock impulse or the gas pressure.

Tabulated data for a number of explosives are given in Table 1 for shock pressure and shock impulse. TNT equivalencies do vary with shock intensity and the data represents an average over the pressure range (incident pressure) specified. In practice, this equivalency is used over all pressures because it is all that is available. The TNT equivalence for pressure is almost always higher than that for impulse. When using these values for structural analysis, it is sometimes clear that the response is sensitive only to impulse and not peak pressure. If this occurs, the TNT equivalency for impulse can be used. When in doubt use the higher number.

When data are not available for an explosive, Equations (1) and (2) can be used to estimate TNT equivalency. For shock (pressure and impulse), equivalency is based on the heats of detonation; for gas pressure, it is based on both the heats of detonation and combustion. An equivalency for gas pressure, Equation (2), must account for the amount of oxygen available in air for complete combustion. Above a loading density of $0.02 \mathrm{lb} / \mathrm{ft}^{3}$, combustion will be incomplete for most explosives. It depends upon the amount of oxidizer in the explosive formulation. The factor $\phi$ accounts for the available oxygen for explosives that have about the same amount of oxidizer as TNT. For explosives with more oxidizer, such as RDX, the equation will give a TNT equivalency that under predicts pressures above a loading density of $0.02 \mathrm{lb} / \mathrm{ft}^{3}$. This is addressed in the section entitled Gas Pressure. Table 2 gives TNT equivalency for a few explosives based on complete combustion (W/V $\left.<0.02 \mathrm{lb} / \mathrm{ft}^{3}\right)$. 
Table 1. Averaged Free-Air Equivalent Weights

\begin{tabular}{|c|c|c|c|}
\hline Explosive & $\begin{array}{c}\text { Equivalent Weight } \\
\text { Pressure }\end{array}$ & $\begin{array}{c}\text { Equivalent Weight } \\
\text { Impulse }\end{array}$ & $\begin{array}{c}\text { Pressure } \\
\text { Range }\end{array}$ \\
\hline Ammonia Dynamite (50\% strength) & 0.9 & - & Estimated \\
\hline Ammonia Dynamite (20\% strength) & 0.7 & - & Estimated \\
\hline ANFO (94/6 Ammonium Nitrate/Fuel Oil) & 0.82 & - & $1-100$ \\
\hline Composition A-3 & 1.09 & 1.076 & $5-50$ \\
\hline Composition B & 1.11 & 0.98 & $5-50$ \\
\hline Composition $\mathrm{C}-4$ & 1.37 & 1.19 & $10-100$ \\
\hline Cyclotol $(70 / 30)^{1}$ & 1.14 & 1.09 & $5-50$ \\
\hline Gelatin Dynamite (50\% strength) & 0.8 & - & Estimated \\
\hline Gelatin Dynamite (20\% strength) & 0.7 & - & Estimated \\
\hline HBX-1 & 1.17 & 1.16 & $5-20$ \\
\hline HBX-3 & 1.14 & 0.97 & $5-25$ \\
\hline $\mathrm{H}-6$ & 1.38 & 1.15 & $5-100$ \\
\hline Minol II & 1.20 & 1.11 & $3-20^{-}$ \\
\hline $\begin{array}{l}\text { Nitroglycerin Dynamite } \\
\text { (50\% strength) }\end{array}$ & 0.9 & - & Estimated \\
\hline Octol $(70 / 30)^{2},(75 / 25)$ & 1.06 & - & Estimated \\
\hline PBX-9404 & 1.13 & - & $5-30$ \\
\hline PBX-90-10 & 1.29 & 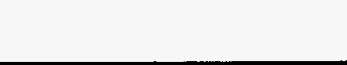 & $5-30$ \\
\hline PETN & 1.27 & - & $5-100$ \\
\hline Pentolite & $\begin{array}{l}1.42 \\
1.38 \\
\end{array}$ & $\begin{array}{l}1.00 \\
1.14\end{array}$ & $\begin{array}{l}5-100 \\
5-600\end{array}$ \\
\hline Picratol & 0.90 & 0.93 & - \\
\hline Tetryl & 1.07 & - & $3-20$ \\
\hline Tetrytol $(75 / 25)^{3},(70 / 30),(65 / 35)$ & 1.06 & - & Estimated \\
\hline TNETB & 1.36 & 1.10 & $5-100$ \\
\hline TNT & 1.00 & 1.00 & Standard \\
\hline TRITONAL & 1.07 & 0.96 & $5-100$ \\
\hline
\end{tabular}

1 RDX/TNT

2 HMX/TNT

${ }^{3}$ TETRYL/TNT 


\section{Table 2. Equivalency Factors (For Complete Combustion) Based on Confined Explosion Gas Pressures}

\begin{tabular}{||ll|ll||}
\hline Comp B & 0.81 & PETN & 0.57 \\
\hline H-6 & 1.13 & TETRYL & 0.83 \\
\hline HBX-1 & 1.11 & TNT & 1.00 \\
\hline HBX-3 & 1.30 & TRITONAL & 1.19 \\
\hline PENTOLITE & 0.79 & RDX & 0.65 \\
\hline
\end{tabular}

SHOCK: $\quad \mathrm{W}_{\text {TNTE }}=\left[\frac{\Delta \mathrm{H}_{\mathrm{d}}^{\mathrm{c}}}{\Delta \mathrm{H}_{\mathrm{d}}^{\mathrm{TNT}}}\right] \mathrm{W}_{\mathrm{c}}$

GAS: $\quad \mathrm{W}_{\mathrm{TNTE}}=\left[\frac{\phi\left(\Delta \mathrm{H}_{\mathrm{c}}^{\mathrm{c}}-\Delta \mathrm{H}_{\mathrm{d}}^{\mathrm{c}}\right)+\Delta \mathrm{H}_{\mathrm{d}}^{\mathrm{c}}}{\phi\left(\Delta \mathrm{H}_{\mathrm{c}}^{\mathrm{TNT}}-\Delta \mathrm{H}_{\mathrm{d}}^{\mathrm{TNT}}\right)+\Delta \mathrm{H}_{\mathrm{d}}^{\mathrm{TNT}}}\right] \mathrm{W}_{\mathrm{c}}$

where:

$$
\begin{aligned}
& \left\{1.0 \text { for } \mathrm{W} / \mathrm{V} \leq 0.02 \mathrm{lbs} / \mathrm{ft}^{3}\right. \\
& \phi \quad=\quad\left\{1.0-12.5(\mathrm{~W} / \mathrm{V}-.02) \text { for } .02<\mathrm{W} / \mathrm{V}<.1 \mathrm{lb} / \mathrm{ft}^{3}\right. \\
& \left\{0 \text { for } \mathrm{W} / \mathrm{V} \geq .1 \mathrm{lbs} / \mathrm{ft}^{3}\right. \\
& \Delta \mathrm{H}_{c}^{\mathrm{c}}=\text { heat of combustion of the charge } \\
& \Delta \mathrm{H}_{\mathrm{c}}^{\mathrm{TNT}}=\text { heat of combustion of TNT } \\
& \Delta \mathrm{H}_{\mathrm{d}}^{\mathrm{c}} \quad=\text { heat of detonation of the charge } \\
& \Delta \mathrm{H}_{\mathrm{d}}^{\mathrm{TNT}}=\text { heat of detonation of TNT } \\
& \mathrm{W}_{\mathrm{TNTE}}=\text { weight of } \mathrm{TNT} \text { that produces blast effects equivalent to the actual charge } \\
& \mathrm{W}=\text { charge weight } \\
& \mathrm{V} \quad=\text { volume }
\end{aligned}
$$

\section{Shock Loads}

A method to determine shock loads in a containment relies heavily upon measurements in free air. Excellent compilations and presentation of such data have been made by Kingery and Bulmash $^{[2]}$. Figure 2 gives scaled values (scaled by the TNT equivalent charge weight) of the positive pressure phase of the shock loading. The range of standoff extends from the charge surface to $\mathrm{Z}=1000 \mathrm{ft} / \mathrm{b}^{1 / 3}$ and all quantities are defined in the figure. To apply this data to shock predictions in containments, one must account for shock reflections and angles of incidence of the shock wave with the surface. This has all been done in the BLASTX2 code, using ray 
tracing, image charges and the Lamb rules of shock reflection ${ }^{[1]}$. Without the use of a code like BLASTX2, one must make estimates of shock reflections, both from the surface being loaded and other surfaces within the containment.

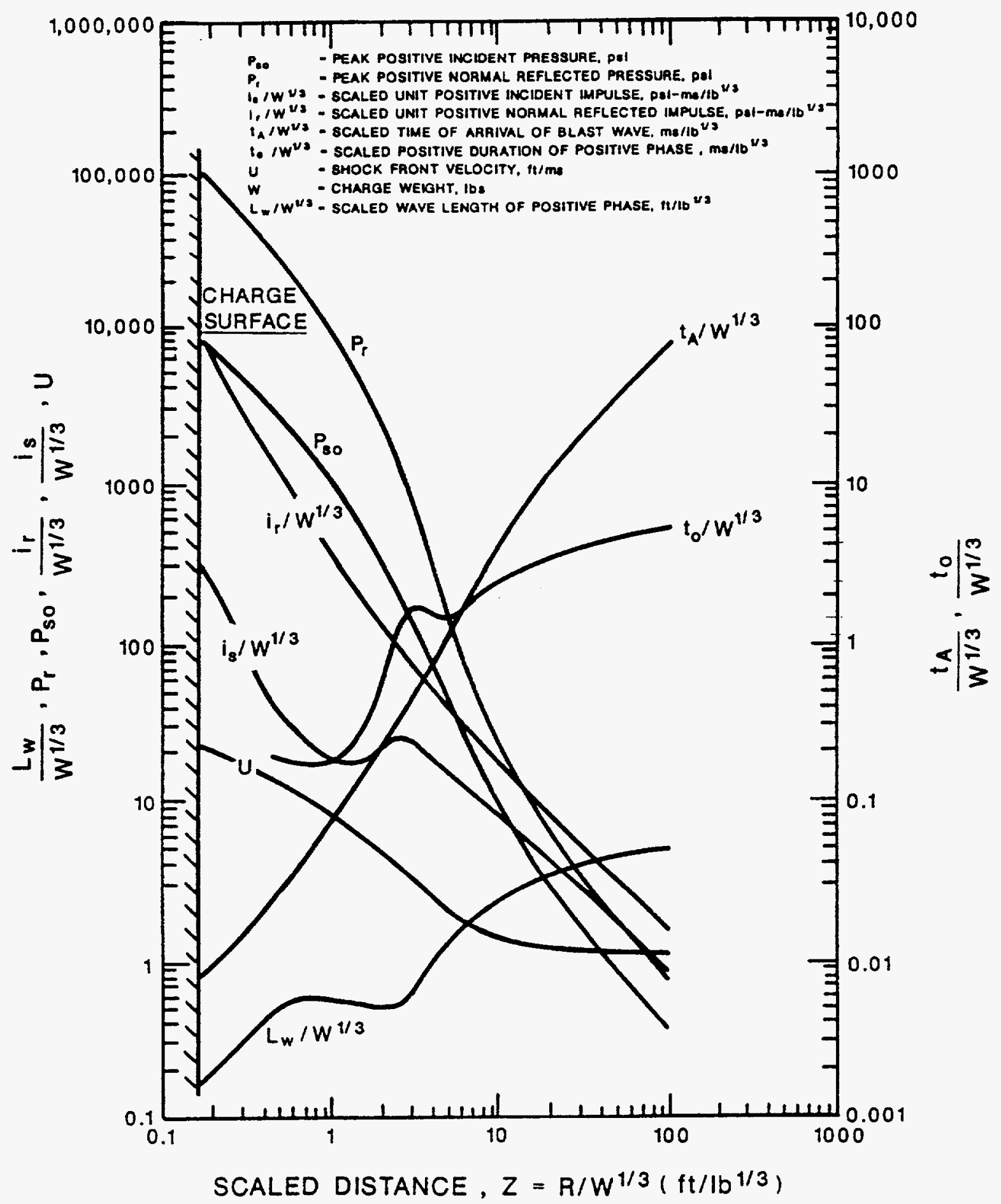

Figure 2. Positive Phase Shock Parameters for TNT in Air ${ }^{[2]}$ 
In this guide, shock loads are determined using BLASTX2. BLASTX2 computes the internal air blast environment (shocks, gas pressure, and temperature) in multi-room ${ }^{2}$ structures from internal detonations (and burning) or from external shocks at openings in the structure. The donor chamber (where the charge is located) may be rectangular, L-shaped, a cylinder (approximated as a polygon), or a general room comprised of up to 30 rectangular panels. All rooms other than the donor, must be rectangular. Provisions for wall failure are a recent addition, as is the diffraction calculation around the internal corner in the L-shaped donor room. The program runs well on a 386 class PC with a color, VGA monitor, hard disk, floating point processor, and DOS 3.3 or higher.

Three versions of the code are available. The smallest version limits pressure-time and temperature-time arrays to 1400 elements and the number of rooms to 10 . It requires 4 megabytes of memory. The largest version expands the number of pressure-time pairs to 10,000, the number of rooms to 20 , and requires 6.2 megabytes of memory. Users are cautioned that large problems require very long run times. Data can be entered into the program through an interactive session, where the program prompts the user for input. Default values are offered for many input values. An input file also can be saved and modified by an experienced user. The input file can be specified when prompted by the program.

A typical input file is shown in Table 3. It is from the example problem given in Appendix A. The two letter variable name and the data in the file were created by the program from an interactive session. Comments at the end of each line have been added for clarity. This example is for two rooms with a vent in between and a single explosive charge in room 1 . Three targets have been established, all in room 1. Targets are points where pressure and impulse generated by the shock (and gas pressure and temperature if requested) will be calculated. The explosive composition is defined by the $\mathrm{CO}$ parameter. It is comprised of an explosive composition number and a fraction by weight. Composition number 1 is TNT, and, in this example, the charge is $100 \%$ TNT by weight.

One of the more important parameters to specify is MA (MAXORD), the maximum order of the propagation paths. It can be different for each room (chamber of the containment). A path order of 1 is the direct, unreflected shock; a path order of 2 includes the direct shock and one reflection from each wall; a path order of $n$ includes $n-1$ reflections from walls. The default for MAXORD is 5. The one specified in this example is 3. As can be seen in Appendix A, peak reflected pressures in the example exceed 30,000 psi. Small values of MAXORD appear to work best for high pressures, and larger values appear to work best for lower pressures. Examples given in Reference 1 use a value for MAXORD of 10 and achieve good correlation with measured pressures in the range of $0-40 \mathrm{psi}$. Reference 1 states that BLASTX2 is most suitable for shock pressures in the lower range; however, it has been applied successfully at higher pressures with the proper choice of MAXORD.

2 BLASTX2 uses rooms to denote different compartments. For small containment structures chambers is a more appropriate description. 
Table 3. Example of BLASTX2 Input File

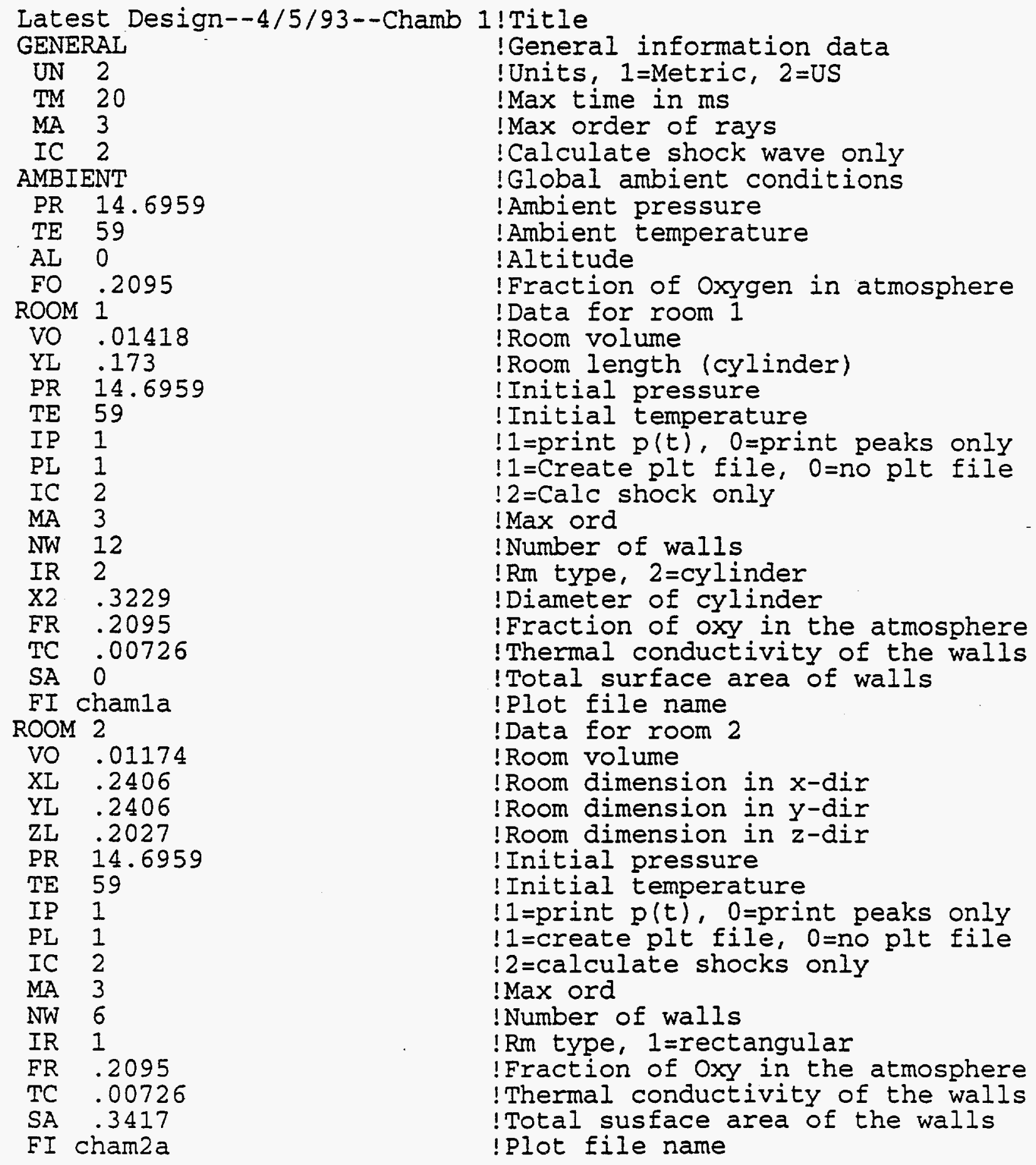


Table 3. Example of BLASTX2 Input File (Continued)

$\begin{array}{ll}\text { OPENING } 1 \\ \text { AR } & .00545 \\ \text { R1 } & 1 \\ \text { X1 } & .1615 \\ \text { Y1 } & .173 \\ \text { Z1 } & 0 \\ \text { R2 } & 2 \\ \text { X2 } & .1204 \\ \text { Y2 } & .1204 \\ \text { Z2 } & 0 \\ \text { TARGET } & 1 \\ \text { XO } & .1615 \\ \text { YO } & 0 \\ \text { ZO } & 0 \\ \text { IR } & 1 \\ \text { FI TGT1a } & \\ \text { TARGET } & 2 \\ \text { XO } & 0 \\ \text { YO } & .0865 \\ \text { ZO } & 0 \\ \text { IR } & 1 \\ \text { FI TGT2a } & \text { TGTET } \\ \text { TARGET } 3 \\ \text { XO } & .1615 \\ \text { YO } & .173 \\ \text { ZO } & 0 \\ \text { IR } & 1 \\ \text { FI } & \text { TGT3a } \\ \text { EXPLOSION } 1 \\ \text { XO } & .1615 \\ \text { YO } & .0417 \\ \text { Z0 } & 0 \\ \text { WE } & .009636 \\ \text { DE } & 0 \\ \text { IR } & 1 \\ \text { TM } & 0 \\ \text { TD } & 0 \\ \text { WB } & .009636 \\ \text { CO } & 1 \\ \text { END } & \\ \text { STOP } & \\ & \end{array}$

\author{
!Data for opening no. 1 \\ !Opening area \\ !Rm number on 1st side of opening \\ !x-ord of opening wrt $\mathrm{rm} 1$ \\ !y-ord of opening wrt rm 1 \\ ! $z$-ord of opening wrt $r m 1$ \\ ! Rm number on 2 nd side of opening \\ !x-ord of opening wrt $\mathrm{rm} \cdot 2$ \\ !y-ord of opening wrt rm 2 \\ !z-ord of opening wrt rm 2 \\ !Data for target 1 \\ !x-ord of the target \\ !y-ord of the target \\ ! $z$-ord of the target \\ $! \mathrm{Rm}$ number where target is located \\ !Plot file name \\ !Data for target 2 \\ !x-ord of the target \\ !y-ord of the target \\ !z-ord of the target \\ ! Rm number where target is located \\ !Plot file name \\ ! Data for target 3 \\ !x-ord of the target \\ !y-ord of the target \\ !z-ord of the target \\ !Rm number where target is located \\ !Plot file name \\ !Data for explosive charge no. 1 \\ !x-ord of the charge center \\ !y-ord of the charge center \\ !z-ord of the charge center \\ !Charge weight \\ ! Detonation delay after time 0 \\ ! Rm number where explosion occurs \\ !Min temp to ignite explosive \\ ! Min time at TM to ignite explosive \\ !Initial weight of explosive burned \\ ! Expl composition no., frac. by wt. \\ ! End of input data \\ ! Last card
}


BLASTX2 has many options that were not utilized in the example input data of Table 3. See Appendix A for several examples of how BLASTX2 was used in design calculations for the sample containment and see Reference 1 for a complete explanation of the code's many features.

\section{Shock Attenuation by Fillers}

Filler materials are added to arrest fragments and attenuate shocks. Their shock attenuating properties are addressed in this section. Their ability to arrest fragments is addressed under Fragment Penetration. The steps for determining shock attenuation are:

(1) determine reflected shock pressure and impulse at the device boundary (start of the filler) from an idealized spherical charge,

(2) attenuate pressure and impulse at the target using the modified Hayes procedure for shock transmission in the filler,

(3) determine impulse at the target from free-air blast curves, as in Figure2,

(4) determine impulse using BLASTX2 to account for reflections,

(5) determine the effects of shock reflections by dividing impulse determined using BLASTX2 in (4) by the value for free air in (3), and

(6) modify the attenuated impulse determined in (2) by the ratios determined in (5).

(1) Reflected Shock at Device Boundary--The shock pressure used in this calculation is that created by normal reflection from the boundary of the device (along the line of sight to the target) for an idealized spherical charge. This idealized calculation ignores:

Inclination of the surface to the shock wave

Reflections within the device

Charge shape

These simplifications are warranted because the device is not hollow, but is filled with potting material, and precise details of the device internal configuration may not be known. The reflected pressure can be determined from the blast data for free-air given in Figure 2 (or similar data in Reference 2) or by using the ConWep program, developed by Hyde ${ }^{[7]}$. ConWep is a collection of conventional weapon effects calculations from the equations and curves in TM 5$855-1^{[8]}$. It includes penetration calculations as well as those for free and reflected shocks. Freeair blast data comes largely from the work by Kingery and Bulmash ${ }^{[2]}$. As for BLASTX2, ConWep executes well on a 386 class PC with a color, VGA monitor, hard disk, floating point processor, and DOS 3.3 or higher. It is available from the Waterways Experiment Station, Vicksburg, MS, and is easy to install and operate. ConWep is simple to use, prompting the user 
for input at each step in the procedure. Use of the code is fully explained by Hyde ${ }^{[7]}$.

(2) Shock Wave Attenuation by the Filler--The procedure developed by Marchand ${ }^{[9]}$ assumes spherical divergence of the impulse. From this assumption, and following the procedure outlined by Hayes ${ }^{[3]}$, expressions were derived for impulse and pressure in the filler material at $\mathrm{x}_{2}$, when the impulse, $\mathrm{i}_{1}$, is known at $\mathrm{x}_{1}$.

$$
\begin{gathered}
i_{2}=i_{1}\left(\frac{x_{1}}{x_{2}}\right)^{2} \\
P_{2}=\frac{i_{1}^{2} \alpha}{\rho_{o o}\left[\left(\frac{x_{2}^{2}}{2 x_{1}^{2}}+\frac{1}{2}\right)\left(x_{2}-x_{1}+l\right)\right]^{2}(\alpha-1)}
\end{gathered}
$$

where $\alpha=\frac{\rho_{o}}{\rho_{o o}}$

$$
\begin{aligned}
& l=\left(\frac{2 i_{1}}{P_{1}}\right) c \quad=\text { length of the pressure wave in the filler } \\
& \mathrm{c}=\text { sound speed in the filler material } \\
& \rho_{0}=\text { "solid" density of the filler material } \\
& \mathrm{\rho}_{\infty}=\text { initial density of the filler material } \\
& \mathrm{i}_{1}=\text { reflected impulse at } \mathrm{x}_{1} \\
& \mathrm{P}_{1}=\text { reflected pressure at } \mathrm{x}_{1} \\
& \mathrm{i}_{2}=\text { impulse at } \mathrm{x}_{2} \\
& \mathrm{P}_{2}=\text { pressure at } \mathrm{x}_{2} \\
& \mathrm{x}_{1}=\text { radius where } \mathrm{i}_{1} \text { is applied to the filler material } \\
& \mathrm{x}_{2}=\text { radius to point where } \mathrm{P}_{2} \text { and } \mathrm{i}_{2} \text { are desired in the filler material }
\end{aligned}
$$

Equation (3) reflects the assumption that total impulse is conserved, and that specific impulse is only diminished by spherical divergence. It forms the basis for the derivation of Equation (4), which gives the pressure at $x_{2}$ in terms of the initial impulse, the positions within the filler, the ratio of solid to initial density of the filler material, and the length of the pressure wave 
in the filler. All terms in the equations are to be defined in consistant units. If the target at $\mathrm{x}_{2}$, is a solid boundary, the values of pressure and impulse given by Equations (3) and (4) are increased by a factor of two (2) to account for acoustic reflection. If the target represents an opening to another room in the containment, the values of incident pressure and impulse are to be used. Table 4 gives properties of typical filler materials. The properties permit computation of the wave length, 1 , and the ratio of solid to initial densities, $\alpha$, both of which are required in Equation (4).

Table 4. Properties of Some Filler Materials ${ }^{[9]}$

\begin{tabular}{||l|c|c|c|c|}
\hline \multicolumn{1}{|c|}{ Material } & $\begin{array}{c}\text { Density, } \rho_{\mathrm{oo}} \\
\text { (gm/cc) }\end{array}$ & $\begin{array}{c}\text { Strength } \\
\text { (psi) }\end{array}$ & $\begin{array}{c}\mathrm{c} \\
\text { (in/s) }\end{array}$ & $\begin{array}{c}\text { Solid Density } \\
\rho_{\mathrm{o}}\end{array}$ \\
\hline Duocell & 0.2 & 350 & 17,670 & 0.43 \\
\hline Vermiculite & $0.08^{*}$ & $100^{*}$ & 8,200 & 0.16 \\
\hline Urethane Foam (.1) & 0.10 & $145^{* *}$ & 17,620 & 0.15 \\
\hline Urethane Foam (.2) & 0.20 & $1088^{* *}$ & 29,929 & 0.30 \\
\hline Urethane Foam (.5) & 0.50 & $5076^{* *}$ & 52,124 & 0.72 \\
\hline
\end{tabular}

* $\quad$ estimated

** from SHPB tests@ = 3000/sec strain rate

(3) Free-air Reflected Shock Parameters at the Target--Free-air blast parameters at the target are determined in the same fashion as for the reflected shock at the device boundary. This calculation ignores the presence of the device and filler material. The reflected shock parameters are computed as though the charge and target were in free air. The only difference in this calculation and the one for reflected shock parameters at the device boundary is that the target lies outside of the device and is thus further away from the charge.

(4) Impulse at the Target in Air and with Reflections--Impulse at the target is now determined using BLASTX2, to account for all reflections within the containment, but neglecting the filler material. This value will be used to account for, in an approximate sense, shock reflections within the containment. The idealized spherical charge, used to determine the free-air reflected shock values at the device boundary and at the target, is used for these calculations as well.

(5) Determine the Effect of Reflections within the Containment--Enhancement of the impulse at the target, caused by reflections within the containment, is determined by dividing the value of impulse computed in (4) by the value determined in (3). It is assumed that the peak pressure is not affected by reflections. 
(6) Modify the Impulse to Account for Reflections--The final values for pressure and impulse at the target in the filler material are obtained by multiplying the impulse by the factor determined in (5). The pressure is unchanged from that determined in (2).

The derivation provided above is based on the observation of the successful uses of a low or medium density material as a solid filler or layer in the path of a shock. It has been shown that shocks (generated by the detonation of an explosive) that pass through these low density layers will attenuate peak pressures dramatically. In work for Sandia National Laboratories it has been estimated that "vermiculite" type cellulose material can attenuate peak shocks estimated to be about 14,000 psi in air to a value of $1250 \mathrm{psi}$ (more than a factor of 10 decrease) over a scaled distance of $0.8 \mathrm{ft} / \mathrm{h}{ }^{1 / 3}$. Impulse actually is estimated to increase in the vermiculite about $55 \%$ over that same scaled distance, however. This data is based on evidence provided by $\mathrm{Neal}^{[10]}$ (as illustrated in Figure 3 ) that compares the response of a spherical test vessel subjected to explosions contained in a vacuum and in vermiculite. The results indicate that the impulse delivered to the vessel wall (assuming the response was impulsive in nature) was similar for scaled standoffs between .75 and $1.15 \mathrm{ft} / 1 \mathrm{~b}^{1 / 3}$. For scaled standoffs less than $.75 \mathrm{ft} / \mathrm{b}^{1 / 3}$, however, the impulse delivered to the vessel wall was significantly larger, while for standoffs greater than $1.15 \mathrm{ft} / 1 \mathrm{~b}^{1 / 3}$ it was reduced over that in air. This data and experience suggest that fill or layers of shock attenuating material can be used to attenuate or mitigate peak shocks, thereby reducing loads and external noise, but the fact that impulse may be more effectively coupled into the structure must also be considered.

Open cell aluminums (one brand is ERG's Duocell) can also be used in a similar application for shock attenuation with the added benefit of fragment deceleration and retention.

\section{Gas Pressure}

Gas pressures measured in closed volumes for four different explosives are given in Figure 4. The volume is initially filled with air at ambient temperature and pressure. The influence of available oxygen, in the air and explosive, is apparent in the figure. RDX, which has sufficient oxidizer for complete combustion, gives a higher pressure at high loading densities and a lower pressure at low loading densities, that the other explosives. The other explosives have more "fuel" but less oxidizer, and lack sufficient oxygen for complete combustion at high loading densities. They give higher pressures at low loading densities where combustion is completed by available oxygen in the air.

If the explosive being used is not in Figure 4, an equivalent weight of TNT can be determined using Equation (2), given previously. Alternately, BLASTX2 can be used to calculate the gas pressure for forty-one (41) different explosives. As mentioned previously, BLASTX2 has provisions for calculating pressures from detonations and burning in containments that have up to 20 rooms, connected by vents or walls that fail. Burning can be time or temperature dependent. The presence of filler material is ignored in any of the methods used to determine the gas pressure. Reasons for neglecting the filler are given in Design Approach and Limitations. 


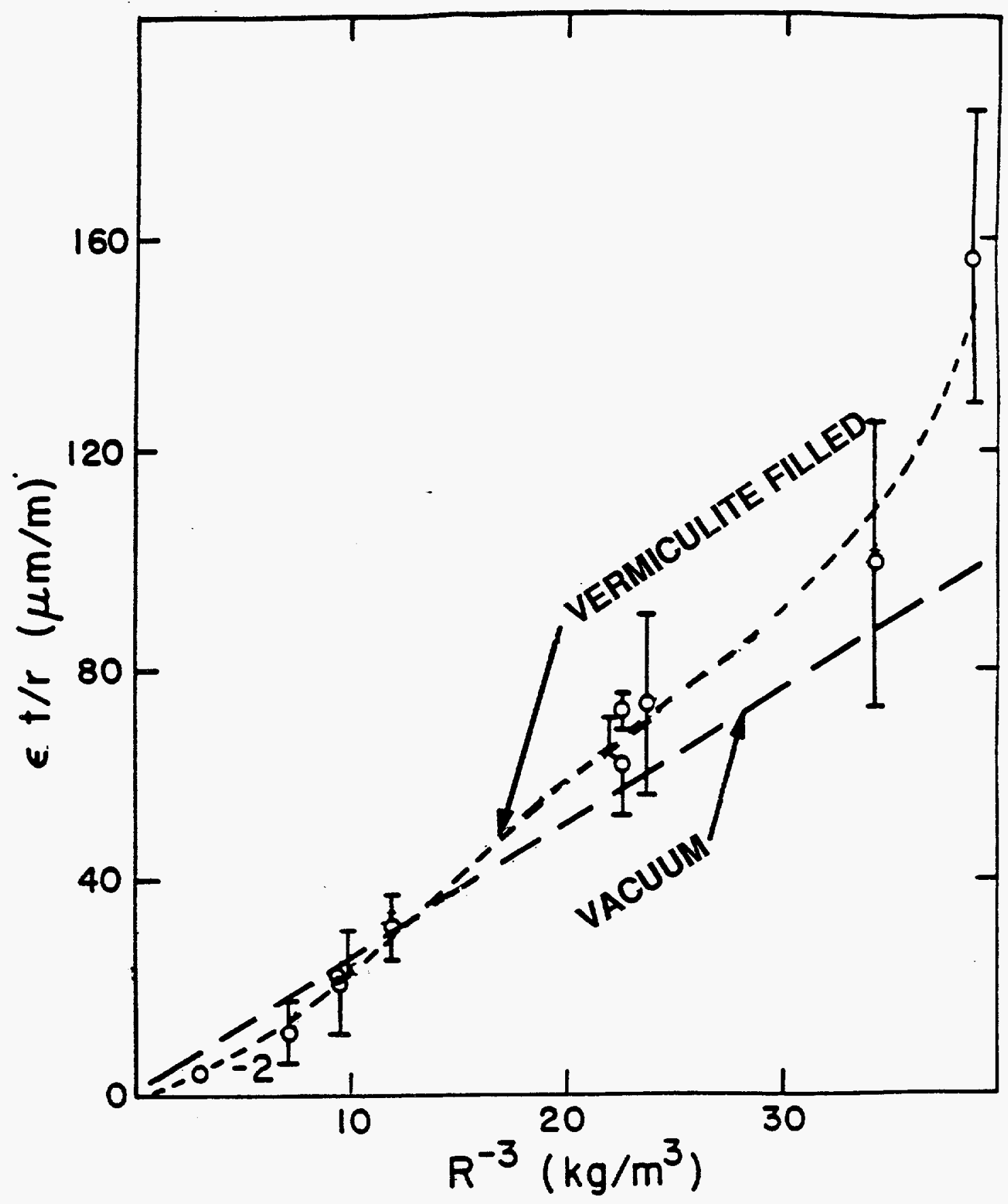

Figure 3. Inverse of Scaled Standoff versus Scaled Strain $(t=$ vessel thickness, $r=$ vessel radius) for Air and Vermiculite Filled Spherical Vessel (taken from Neal ${ }^{[10]}$ ) 


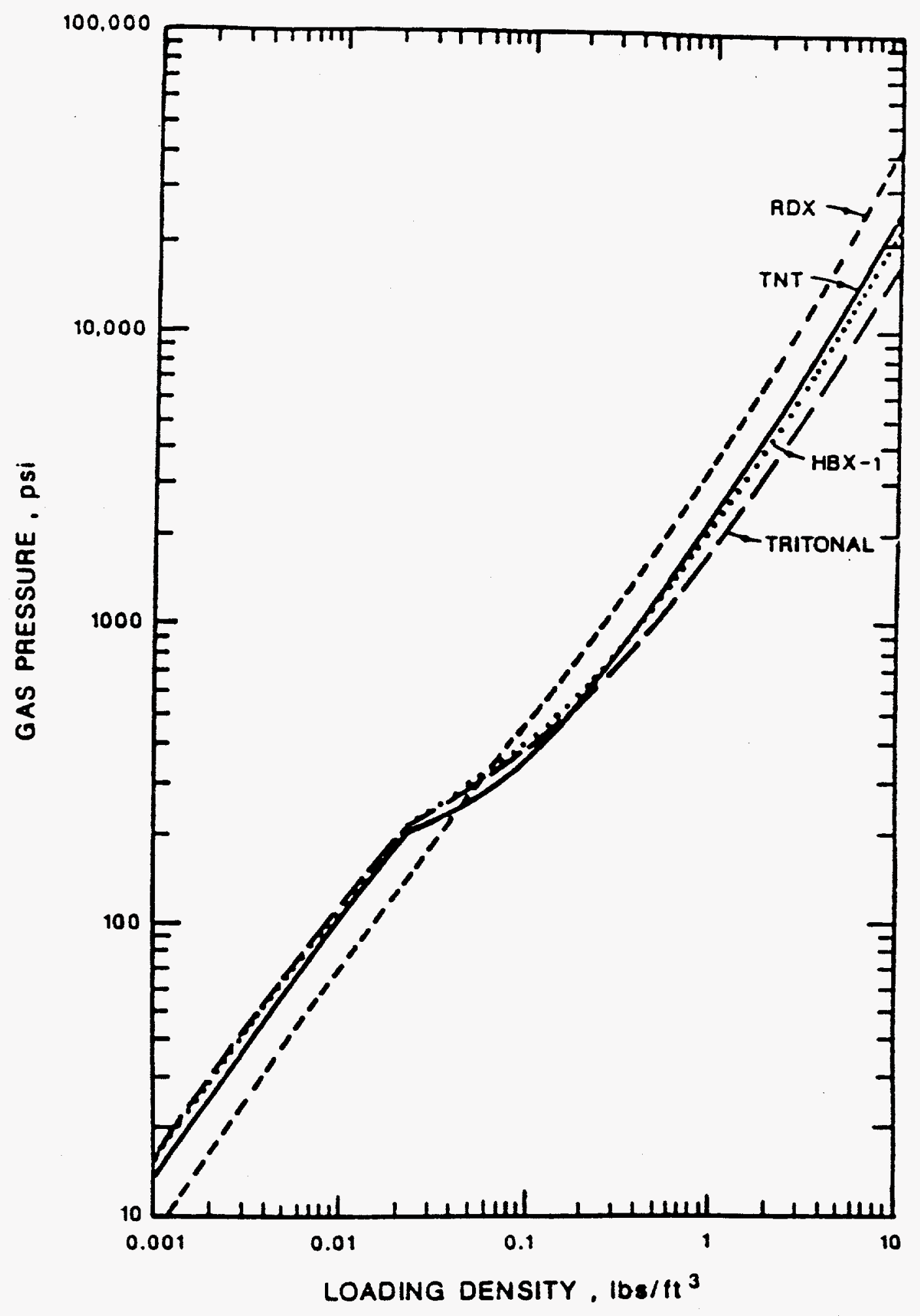

Figure 4. Gas Pressure as a Function of Loading Density ${ }^{[13]}$ 


\section{Design Fragment}

Initial velocities from an explosive device will be estimated using the Gurney ${ }^{[4]}$ equation:

$$
V_{0}=\frac{G}{\left(\frac{W_{c}}{W}+\frac{n}{n+2}\right)^{\frac{1}{2}}}
$$

where $\quad V_{0}=$ initial fragment velocity (fps),

$\mathrm{G}=$ Gurney constant $=\sqrt{2 E^{\prime}}(\mathrm{fps})$,

$\mathrm{W}=$ actual explosive weight in the device,

$\mathrm{W}_{\mathrm{c}}=$ case weight,

$\mathrm{n}=1,2,3$ for plane, cylindrical or spherical geometry,

and $\mathrm{W}$ and $\mathrm{Wc}$ are in consistant units. Figure 5 shows the geometries associated with $\mathrm{n}=1,2$, and 3 in Equation (5) and gives the resulting Gurney initial velocity equations. It also gives initial velocity equations for more complicated geometries. Table 5 gives the Gurney constant for various explosives. For an explosive not listed in Table 5, the Gurney constant can be estimated using Equation (6).

$$
G=\sqrt{2 F_{e} \Delta H}
$$

where $F_{e}=$ "efficiency" factor

$\Delta H \quad=$ heat of detonation

The efficiency factor $F_{e}$ can be determined from a similar explosive for which both the Gurney constant and $\Delta \mathrm{H}$ are known.

Equations to predict the size distribution of fragments from an exploding device are limited. Equations have been developed by Mott ${ }^{[5]}$ for the detonation of an explosive-filled cylinder. No other geometries have been treated. Thus, one must decide, based on geometry of the explosive device, how it will fragment, or simply use the Mott equations. A modified form of the Mott equation, for relating fragment weight to a confidence level that the fragment weight will not be exceeded, is given by Equations (7) and (8): 


$$
\begin{gathered}
W_{f}=M_{A}^{2} \ln ^{2}(1-C L), \text { for } C L \leq .9999 \\
\mathrm{~W}_{\mathrm{f}}=\mathrm{M}_{\mathrm{A}}^{2} 1 n^{2}\left[1-C L\left(1-e^{-\left(\frac{w_{:}^{i n}}{M_{A}}\right)}\right)\right], \text { for } C L>0.9999
\end{gathered}
$$

where $\quad \mathrm{W}_{\mathrm{f}}=$ fragment weight $(\mathrm{lb})$

$\mathrm{CL}=$ confidence level

$M_{A}=B t_{c}^{5 / 6} d_{i}^{1 / 3}\left(1-t_{c} / d_{i}\right)$

$\mathrm{W}_{\mathrm{c}}=$ total casing weight (lb)

$\mathrm{B}=$ explosive constant (Table 6)

$\mathrm{t}_{\mathrm{c}}=$ average casing thickness (in)

$\mathrm{d}_{\mathrm{i}}=$ average casing inside diameter (in)

Equations (7) and (8) are only valid for the units shown. When using Equation (7), a $\mathrm{CL}=0.99$ is recommend for calculations in this guide. Equation (8) is provided for the case where a higher confidence level is desired. The velocity from Equation (5) and the fragment weight from Equation (7) define the fragment for which the containment must be designed. Ways of arresting the fragment, with fillers or by impact with the case, are addressed in Fragment Penetration. 


\begin{tabular}{|c|c|c|}
\hline SECTIONS & INITIAL VELOCITY, VO & NOTES \\
\hline 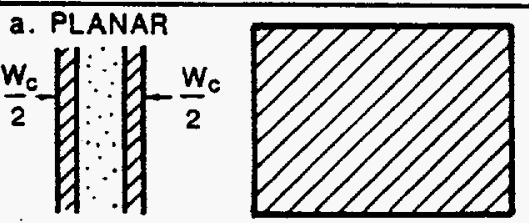 & $\frac{G}{\left(\frac{W_{c}}{W}+\frac{1}{3}\right)^{1 / 2}}$ & $n=1$ \\
\hline 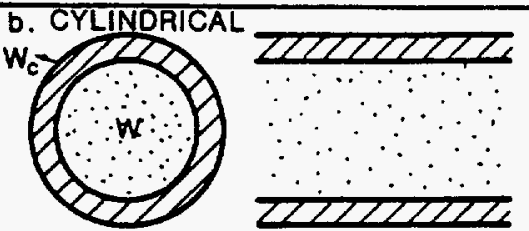 & $\frac{G}{\left(\frac{W_{c}}{W}+\frac{1}{2}\right)^{1 / 2}}$ & $n=2$ \\
\hline$\therefore \because \because y$ & $\left(\frac{G}{W_{c}}+\frac{3}{5}\right)^{1 / 2}$ & $n=3$ \\
\hline
\end{tabular}

(a) Planar, Cylindrical, and Spherical Geometries

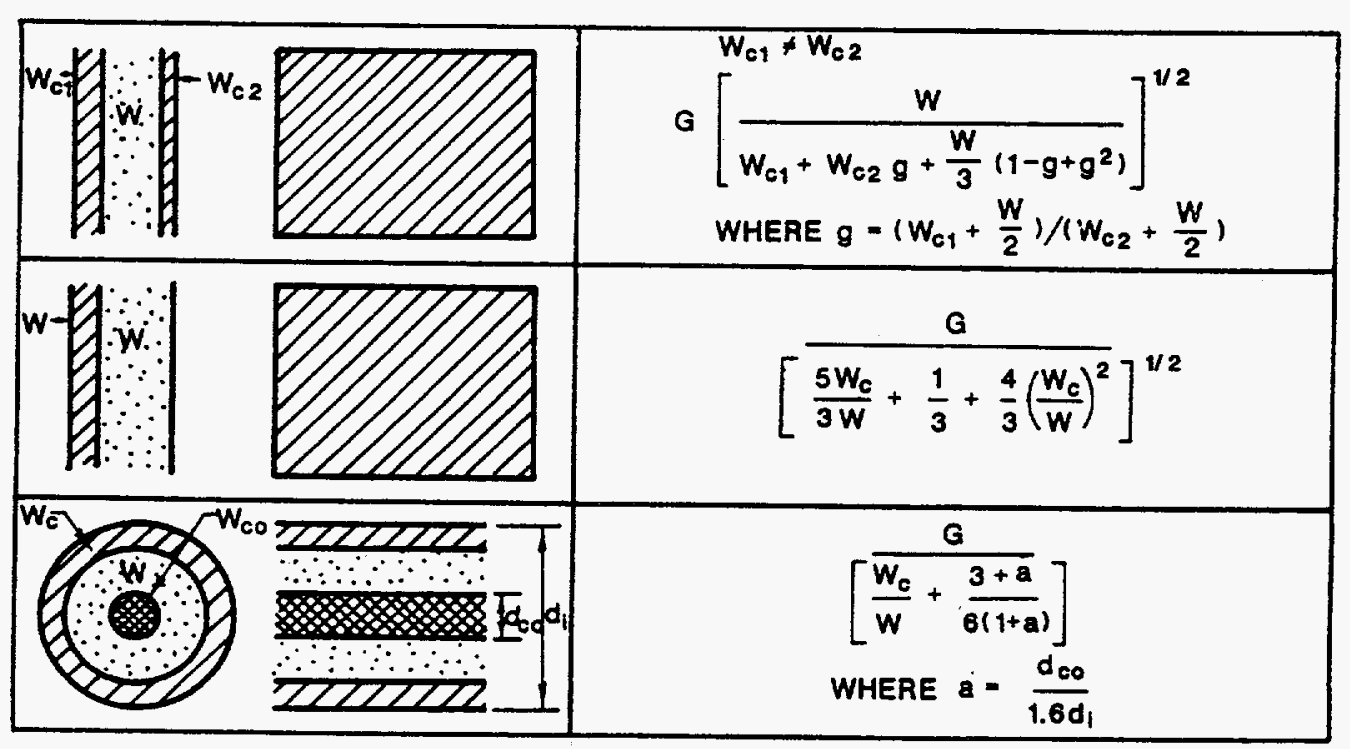

(b) More Complicated Geometry

Figure 5. Gurney Equation for Different Cases ${ }^{[t]}$ 
Table 5. Gurney Constant for Various Explosives ${ }^{[4]}$

\begin{tabular}{|c|c|c|}
\hline $\begin{array}{c}\text { Specific Weight } \\
\left(1 \mathrm{lb} / \mathrm{in}^{\mathbf{3}}\right)\end{array}$ & Explosives & (fps) \\
\hline 0.0639 & $\mathrm{RDX}$ & 9600 \\
\hline 0.0578 & Composition C-3 & 8800 \\
\hline 0.0588 & TNT & 8000 \\
\hline 0.0621 & $\begin{array}{l}\text { Tritonal }{ }^{*} \\
(\text { TNT/A1 }=80 / 20)\end{array}$ & 7600 \\
\hline 0.0621 & $\begin{array}{l}\text { Composition B } \\
\text { (RDX/TNT) }\end{array}$ & 9100 \\
\hline 0.0682 & HMX & 9750 \\
\hline 0.0664 & PBX-9404 & 9500 \\
\hline 0.0585 & Tetryl & 8200 \\
\hline 0.0581 & TACOT & 7000 \\
\hline 0.0411 & Nitromethane & 7900 \\
\hline 0.0635 & PETN & 9600 \\
\hline 0.0527 & $\begin{array}{l}\text { duPont Sheet: } \\
\text { EL506D }\end{array}$ & 8200 \\
\hline 0.0563 & EL506L & 7200 \\
\hline 0.0397 & Trimonite No. $1^{*}$ & 3400 \\
\hline
\end{tabular}

* Denotes nonideal 
Table 6. Mott Scaling Constants for Mild Steel Casings and Various Explosives ${ }^{[5]}$

\begin{tabular}{|c|c|c|}
\hline Explosive & $\begin{array}{c}\text { B } \\
\left(\text { lb }^{1 / 2} \text { inches }^{-7 / 6}\right) \\
\end{array}$ & $\begin{array}{c}\text { Heat of Detonation, } \Delta H \\
f \mathbf{f t}-\mathrm{lb} / \mathbf{b}\end{array}$ \\
\hline Baratol & 0.128 & $1,036,000$ \\
\hline Comp B & 0.0554 & $2,150,000$ \\
\hline Cyclotol (75/25) & 0.0493 & $2,198,000$ \\
\hline $\mathrm{H}-6$ & 0.0690 & $1,292,000$ \\
\hline $\mathrm{HBX}-1$ & 0.0639 & $1,286,000$ \\
\hline HBX-3 & 0.0808 & $1,228,000$ \\
\hline Pentolite $(50 / 50)$ & 0.0620 & $1,722,000$ \\
\hline PTX-1 & 0.0554 & \\
\hline PTX-2 & 0.0568 & \\
\hline TNT & 0.0779 & $1,526,000$ \\
\hline Comp A-3 & 0.0549 & \\
\hline RDX/WAX (95/5) & 0.0531 & $2,114,000$ \\
\hline Tetryl & 0.0681 & $1,595,000$ \\
\hline
\end{tabular}




\section{Response Prediction}

This section of the guide describes methods for predicting structural response of the containment to the shock and gas pressure loads defined in Loads Prediction. It covers the use of the methods and the interpretation of results from the calculations. Response predictions are based on sdof equivalent systems. More complex methods are mentioned but are not described in detail. Calculations are to be made for two load levels: a $125 \%$ over-charge and a $200 \%$ overcharge. Yielding is permitted at the $200 \%$ over-charge and the sdof methods can treat the nonlinear behavior that occurs when the containment yields. Yielding is not permitted at the $125 \%$ over-charge.

\section{Containment Response Modes}

The first step is to decide how the containment will respond to the applied loads. For containments that are box-like, even though they may not be of regular shape, the primary response will be in bending. Bending will occur in the flat walls, generating shear reactions at supporting structure or intersecting walls. The shear reactions can produce tension in connecting walls, but the tension is of little consequence in the overall structural response. For containments that are either cylindrical or spherical in shape, the primary response will be in tension, through membrane action in the walls. Bending may occur in a spherical shaped containment, at penetrations, or in a hemisphere, at the base, but it is of little consequence in the overall structural response. Some containments will have a combination of bending and membrane action; a cylinder with flat ends is an example. Bending and membrane behavior are referred to as the response modes of the structure. In sdof equivalent systems, the structure is assumed to respond in its fundamental mode of behavior for the applied loads. It is closely akin to the fundamental mode of vibration of the structure, except that the loading influences the structural response mode.

Each loaded component in the containment must be checked for allowable stress or strain. Often critical components can be chosen by inspection, and less critical components omitted from the response calculations. An example would be a cylinder of constant internal diameter and loading, but with thickness variations along its length. Clearly, the critical section is the one with the thinnest wall. For bending behavior similar observations can be made. If two walls of the same material are equal in area and shape, and have equal loading and support conditions, the thinner one will experience the largest bending stresses, strains, and deflections; however, the thicker wall will have the highest shear reactions. Once the components to be analyzed have been identified, it is necessary to select an sdof equivalent system to represent them.

\section{SDOF Equivalent System}

The selection of a sdof equivalent system is based on its loading, response mode, and boundary conditions. Tables of transformation factors, the factors used to transform the structural component to an sdof system, and equations for resistance, stiffness, and shear have been 
assembled for a variety of structural components. These are discussed next. A good treatise on sdof systems is given by Biggs ${ }^{[11]}$. It is important to use consistent units in the equation presented in this section.

Beams and Plates--Appendix $C$ contains tables of transformation factors and equations for beams and rectangular and circular plates (or slabs). Values for beams (Tables C-1 through C-3) cover variations in loads (concentrated and uniform) and in support conditions. Transformation factors and equations for plates (Tables C-4 through C- ${ }^{[12]}$ ) cover different boundary conditions and uniform loading. The last table in Appendix $\mathrm{C}$ gives an explanation of terms in the tables. Because the tables for plates are for reinforced concrete (slabs) as well as for homogeneous materials, they contain provisions for differences in negative and positive moments and for different moments in different directions. These are unit moments (moment per unit of length) so, for homogeneous materials, all moments are the same and the equations can be simplified as they are used. Also, when the boundary conditions are not well defined, that is, they are not pinned or fully fixed, it is customary to select the boundary condition that results in the maximum response. This approach introduces some conservatism into the analysis when using sdof methods. If more complex methods, such as FEA, are used, boundary conditions and the coupled response of the entire structure can be represented. It must be stated that FEA calculations, particularly if non-linear behavior is to be treated, are not trivial.

Elastic, Elastic-Plastic, and Plastic Behavior--The tables in Appendix $\mathrm{C}$ givetransformation factors and equations for elastic, elastic-plastic, and plastic behavior. Elastic behavior holds until the component yields. Yielding is represented by the formation of a plastic hinge. If only one hinge can form, as for a simply-supported beam, the response is then fully plastic. If another hinge can form, as for a beam with clamped ends, the response is elasticplastic until the second hinge forms and is then fully plastic. No components have more than two hinge formations in the tables of Appendix C. Because yielding is permitted in some of the calculations that will be made, one will usually evaluate values for the component in all ranges that apply. The methodology used to compute the response of the sdof system selects the proper values to use in each response regime.

Mass and Force--None of the tables in Appendix $\mathrm{C}$ give values for the mass of the components or the force acting on it. Both mass and a dynamic forcing function are, of course, necessary in dynamic calculations. The mass is simply the total mass of the component being analyzed, and the force is simply the total force acting on the component in the response direction being analyzed. If the applied load is a pressure, then the force is pressure times the area on which it acts. If the pressure varies in time, then the force does also. The mass and load factors, $\mathrm{K}_{\mathrm{M}}$ and $\mathrm{K}_{\mathrm{L}}$, "transform" the total mass and force to values that are applied to the sdof system. Transformation factors are necessary because all mass does not move through the same motions and all force does not act on the same displacements (consider the center versus the end of a simple beam, for example). Different factors apply for different types of behavior, i.e., elastic, elastic-plastic, and plastic. As will be discussed in the next section, the full "transformation" can be achieved by using only the load-mass factor. Tables of transformation factors and equations are not available for cylinders and spheres, and these components are 
addressed next.

Cylinder--Equations to represent cylinders as a sdof system are easily derived if the cylinder is acted on by a uniformly distributed loading. They are easy to derive because the assumed deformation pattern is a uniform radial expansion. Since displacements are uniform throughout the structure, all transformation factors are equal to one (1). Equations derived to calculate the mass, stiffness, resistance, and loading of cylinders are:

Mass:

$$
M=\frac{\pi}{4}\left(D_{0}^{2}-D_{i}^{2}\right) L \rho / g_{0}
$$

Resistance:

$$
\mathrm{R}_{\mathrm{m}}=2 \pi \sigma_{\mathrm{y}} \mathrm{tL}
$$

Stiffness:

$$
\mathrm{K}_{\mathrm{e}}=\frac{4 \pi \mathrm{EtL}}{\mathrm{D}_{\mathrm{i}}}
$$

Force:

$$
\mathrm{F}(\tau)=\pi \mathrm{D}_{\mathrm{i}} \mathrm{L} \mathrm{p}(\tau)
$$

where

$$
\begin{aligned}
& \mathrm{L}=\text { cylinder length } \\
& \rho=\text { weight density of cylinder } \\
& \mathrm{g}_{\mathrm{o}}=\text { gravitational acceleration } \\
& \mathrm{D}_{\mathrm{i}}=\text { inside diameter } \\
& \mathrm{D}_{\mathrm{o}}=\text { outside diameter } \\
& \sigma_{\mathrm{y}}=\text { material yield strength } \\
& \mathrm{E}=\text { material elastic modulus } \\
& \mathrm{p}(\tau)=\text { pressure history applied to the inside surface } \\
& \mathrm{t}=\text { thickness of the cylinders }
\end{aligned}
$$

The equations are for a cylinder of length $\mathrm{L}$. This may be the full length of the cylinder or a section for which the load is highest or the wall is thinnest. Often, calculations are performed for a cylinder of unit length, and this is done by setting $L=1$. Equations (9) through (12) give the total mass, resistance, stiffness, and force for the cylinder of length $L$. This is true 
for the values given in the tables of Appendix C--they represent the actual values for the component being analyzed. If one wishes to apply the pressure-time, $p(\tau)$, as the forcing function instead of the force, each of Equations (9) through (12) would be divided by $\pi D_{i} L$, the area over which the load is applied. Yielding in cylinders is denoted by a change in stiffness at the yield point, i.e., when the force in the spring reaches $R_{m}$. Further, it is customary to assume that response above yield is perfectly plastic. Thus, the only change when yielding of the cylinder occurs, is to set the stiffness to zero in the plastic range.

Sphere, Hemisphere, or Dome--As for a cylinder, equations are easy to derive for spheres with a uniform loading because the response is a uniform radial expansion. Equations for the mass, resistance, stiffness, and force for a sphere are:

Mass:

$$
\mathbf{M}=\frac{\pi \mathrm{D}_{\mathrm{i}}^{2} \rho \mathrm{t}}{\mathrm{g}_{\mathrm{o}}}
$$

Resistance:

$$
R_{m}=\pi\left(D_{o}^{2}-D_{i}^{2}\right) \sigma_{y}
$$

Stiffness:

$$
\mathrm{K}_{\mathrm{e}}=\frac{2 \pi \mathrm{E}\left(\mathrm{D}_{\mathrm{o}}^{2}-\mathrm{D}_{\mathrm{i}}^{2}\right)}{(1-v) \mathrm{D}_{\mathrm{i}}}
$$

Force:

$$
F(\tau)=p(\tau) \pi D_{i}^{2}
$$

where

$$
\begin{aligned}
& \mathrm{D}_{\mathrm{i}}=\text { inside diameter } \\
& \mathrm{D}_{\mathrm{o}}=\text { outside diameter } \\
& \mathrm{g}_{\mathrm{o}}=\text { gravitational constant } \\
& \rho=\text { weight density of the sphere } \\
& \mathrm{\sigma}_{\mathrm{y}}=\text { material yield strength } \\
& \mathrm{E}=\text { material elastic modulus } \\
& \mathrm{p}(\tau)=\text { pressure history applied to the inside surface } \\
& \mathrm{t}=\text { sphere wall thickness }
\end{aligned}
$$

If the component is a dome or hemisphere, instead of a sphere, the equations would each be 
divided by two (2). Bending, which may occur at the base of a dome or hemisphere, is ignored. If the dome does not yield in membrane action, bending at the base is usually small. If one wished to apply the pressure-time, $p(\tau)$, as the forcing function instead of the force, each of Equations (13) through (16) would be divided by $\pi D_{i}^{2}$, the inside surface of the sphere over which the load is applied. Yielding of a sphere or dome is treated the same as for a cylinder.

\section{Response Calculations}

The usual steps in a response calculation are:

(1) Calculate the resistance and stiffness of the component for all types of behavior, i.e., elastic, elastic-plastic, and plastic, as required

(2) Calculate the mass of the component

(3) Calculate the force acting on the component in the response direction

(4) Select the transformation factors for all types of behavior

(5) Select the proper equations to calculate component shear reactions

(6) Enter the values in a computer code to make the response calculations

(7) Evaluate the behavior of the structure for compliance with design requirements.

These seven steps are repeated for each component analyzed and, if more than one loading is to be considered, steps (3), (6), and (7) may be repeated for each component.

Resistance and Stiffness--Using equations from the tables in Appendix C or those provided for cylinders, spheres and domes, the resistance and stiffness of the component are calculated for each type of behavior. This will give two or three sets of values that correspond to elastic, elastic-plastic, or fully plastic behavior of the component. Use a consistent set of units for the calculations.

Mass--Compute the total mass of the component that is being analyzed. In English units divide the components total weight by go, the gravitational acceleration, being sure that units are consistent with those used for resistance and stiffness. Equations for mass are given in the guide only for cylinders and spheres. The user must derive the equations for other components.

Force--In most cases the force is a pressure multiplied by the area over which it acts. Force is a vector, so the component in the direction of response must be determined. Time varying forces are entered into the program used to compute response as force-time pairs. A limit of twenty force-time pairs is allowed by the program used in the example for this guide; whereas, pressures computed by BLASTX2 may be stored as hundreds of pressure-time pairs. 
The program DPLOT (an integral part of the BLASTX2 code) is used to convert BLASTX2 output to a limited set of values suitable for input. The program can also be used to combine pressure-time histories, such as for shock and the gas pressure, if they have been calculated separately. It was noted for cylinders and spheres that equations for resistance, stiffness, and mass can be calculated on a unit area basis. This is done by dividing each one by the area over which the load acts. When this is done for cylinders, spheres, or any other component, pressuretime pairs can be used as the forcing function. Pay particular attention to the units for time in the force-pairs. BLASTX2 results are in $\mu \mathrm{sec}$. The program for computing response expects seconds.

Transformation Factors--These factors apply to beams and plates and are selected from the tables in Appendix C for elastic, elastic-plastic, and plastic behavior, as required. The program used in the example problems expects the load-mass factor, $\mathrm{K}_{\mathrm{LM}}$. As noted previously, this single factor effectively transforms the component system into the sdof equivalent model.

Shear Equations--Shear reactions are expressed in terms of the resistance of the system and the applied force. As for the other parameters, the equations are different for elastic, elasticplastic, and plastic behavior. A limitation to the program used in the examples is that a provision has been made for only one shear equation. A conservative approach is to select the highest coefficients for each term (resistance and force) and to use them as input to the program. This will give an upper limit to the shear reaction as computed by the program. Because shearreactions are known to be underestimated by the sdof method for very short duration loads, this is a suitable approach. The reaction will vary throughout the solution, and the program will select and display the maximum and minimum values.

Response Calculations--Response calculations in this guide have been performed by the BIGGS computer program available for a fee from W.E. Baker Engineering. It operates well on a 386 class PC with a VGA color monitor, 1 Meg of memory, and a hard disk. A menu system and data forms are used to prompt the user for input. Data symbols and names correspond well to those found in the tables of Appendix C. Plotting options are provided for displacement, force, resistance and shear. Each plot heading includes a summary of response maximums and minimums for most of the variables in the solution. In addition to the input described in this guide, the BIGGS program requires that the following be specified:

Title for the problem

Rebound parameters--use the same parameters for response and rebound unless support conditions change during rebound

Initial displacement--usually zero

Initial velocity--usually zero unless impulse is represented as an initial velocity 
Damping--usually zero for metals

Number of cycles over which the response is to be computed--set to ensure that the maximum response is reached--as a minimum, enough cycles to reach maximum load

Integration time step--set less than one-tenth of the fundamental period of vibration of the component and small enough to resolve the loading history (a suggested value is computed by the program)

After the parameters have been input to the program, the user has the option of naming and saving the input file (recommended), editing the file, and a number of other things, including calculation. When calculations are complete, menu options permit the user to view an output listing and plot the results. An output file is written. If another run is made with the same input file name, the output file is overwritten.

Compliance--The design goals are no yielding at the design load (125\% overcharge) and yielding that does not exceed three times the yield strain at $200 \%$ overcharge. Yielding is evaluated by the Biggs program as the ratio of maximum deflection to an equivalent elastic displacement. If the component being analyzed is bi-linear (elastic-plastic with a single yield point) this is the deflection at which the component first yields. This ratio of displacements, $\mu$, is calculated and displayed by the program on each plot. It is also given in the listing. If it is less than one at the design charge and less than three at a $200 \%$ over-charge, the component being analyzed satisfies the design requirements. A minor problem arises when the component being analyzed has a tri-linear yield curve (elastic, elastic-plastic and plastic) as for a beam with fixed ends. For such components the equivalent elastic displacement does not correspond to first yield. In this case the displacement at first yield must be computed manually as the resistance at the end of the elastic response, $R_{e}$, divided by the elastic stiffness $K_{e}$. This value is divided into the maximum computed displacement to find $\mu$. In this Guide, $\mu$ is always to be computed based on first yield. The designer also must assure that each component in the containment structure satisfies these requirements, that all design details are properly treated, as set forth in Design Details, and that excessive fragment damage to the containment boundary does not occur. 


\section{Fragment Penetration}

This section gives guidance for arresting the design fragment determined in Loads Prediction. It includes equations for determining penetration depth, and residual velocity in filler materials and penetration in metals. It is important to use consistent units in the equations of this section when specific units are not given.

\section{Penetration in Filler Materials}

Penetration of Compact Fragments--Penetration in filler materials is based on penetration of a rigid fragment through an elastic/plastic locking material. For the Standard Compact Fragment, defined in Figure 6, Drake ${ }^{[13]}$ defines the penetration depth as:

$$
\mathrm{x}_{\mathrm{p}}=\mathrm{k}_{\mathrm{s}_{1}} \mathrm{~W}_{\mathrm{f}}^{1 / 3} \ln \left(1+\mathrm{k}_{\mathrm{s} 2} \mathrm{~V}_{\mathrm{s}}^{2}\right)
$$

where

$$
\begin{aligned}
& \mathrm{x}_{\mathrm{p}}=\text { penetration (in) } \\
& \mathrm{W}_{\mathrm{f}} \quad=\quad \text { fragment weight (lbs) } \\
& \mathrm{V}_{\mathrm{s}} \quad=\text { striking velocity (kfps) } \\
& \mathrm{k}_{\mathrm{sl}}=\frac{16.74+.4380 \rho_{\mathrm{p}} \phi_{1}}{\rho_{\mathrm{p}} \phi_{2}} \\
& \mathrm{k}_{\mathrm{s} 2}=\frac{2 \times 10^{6} \rho_{\mathrm{p}} \phi_{2}}{3 \phi_{3}}
\end{aligned}
$$

For a general fragment, the equation becomes:

$$
x=\left(\frac{3 W_{f}}{4 A g_{0} \rho_{\rho} \phi_{2}}+\frac{\phi_{1} d}{\phi_{2}}\right) \ln \left(1+\frac{2 \phi_{2} \rho_{\rho} V_{s}^{2}}{3 \phi_{3}}\right)
$$

where $\mathrm{A}=$ presented area $\left(\mathrm{in}^{2}\right)$

$\mathrm{d}=$ projectile diameter (in)

$\mathrm{g}_{\mathrm{o}}=$ gravitational acceleration $\left(\mathrm{in} / \mathrm{sec}^{2}\right.$ ) 


$$
\begin{aligned}
& \rho_{\mathrm{o}}=\text { initial mass density of the filler }\left(\mathrm{lb}-\mathrm{sec}^{2} / \mathrm{in}^{4}\right) \\
& \mathrm{e}_{\mathrm{i}}=\text { elastic volumetric strain } \\
& \rho_{\mathrm{p}}=\text { mass density in the locked state }\left(\mathrm{e}=\mathrm{e}_{\mathrm{p}}\right)\left(\mathrm{lb}-\mathrm{sec}^{2} / \mathrm{in}^{4}\right) \\
& \mathrm{e}_{\mathrm{p}}=\text { lockup strain } \\
& \phi_{1}=1-\delta^{1 / 3} \\
& \phi_{2}=\frac{3}{2}-\left(1+\alpha_{\mathrm{p}}\right) \delta^{1 / 3}+\frac{1}{2} \delta^{4 / 3} \\
& \phi_{3}=\frac{4}{9} \mathrm{E}\left[1-\mathrm{e}^{-3 \beta}\right]-\frac{2}{3} \mathrm{Y} \ln \delta+\frac{2}{27} \pi^{2} \mathrm{E}_{\mathrm{t}}-\frac{4}{9} \mathrm{E}_{\mathrm{t}} \eta \\
& \mathrm{E}=\text { uniaxial locked elastic modulus (psi) } \\
& \mathrm{Y}=\text { uniaxial locked yield point (psi) } \\
& \mathrm{E}_{\mathrm{t}}=\text { uniaxial locked "plastic" modulus (psi) } \\
& \eta=\delta+\frac{\delta^{2}}{4}+\frac{\delta^{3}}{9} \\
& \delta=1-\left(\rho_{\mathrm{o}} / \rho_{\mathrm{p}}\right) \mathrm{e}^{-3 \beta} \\
& \left.\beta=(\mathrm{Y} / 2 \mathrm{E})-\frac{\mathrm{e}_{\mathrm{i}}}{3} \text { (also see Table } 4\right) \\
& \alpha_{\mathrm{p}}=1-\rho_{\mathrm{o}} / \rho_{\mathrm{p}}
\end{aligned}
$$

Ideally, the amount of filler material will exceed the penetration depth of the fragment. If this is not the case, the residual velocity of the fragment is predicted by Equation (19):

$$
\mathrm{V}_{\mathrm{r}}=\mathrm{V}_{\mathrm{s}}\left(1-\frac{\mathrm{t}}{\mathrm{x}}\right)^{0.555}
$$

where

$$
\begin{aligned}
& \mathrm{V}_{\mathrm{s}}=\text { striking velocity } \\
& \mathrm{t}=\text { layer thickness } \\
& \mathrm{x}=\text { penetration determined by Equations (17) or (18) }
\end{aligned}
$$

and $t$ and $x$ must have consistent units. These calculations are somewhat tedious, requiring more than ten parameters for the filler material. Table 7 gives a number of the parameters for selected materials. Strain parameters are determined from hydrostatic compression tests of the material, and the yield strength and modulii are determined from uniaxial tests. These parameters are demonstrated for idealized stress-strain behavior in Figure 7. 


\section{Fragment Calculations Typically Assume a "Standard Compact Fragment"}

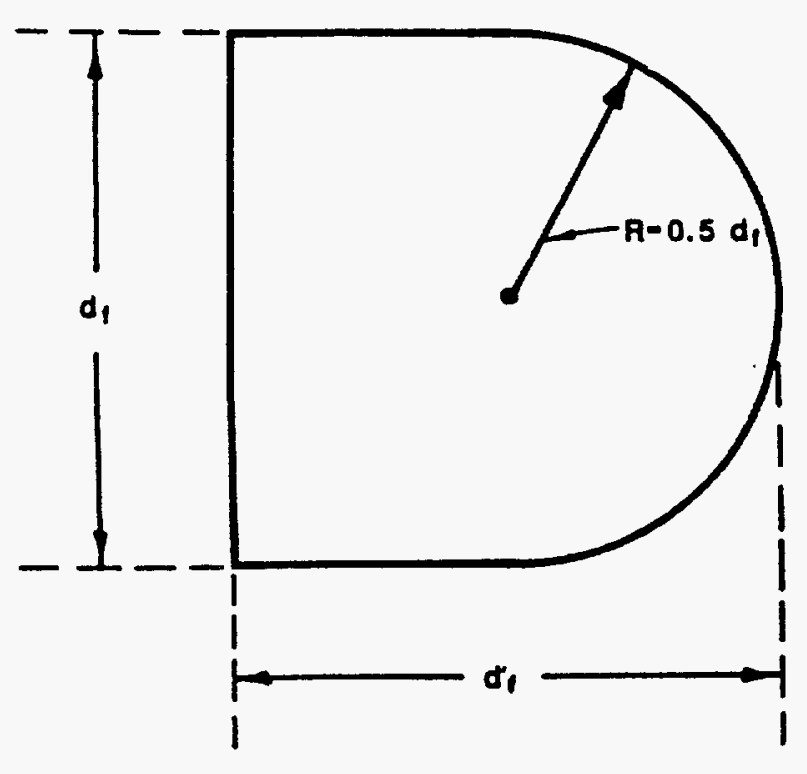

$$
\begin{aligned}
\mathrm{V}_{\mathrm{f}} & =\frac{5 \pi d_{f}^{3}}{24}=0.654 d_{f}^{3} \\
\mathrm{~A}_{\mathrm{f}} & =\frac{\pi d_{f}^{2}}{4}=0.785 d_{f}^{2} \\
\mathrm{~W}_{\mathrm{f}} & =\gamma_{f} V_{f}, \gamma_{f}=\text { density } \\
\mathrm{V} & =\text { volume } \\
\mathrm{d}_{\mathrm{f}} & =\left(\frac{24 \mathrm{w}_{f}}{5 \pi \pi_{f}}\right)^{\frac{1}{3}} \\
D & =\frac{w_{f}}{d_{f}^{3}}
\end{aligned}
$$

Figure 6. Standard Compact Fragment ${ }^{[13]}$ 
Table 7. "Lockup" Parameters for Selected Filler Materials ${ }^{[9]}$

\begin{tabular}{||l|c|c|c|c|c|c||}
\hline \multicolumn{1}{|c|}{ Material } & $\mathbf{e}_{\mathrm{i}}$ & $\mathbf{e}_{\mathrm{p}}$ & $\rho_{\mathrm{o}}$ & $\begin{array}{c}\mathbf{E} \\
\mathbf{p s i})\end{array}$ & $\begin{array}{c}\mathbf{E}_{\mathrm{t}} \\
(\mathbf{p s i})\end{array}$ & $\begin{array}{c}\mathbf{Y} \\
(\mathbf{p s i})\end{array}$ \\
\hline Duocell Metal Foam & .06 & .8 & .000018 & 5,833 & 0 & 350 \\
\hline Vermiculite & $.15^{*}$ & .71 & .0000075 & $500^{*}$ & 0 & $100^{*}$ \\
\hline $\begin{array}{l}\text { Urethane Foam } \\
(.1 \mathrm{gm} / \mathrm{cc})\end{array}$ & .05 & .4 & .0000093 & 2,900 & 0 & $145^{* *}$ \\
\hline $\begin{array}{l}\text { Urethane Foam } \\
(.5 \mathrm{gm} / \mathrm{cc})\end{array}$ & .04 & .3 & .000045 & 126,900 & 2,789 & $5,076^{* *}$ \\
\hline
\end{tabular}

\begin{tabular}{||l|l|l|l|c||}
\hline \multicolumn{1}{|c|}{ Material } & & $\phi_{1}$ & $\phi_{2}$ & \\
\hline Duocell Metal Foam & .00004 & .174 & .45 & 210.7 \\
\hline Vermiculite & .000015 & .24 & .205 & 87.2 \\
\hline $\begin{array}{l}\text { Urethane Foam } \\
(.1 \mathrm{gm} / \mathrm{cc})\end{array}$ & .000014 & .30 & .69 & 135.0 \\
\hline $\begin{array}{l}\text { Urethane Foam } \\
.5 \mathrm{gm} / \mathrm{cc})\end{array}$ & .000067 & .024 & .070 & 1869.8 \\
\hline
\end{tabular}

$\begin{array}{ll}* & \text { estimated } \\ * * & \text { from SHPB tests @ } \xi=3000 / \mathrm{sec} \text { strain rate }\end{array}$

It is assumed that the fragment will not be eroded by the filler material. Thus, if it has a residual velocity after passing through the filler, the fragment, with a residual velocity predicted by Equation (19), must be arrested by additional filler material, another barrier, or the wall of the containment. For penetration in a different filler material, Equations (17) through (19) are used again. For penetration into a metal barrier or the wall of the containment, equations are found in Penetration into Solid Materials. 


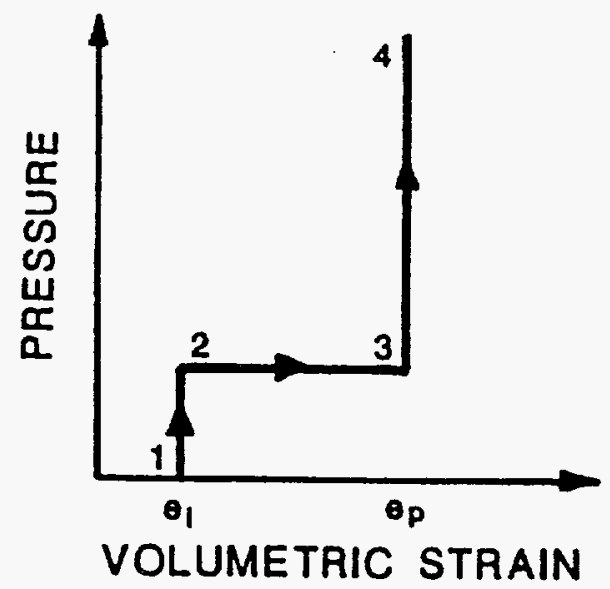

a. HYDROSTATIC COMPRESSION

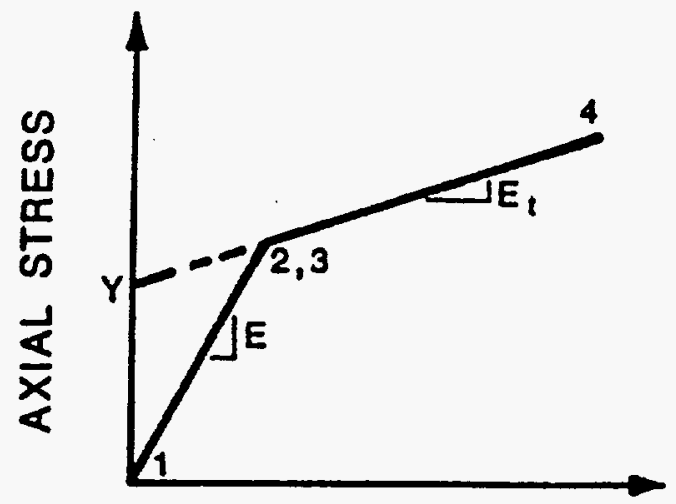

AXIAL STRAIN

b. UNIAXIAL STRAIN

Figure 7. Idealized Locking Stress-Strain Behavior

Penetration of Large, Low-Density Fragments--Equations presented here are for fragments that may be determined by the designer/analyst, based on the geometry of the explosive device. Generally they will not fit the Standard Compact Fragment description. They may represent the top, side, or lid of a container. The only requirement is that the characteristic dimension of the fragment be at least five times the cell size of the filler material. For such fragments, penetrating into a lowdensity, cellular type material, the penetration depth is given by Equation (20).

$$
x_{p}=\frac{K E}{f_{c r} A_{p}}
$$

where $x_{p}=$ penetration depth

$\mathrm{KE}=$ kinetic energy of the fragment

$\mathrm{f}_{\mathrm{cr}}=$ average crush strength over the penetration distance

$\mathrm{A}_{\mathrm{p}}=$ presented area of the fragment 
The kinetic energy of the fragment is computed by Equation (21):

$$
\mathrm{KE}=\frac{1}{2} \frac{\mathrm{W}_{\mathrm{f}}}{\mathrm{g}_{\mathrm{o}}} \mathrm{V}_{\mathrm{s}}^{2}
$$

where $\quad W_{f}=$ fragment weight, Equations (7) or (8)

$\mathrm{V}_{\mathrm{s}} \quad$ = fragment striking velocity, Equation (5) or Equation (19)

$\mathrm{g}_{\mathrm{o}} \quad=$ gravitational acceleration

The resulting penetration depth is the thickness of the filler material that will be crushed at the average crush strength. If the material crushes to $80 \%$ of its original thickness, then a thickness equal to $120 \%$ of the penetration depth, $\mathrm{x}_{\mathrm{p}}$, is required to arrest the fragment. Because this is not a penetrating type of fragment, any kinetic energy that is not absorbed by the filler, must be absorbed by deformations in the structure that backs the filler material.

\section{Penetration into Solid Materials}

Penetration of Steel--Penetration into solid materials will assume the Standard Compact Fragment of Figure 6. For penetration of steel fragments into steel, the equation is:

$$
x_{p}=0.749 W_{f}^{0.33} V_{s}^{1.22}
$$

where $\mathrm{x}_{\mathrm{p}}=$ penetration depth (in.)

$\mathrm{W}_{\mathrm{f}}=$ fragment weight (lbs), Equations (7) or (8)

$\mathrm{V}_{\mathrm{s}} \quad$ = fragment striking velocity (kfps) from Equation (5) or Equation (19)

For fragments other than steel, the penetration depth given by Equation (22) is adjusted by:

$$
x_{m}=k_{p} x_{p}
$$


where $\mathrm{k}_{\mathrm{p}}=\frac{0.632 \mathrm{BHN}+94.88}{275}\left(\frac{\rho_{i}}{\rho_{s}}\right)=$ penetrability coefficient

$\mathrm{BHN}=$. Brinell Hardness of the fragment material

$\rho_{\mathrm{f}} \quad=$ density of the fragment material

$\rho_{\mathrm{s}} \quad=$ density of steel

Table 8 gives data on the relative penetrability of fragments made from other materials for use in Equation (23).

Table 8. Relative Penetrability ${ }^{[13]}$

\begin{tabular}{||l|c|c|c|}
\hline Fragment Material & $\begin{array}{c}\rho_{\mathbf{f}} \\
\text { Density } \\
\text { (lb/in3) }\end{array}$ & $\begin{array}{c}\text { BHN } \\
\text { Brinell Hardness } \\
\text { Number }\end{array}$ & $\begin{array}{c}\mathbf{k}_{\mathrm{p}} \\
\text { Penetrability } \\
\text { Coefficient }\end{array}$ \\
\hline *AP Steel & 0.286 & 285 & 1.00 \\
\hline Mild Steel & 0.286 & 140 & 0.70 \\
\hline Lead & 0.385 & 10 & 0.50 \\
\hline Aluminum & 0.098 & 32 & 0.15 \\
\hline
\end{tabular}

* armor piercing

Penetration of Other Materials by Steel Fragments--If one chooses materials other than lowdensity fillers or steel to arrest fragments, the Thor equations ${ }^{[14]}$ given in Appendix D can be used. They have been derived from empirical data to predict the ballistic limit and residual fragment mass and velocity for chunky steel fragments penetrating a variety of materials. The Standard Compact Fragment of Figure 6 is appropriate for the Thor equations.

Spallation by High Velocity Planar Impact--Impacts can occur for which penetration is not an issue but which may produce spallation (to include internal fractures which delaminate a plane of material parallel to the containment boundary surface, but does not displace the material) of the containment boundary. Such impacts are characterized by relatively large, thin, flat or curved fragments striking the wall of the containment such that simultaneous contact is made over a large part of the fragment surface (planar impact). If the fragment impact velocity is high enough, and if the lateral extent of the contact area is greater than the thickness of the containment wall, spallation may occur. Equation (24), from Zukas, etal, ${ }^{[15]}$ gives the peak stress, $\sigma_{\mathrm{I}}$ produced by an elastic impact of two materials: 


$$
\sigma_{1}=\frac{\rho_{1} C_{L_{1}} \rho_{2} C_{L_{2}}}{\rho_{1} C_{L_{1}}+\rho_{2} C_{L_{2}}} V_{s}
$$

$$
\begin{aligned}
& \text { where } \mathrm{C}_{\mathrm{Li}}=\text { longitudinal sound speed in material } i=\sqrt{\frac{\mathrm{E}_{\mathrm{i}}\left(1-v_{\mathrm{i}}\right)}{\left(1+\mathrm{v}_{\mathrm{i}}\right)\left(1-2 v_{\mathrm{i}}\right) \rho_{\mathrm{i}}}}, i=1.2 \\
& \mathrm{E}_{i}=\text { elastic modulus of material, } i, i=1,2 \\
& \rho_{i}=\text { mass density of the material } i, i=1,2 \\
& \mathrm{~V}_{\mathrm{s}}=\text { fragment striking (impact) velocity } \\
& v_{i}=\text { Poisson's ratio of material } i, i=1,2
\end{aligned}
$$

The impact stress, $\sigma_{\mathrm{I}}$, is compared to the Hugoniot elastic limit stress given by Equation (25). If $\sigma_{\mathrm{I}}$ exceeds $\sigma_{\mathrm{HEL}}$ of the containment material, a more thorough analysis, such as provided by Kinslow ${ }^{[16]}$, must be performed to see if spallation will indeed occur. If spallation is predicted to occur, the designer should attempt to reduce the fragment impact velocity using the methods in this Guide, place a shock mitigating layer between the fragment and the containment boundary, or make other changes to prevent spall. The methodology provided by Kinslow can be used to explore the use of a shock mitigating material and to show the effects of material or geometric changes. If it is not possible to prevent spall, the design will not satisfy the requirements of this Guide.

$$
\sigma_{\mathrm{HEL}}=\mathrm{F}_{\mathrm{ty}} \frac{1-v}{1-2 v}
$$

where $\quad F_{t y}=$ tensile yield stress of the containment material

$v=$ Poisson's ratio of the containment material 


\section{Design Details}

This section of the guide addresses connections, closures and material selection. While not specifically recommended for the design of containment closures, bolted connections are included because they cannot easily be avoided for box-like containments.

\section{Static Equivalent Loads for Connection Analysis}

Sdof methods of analysis do not provide sufficient detail to permit dynamic stresses and deformations in fasteners to be determined in conjunction with deformations in the containment structure. Consequently, stresses in fasteners must be determined separately, and it is convenient to use formulas that have been developed for static loads, such presented by Roark ${ }^{[7]}$. One way of determining an equivalent static load is to consider a dynamic load factor. For elastic behavior, a load factor can be expressed as a function of the peak load, the load duration and the response period of the component; however, this approach is inappropriate for plastic behavior that is permissible in contaimments at the $200 \%$ overload. An alternate approach is to use the maximum load transmitted to the fastener from the sdof analysis, without regard to loading and response times. While flexibility in the connection is ignored, flexibility of the component that transmits load to the connection is included. Thus, the approach suggested in this guide is to take the maximum calculated reaction force at the boundary where the fastener is located, as the equivalent static design load. To consider additional flexibility, i.e., in the connection, requires additional degrees of freedom, and that is left for more complex methods. In addition to the loads from the sdof analysis, other forces may be present that can affect bolt loads. The most likely source of additional forces is accelerations produced when tests are performed on a centrifuge. The designer/analyst must judiciously account for such forces in the analysis.

This approach is demonstrated in the example problem of Appendix B. A dome-shaped lid is retained on the base of the containment with a Spirolox ring. The load used to compute stresses in the flange, ring and restraining structure is the maximum reaction at the base of the lid. This is done by selecting the maximum reaction forces from the sdof analysis of the lid.

\section{Connections}

Retaining Rings--Analysis methods for connections can be developed using equations presented by Roark ${ }^{[6]}$. The calculations can be tedious, and are demonstrated for the lid of the sample containment in the example problem. Equations in the example account for bending flexibility in the dome sidewall and flange. Data from the manufacturer were used to evaluate adequacy of the ring and retaining groove.

Circular Bolted Joints--Methods, similar to that demonstrated for rings in the example problem, can be used for circular bolt patterns as well. The solution described for the Spirolox ring is expanded to consider concentrated forces and moments on the flange at the bolt circle, bolt stretch, bolt bending, and restraint at the flange outer edge (prying action). Examples of this approach were given by Marchand and $\mathrm{Cox}^{[9]}$ in a short course entitled, "Small Containment 
Design for Testing Explosive Devices." Solutions obtained with the EXCEL spreadsheet program were provided in the course. Many users of this guide will have access to the programs. Also, a program of the equations given by Roark ${ }^{[6]}$ is available for the PC and should make such calculations much easier.

Rectangular Bolted Joints--More complex solutions are required for rectangular bolt patterns. Solutions, written in the Basic language, have been developed for PC's. One such program was provided in the short course by Marchand, et $\mathrm{al}^{[9]}$ for flat rectangular covers attached to a stiff flange. It is based on the assumption that the flange to which the cover is bolted does not rotate and considers cover bending, bolt stretch, bolt bending and prying action. Its use is limited to elastic behavior. For more complex geometry, or for problems that involve non-linear material behavior, FEA methods or their equivalent must be used. They can be applied to examine the behavior of the containment, including connections, under dynamic loading, or to examine static behavior of the containment and connections for the equivalent static load.

Bolt Engagement Length--Equations in the Machinery's Handbook ${ }^{[17]}$ are recommended for calculating the length of thread engagement required to fully utilize the strength of a bolt. The equations are found on pp. 1278 and 1279 in the 23rd edition. Detailed information on the bolt threads are required by the equations, and can be found in the table beginning on pg. 1498 of the handbook.

Bolt Torque--If tightness requirements are imposed on containments used for testing explosive devices, the designer must ensure that the joints are tight and remain tight during the test. To do this he must show that the bolt preload is not exceeded by the test loads. It is suggested that the designer rely on the bolt manufacture's data to determine the allowable load and torque. Information on the relationship between the bolt load and bolt torque also can be found in the Machinery's Handbook ${ }^{[17]}$ (pg. 150 of the 23rd edition). The preload placed on the bolts by the bolt torque is then compared to the maximum bolt loads estimated from an sdof or more complex analysis, and accounting for bolt loads from other superimposed forces. If tightness requirements are not imposed, then it is recommended that the joint be made snug. This can be achieved at $10 \%$ to $20 \%$ of the maximum allowable bolt load specified by the manufacturer. Under dynamic loads a low preload can be advantageous because preload reduces the total energy the bolt can absorb during the dynamic loading.

Inserts--Inserts are recommended for for bolted joints where gauling or excessive wear is a potential problem. Examples would be for aluminum or stainless steel containers that are drilled and taped for steel bolts. The designer is to rely on the manufacturer's design data when using inserts. Helicoil inserts have been used successfully in past containments.

\section{Material Selection}

Materials for explosive containment must be ductile, tough and have nil-ductility transition temperatures that are well below the minimum expected operating temperature. This applies to 
materials used for the containment structure itself as well as to the fasterners used hold it together. Some metals that have been used successfully for such applications are:

\author{
HY80 and HY100 steel \\ 516 Grade 70 steel \\ 304 stainless steels \\ 4130 steel \\ 4340 steel \\ 5083 aluminum \\ 5986 aluminum \\ 6061 aluminum
}

Material selection is not limited to this list. Any material can be used that possesses good ductility and toughness at the minimum service temperature (the minimum test temperature, for example), so long as good design procedures, as outlined in this guide, are followed. 


\section{Inspection and Testing Recommendations}

This section covers proof testing and inspection procedures for the containments to insure that they meet design requirements and do not fail in service. Proof testing is to be done at the design charge weight ( $125 \%$ over-charge) and no evidence of yielding or cracking is permitted. Inspections are to be performed before each test or test series to insure that the containment is suitable for use. No periodic recertification testing is recommended.

\section{Proof Testing}

Test Charge Weight--Proof testing for pressure containment is to be performed at the design charge weight $(1.25 \times$ Actual Charge Weight). If testing is to be performed with a substitute explosive, an equivalent charge must be established. This is done using the procedures described in TNT Equivalent Explosive Weight. The TNT equivalency is determined for the actual explosive and for the substitute explosive. Dividing the TNT equivalency of the actual explosive by that for the substitute explosive, will give the equivalency ratio of the substitute to the actual explosive. Use this ratio to determine the test charge weight. If a test is required to evaluate fragment containment, this test is to be performed with a device simulant that contains the actual charge weight. If a substitute explosive is to be used, it is determined in the same way as the test charge.

Charge Geometry and Placement--The test charge must simulate the geometry of the actual charge and be placed in the containment in position that is consistent with the position of the charge when in the actual explosive device. It is recommended that the explosive be assembled in a low density non-structural container that has approximately the same geometry as the explosive device.

Device Simulant--If the design of the containment is driven by a fragment threat, fragment containment must be evaluated in a separate test that uses a device simulant. The device simulant must mimic the geometry and material of the actual device and contain the actual amount of explosive or explosive simulant, determined in Test Charge Weight.

Test Configuration--The test configuration is to match, as closely as possible, the conditions that will exist in a real, in-service test. This is to include the use of filler material, wiring to mimic that of the explosive device, and all other conditions except imposed accelerations. If bolting is used to assemble and close the containment, bolts shall be torqued to the level specified in Design Details.

Pre-Test Inspection--Inspection of the completed containment is to be performed prior to proof testing. Inspection is to include:

(1) visual inspection

(2) dimensional checks

(3) full surface dye penetrant or magnetic particle (MT) for steel/ferrous material 
(4) radiograph of all weldments

(5) ultrasonics (only required if spalling is a potential problem)

No linear indications, such as laps, seams or cracks, are permissible. Weldments shall conform to the inspection requirements of the American Welding Society Standard D1.1, "Classification and Application of Welded Joints for Buildings, Bridges and Tubular Construction," latest revision, or equivalent.

Post-Test Inspection--All pre-test inspections, except radiography, are to be performed in the post-test inspection. No permanent deformation or cracking shall be evident from the posttest inspection.

\section{In-Service Inspections and Usage}

Inspections--The containment shall be inspected prior to each in-service test. Inspections shall consist of:

(1) visual inspection

(2) dimensional check

(3) full surface dye penetrant or magnetic particle (MT) for steel/ferrous material

No damage shall be evident in the visual inspection. Dimensions shall not exceed $100.1 \%$ of the characteristic length being measured, relative to the post-proof-test inspection. No linear indications, such as laps, seams or cracks, are permissible. This procedure requires only that records be kept of the post-test inspection following the proof test and that a procedure be established to assure that the in-service inspections are performed and results are consistent with these requirements. It is recommended that a $\log$ be kept, with files of the post-proof-test inspection records, of inspection dates, pass-fail indication, initials of inspector and initials of person verifying the results.

At his discretion, the design engineer may wave inspections before every test in a test series. In this case the engineer assumes responsibility for containment integrity. Waving the inspection requirement before each test is not recommended for new containments that have not proven themselves through a series of successful tests (and inspections). If it is desirable to submit a new containment to a series of tests between inspections, it is suggested that the containment be initially proof tested for the same test series, i.e., perform repeated proof tests to equal the number of tests in the series.

Usage--With this inspection procedure, no limit is placed on the life of the containments, so long as they are used for the explosive device for which they were designed. It is recommended that new bolts, as required, be used for each test. 


\section{References}

1. Britt, J.R., "Enhancements of the BLASTX Code for Blast and Thermal Propagation in Protective Structures: BLASTX Version 2.0," SAIC 405-92-3, Science Applications International Corporation, 1992.

2. Kingery, C.N. and Bulmash, G., "Airblast Parameters from TNT Spherical Air Burst and Hemispherical Surface Burst," Technical Report ARBRL-TR-02555, U.S. Army ARDC-BRL, Aberdeen Proving Ground, MD, April 1984.

3. Hayes, D.B., "Introduction to Stress Wave Phenomena," SLA-73-0801, Sandia National Laboratories, 1976.

4. Gurney, R.W., "The Initial Velocities of Fragments from Bombs, Shells and Grenades," Report No. 648, Ballistic Research Laboratory, Aberdeen Proving Ground, MD, September 1947.

5. Healey, J., Werner, H., Weissman, S., Dobbs, N. and Price, P., "Primary Fragment Characteristics and Impact Effects on Protective Barriers," Picatinny Arsenal Technical Report No. 4093, Amman and Whitney, Consulting Engineers, New York, NY, December 1975.

6. Young, W.C., "Roark's Formulas for Stress and Strain," Sixth Edition, McGraw-Hill Book Company, New York, NY, 1989.

7. Hyde, D.W., "User's Guide for Microcomputer Programs CONWEP and FUNPRO, Applications of TM5-855-1," Instruction Report SL-88-1, U.S. Army COE Waterways Experiment Station, Vicksbury, MS, April 1988, Revised February 1991.

8. Fundamental of Protective Design for Conventional Weapons, U.S. Army Technical Manual TM5-855-1, November 1986.

9. Marchand, K.A. ,Cox, P.A., and Polcyn, M.A., "Small Containment Design for Testing Explosive Devices," Course Notes, Southwest Research Institute, 1992.

10. Neal, T.R., "Use of Mitigating Materials for Blast Design," M-4: GR-88-12, M-4 Hydrodynamics, Los Alamos National Laboratory, Los Alamos, NM, 1988.

11. Biggs, J.M., "Introduction to Structural Dynamics," McGraw-Hill Book Company, New York, NY, 1964.

12. U.S. Army Corps of Engineers Manual EM 1110-345-415, Design of Structures to Resist the Effects of Atomic Weapons, 1975.

13. Drake, J.L., Twisdale, L.A., Frank, R.A., Dass, W.C., Rochefort, M.A., Walker, R.E., Britt, J.R., Murphy, C.E., and Sues, R.H., "Protective Construction Design Manual: Fragment Protection (Section VI)," Final Report No. ESL-TR-87-57, prepared for the Air Force Engineering \& Services Center, Tyndall AFB, FL, November 1989. 
14. Ballistic Analysis Laboroatry, Johns Hopkins University, "The Resistance of Various Metallic Materials to Perforation by Steel Fragments; Empirical Relationships for Fragment Residual Velocity and Residual Weight," Institute for Cooperative Research, Project THOR Technical Report No. 47, April 1961.

15. Zukas, J.A., Nicholas, T., Swift, H.S., Lbgrezczak, L.B., and Curran, D.R., Impact Dynamics, John Wiley and Sons, Inc., New York, N.Y., 1982.

16. Kinslow, R., 1976 (May). "Spallation Resulting from High-Velocity Impacts," AD-A031907, Report 2179, US Army Mobility Equipment Research and Development Command, Fort Belvoir, Virginia.

17. Oberg, E., Jones, F., and Horton, H., Machinery's Handbook, 23rd Revised Edition, Ryffel, H. Sr. Editor, Industrial Press, Inc., New York, NY, 1988. 


\section{Appendix A. Example Loads Calculations}

As a prelude to the development of this standard, the sample containment shown in Figure 1 was analyzed using the procedures outlined in this standard. Figures A1 - A5 on the following pages further define the characteristics of that containment. The example case presented here includes the details of the $125 \%$ overcharge case. As noted in Appendix B, the $100 \%$ and $200 \%$ cases were also analyzed, as well as the case with complete (both chambers) vermiculite fill. 


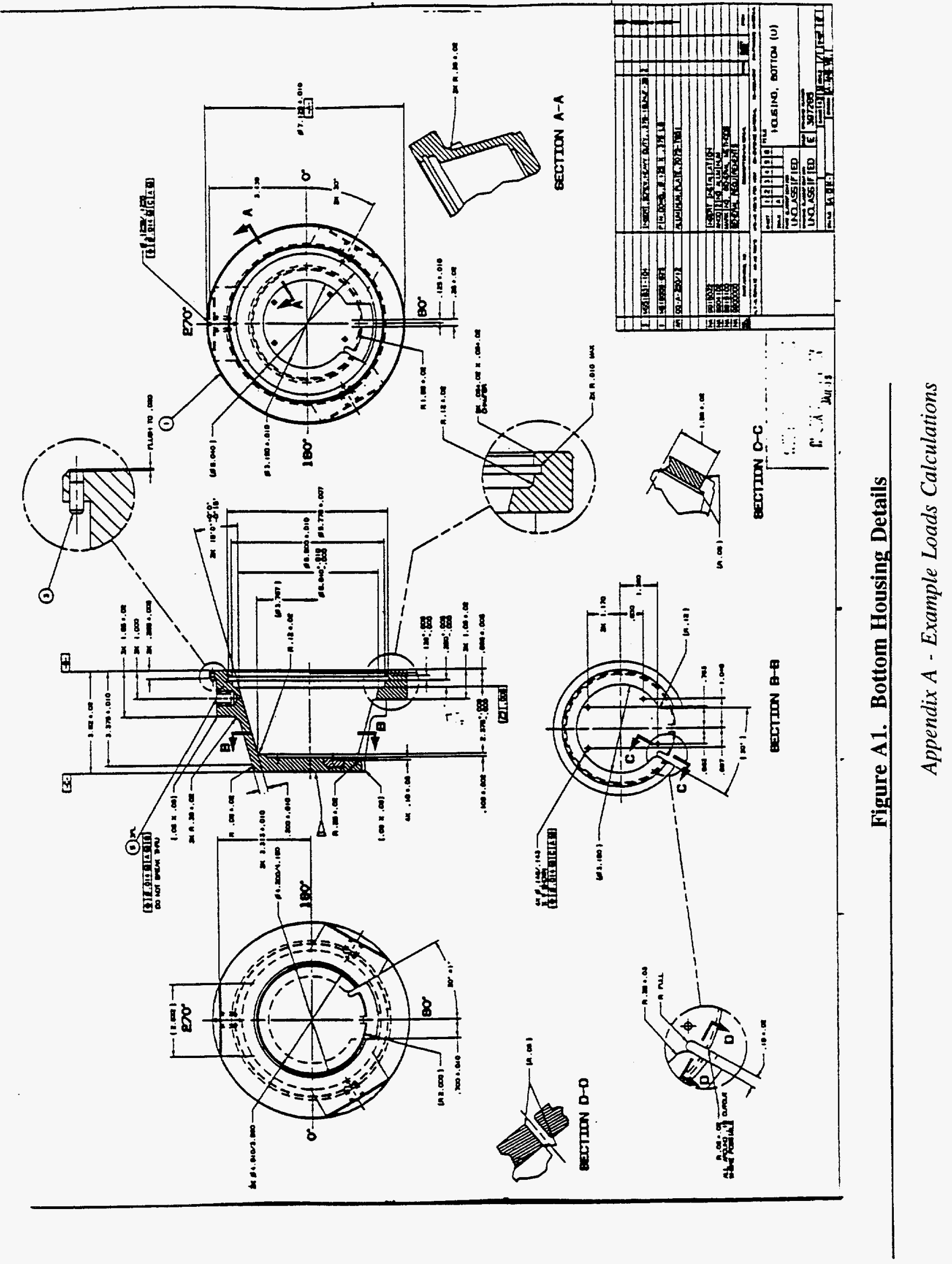




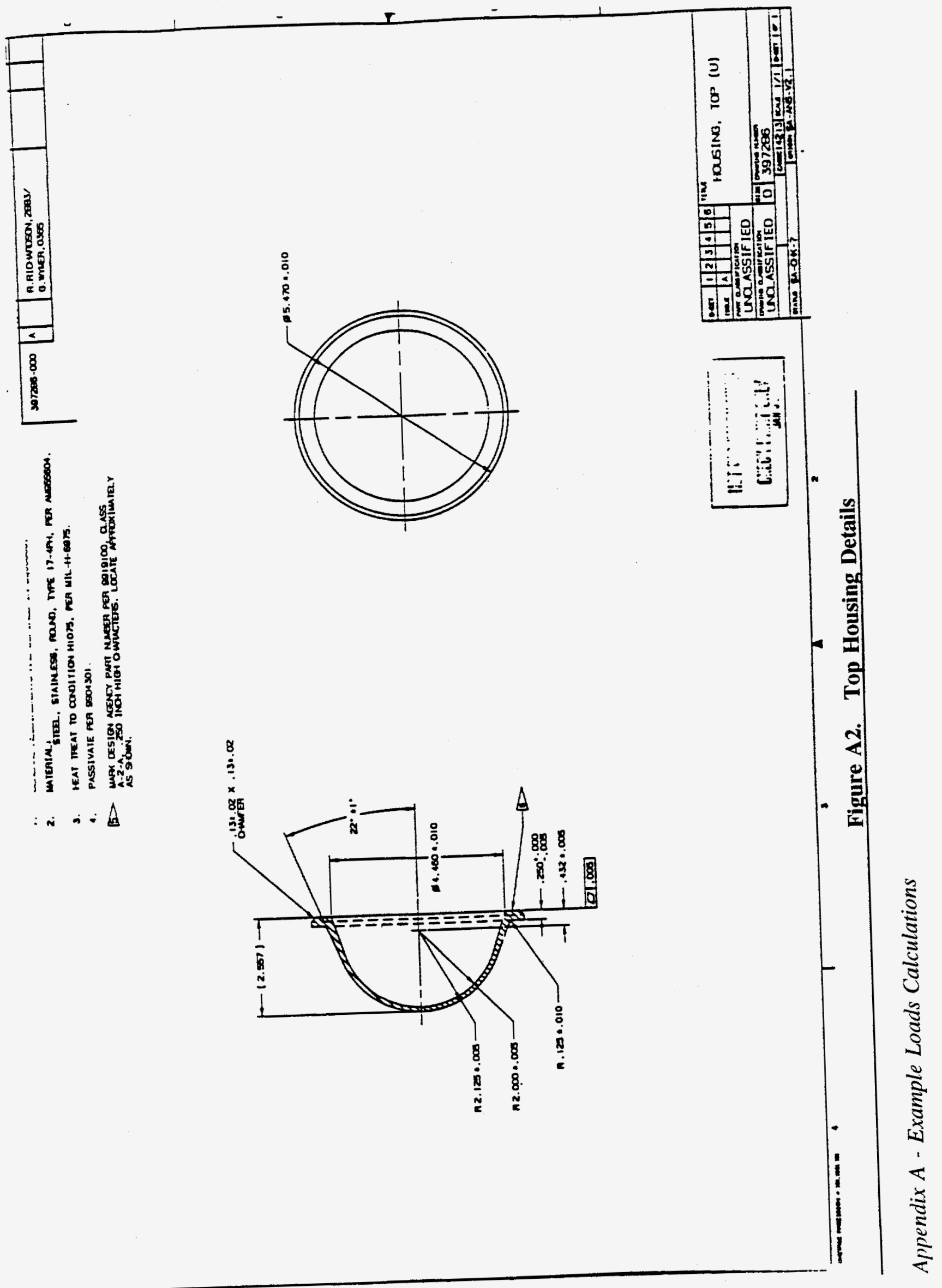




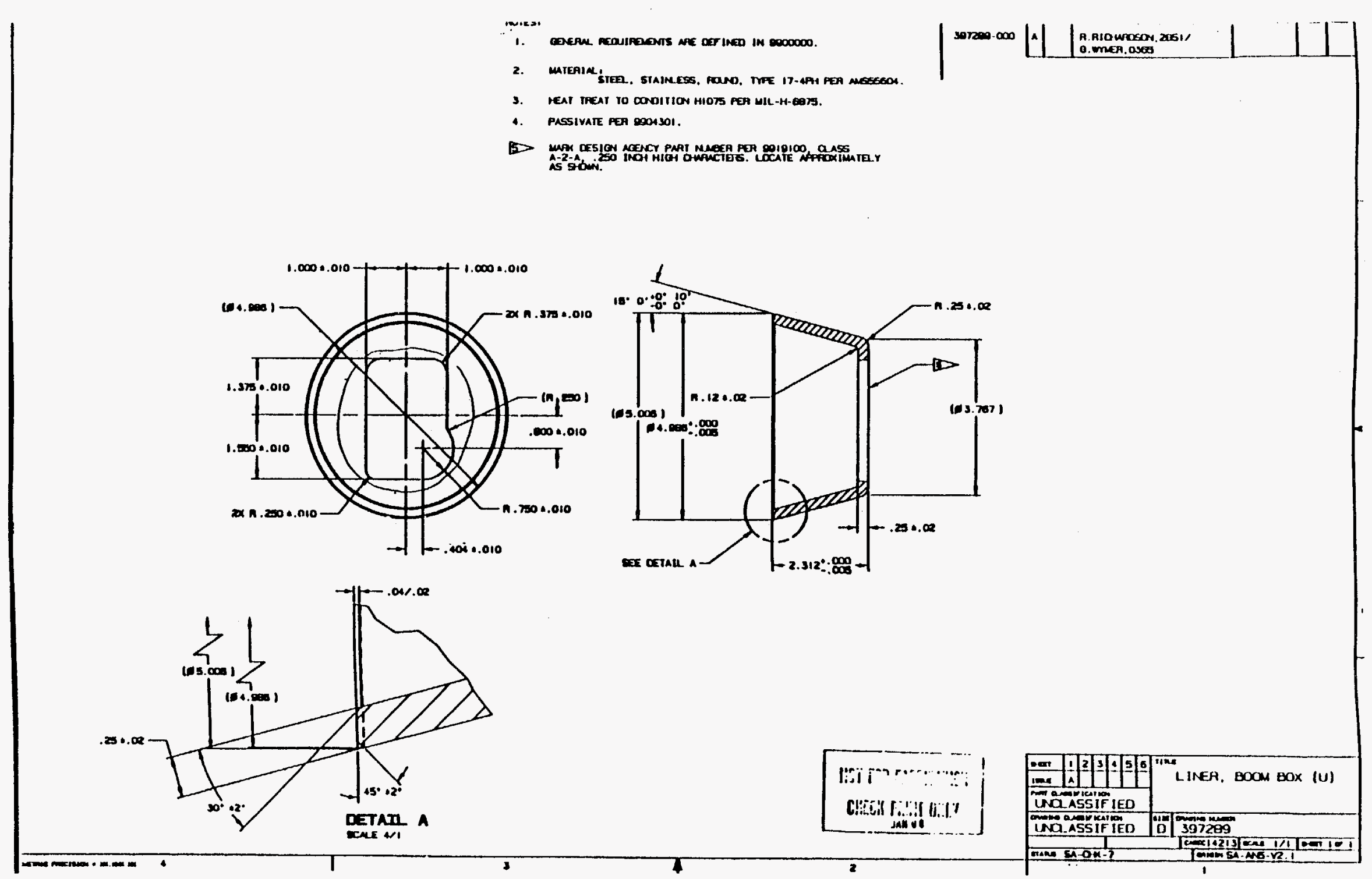

Figure A3. Bottom Liner Details

Appendix A - Example Loads Calculations 


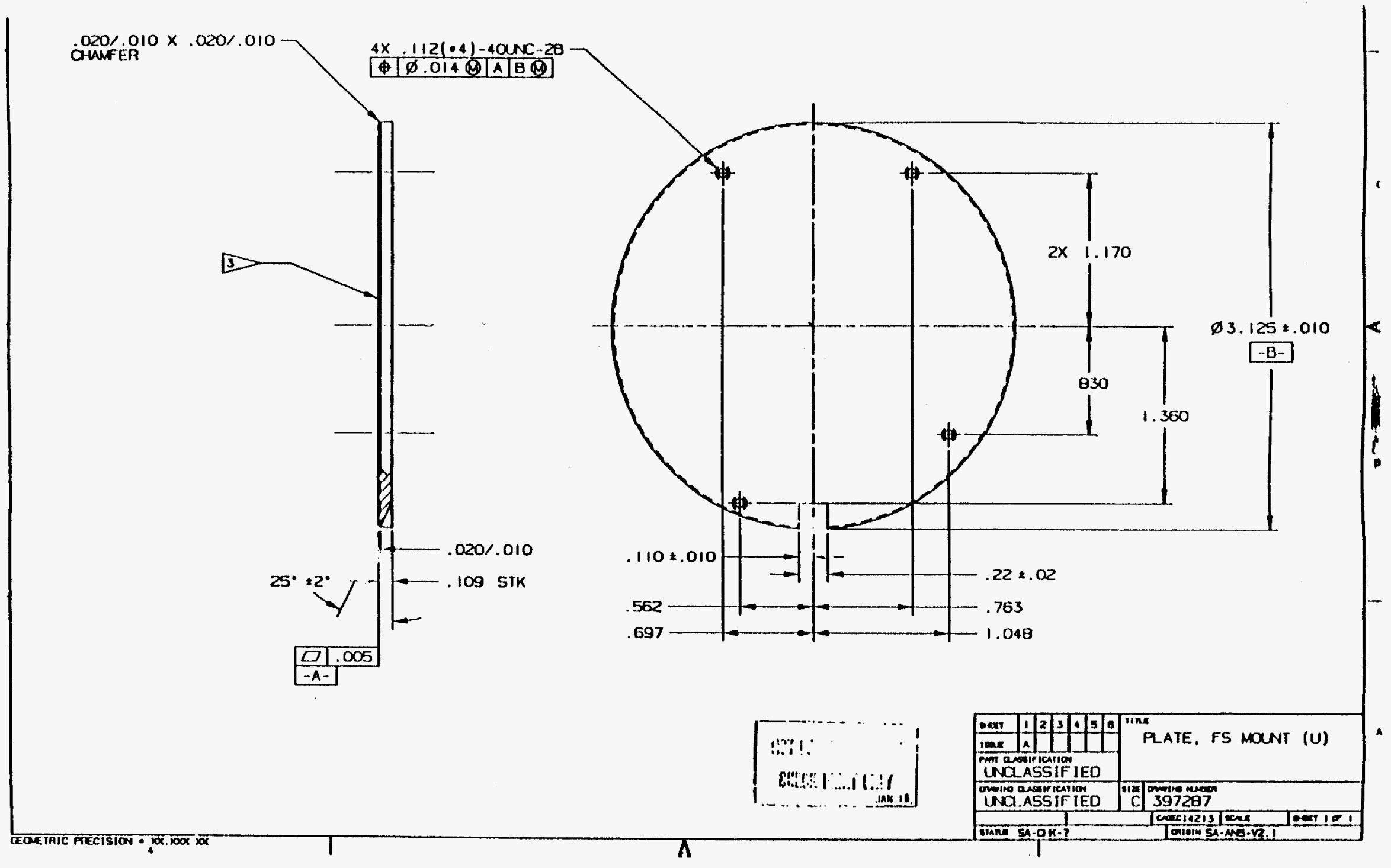

Figure A4. Mounting Plate Details

Appendix A - Example Loads Calculations 

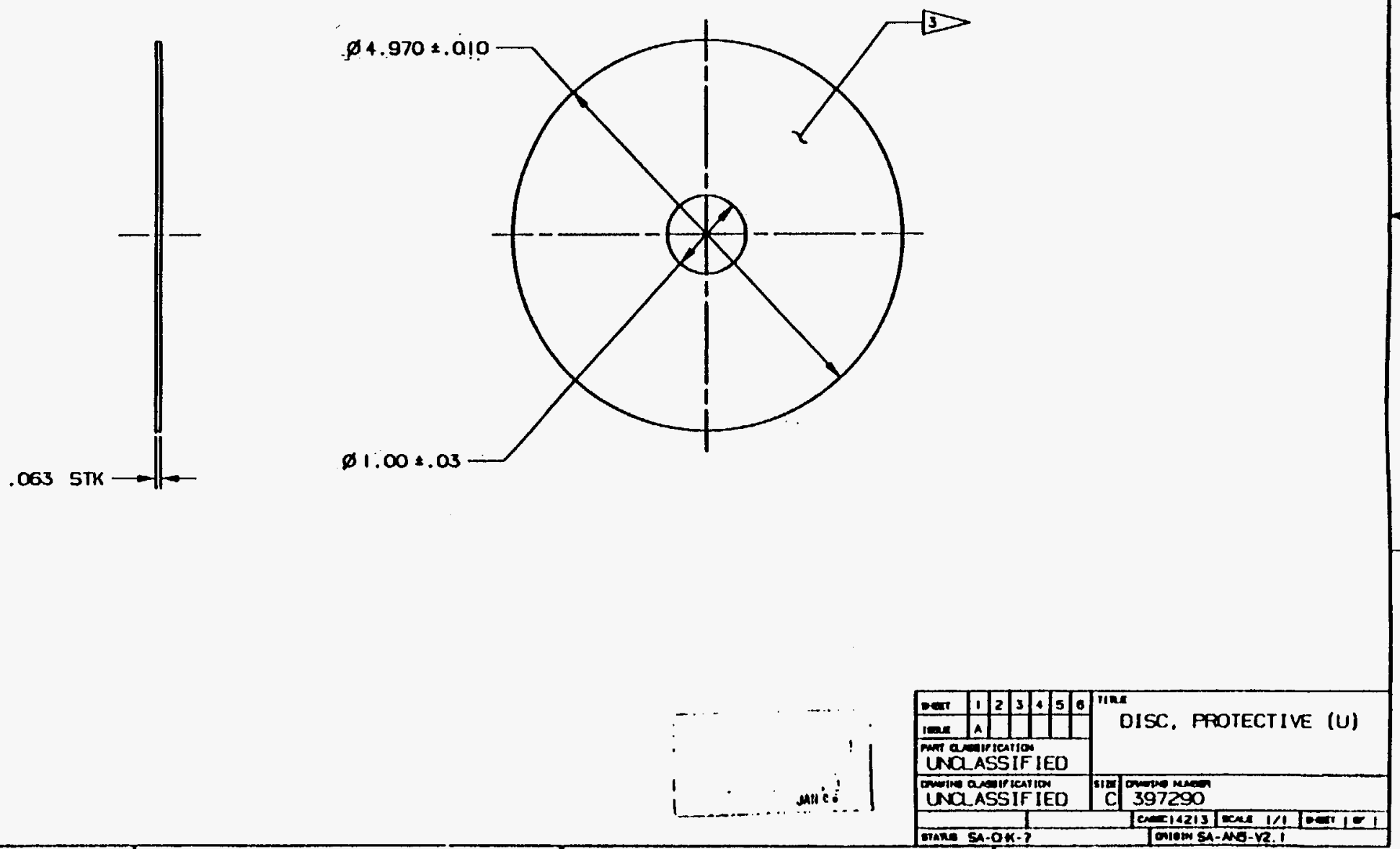

1

3
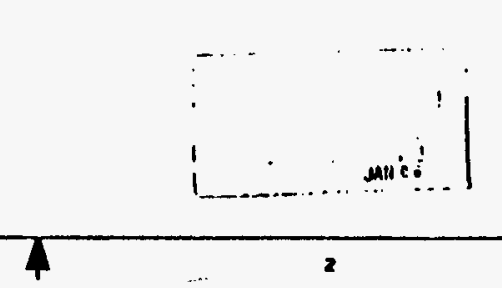

2 1

Figure A5. Protective Disk Details

Appendix A - Example Loads Calculations 


\section{Summary of Loads Predictions for Sample Containment}

Geometrical Modelling--The blast loads (shock and gas loads) for the sample containment were calculated using the BLASTX2 software, made available by the US Army Waterways Experiment Station at Vicksburg, Mississippi. As described previously in this report, the BLASTX2 software allows multiple rooms of a containment to be modelled for shock and gas propagation throughout the containment. The code allows only the charge chamber to be modelled as anything other than a parallelpiped. In this case the charge chamber, or bottom housing, was modelled as a cylinder, with the same volume as the actual bottom housing. The top housing was modelled as a parallelpiped, as required, and in this case was modelled with an 8.33 in 2 base area, a 2.89 in width and a volume equal to that of the actual top housing.

Bottom Housing Shock Predictions--Shocks were first predicted in the bottom housing in air to determine a reflection factor to be placed on impulse as generated by subsequent reflections from the walls and base of the containment. BLASTX2 was run with a MAXORD value of 3 , or with the routine set to calculate and include only up to second order reflections in impulse calculations. Targets were placed on the base, on the sidewall of the equivalent cylinder and at the opening into the top housing. Free air shocks at the device perimeter were then determined using CONWEP (the Kingery curves) and attenuation of amplitude at the targets was calculated using a procedure derived from Hayes ${ }^{[1]}$ pp. 124-127, modified to include spherical diversion of impulse, where pressure is calculated as a function of propagation distance, and impulse diverges proportional to the square of the ratio of the target and device radii. The calculated values were then compared qualitatively to data generated by $\mathrm{Neal}^{\left[{ }^{[10]}\right.}$ where strain versus scaled distance data is presented for tests of charges in spherical vessels in a vacuum and in vermiculite. Comparisons of shock impulse can be made for these cases since quasistatic effects are assumed negligible in a vacuum. In those tests the data show that for scaled distances between 0.3 and $0.46 \mathrm{~m} / \mathrm{kg}^{1 / 3}\left(0.75-1.15 \mathrm{ft} / 1 \mathrm{~b}^{1 / 3}\right)$, little difference in response is observed between tests with a vermiculite fill and tests in an evacuated chamber. If the response of the vessel to these loads is impulsive, this suggests that the impulse is about the same for the two cases over that range of scaled standoffs. The data also shows, however, that the response, and, hence, the impulse, is greater in vermiculite at scaled standoffs smaller than $0.75 \mathrm{ft} / 1 \mathrm{~b}^{1 / 3}$, and less at scaled distances larger than $1.15 \mathrm{ft} / 1 \mathrm{~b}^{1 / 3}$.

In our analysis, we took the spherically diverging impulse, doubled it to account for an acoustic reflection at the target, and increased it by the reflection factor generated from our BLASTX2 shock runs, where the factor was the ratio of calculated impulse at the target in air from the BLASTX2 run to the free air shock at the target.

Top Housing Shock Predictions--The attenuated value for shock calculated for Target 3 (at the opening between the bottom and top housing) was used without doubling but with the adjustment to account for reflections as an input to BLASTX2 for shock calculations at targets 4 and 5, on the top housing side and top surfaces, respectively. This was a conservative assumption, since it was assumed that perfect coupling occurred between the vermiculite and air at the interface. 
Baseplate Shock Predictions--After the initial calculations of shock on the baseplate, (target 1), it was recognized that the standoff for the $4.375 \mathrm{gm}$ charge was less than the minimum for realistic BLASTX2 calculations. The loads on the baseplate were then calculated from the Kingery curves in two ways, first the peak pressure and impulse based on a free air burst were calculated, then a distributed impulse and peak pressure were calculated. It was finally decided that a better representation of the "disk shaped" explosive configuration would be employed by distributing the 4.375 gms. among 4 charges located $0.5^{\prime \prime}$ above the baseplate, and then calculating the resulting shock pressure and impulse at target 1 . This was done first including reflections off of the bottom housing walls. Shock pressure and impulse was subsequently calculated neglecting those reflections, since the "disk shaped" charge is entirely enclosed in the friable device.

Gas Pressure Predictions--The predictions of gas pressure provided by BLASTX2 were used without modification, for the reasons stated earlier in this guide. It was assumed that the reduced air heating offset the reduced air volume, and thus there was no net change in pressure produced by the vermiculite, i.e., the pressures predicted were those in ambient air.

Total Loads at Targets 1-5--The shock predictions described above (shock history from BLASTX2 for 4 distributed charges for target 1, attenuated triangular pulse for target 2; and results from BLASTX2, where the target 3 triangular pulse at the opening to the top housing was used as the source pressure to calculate the pressures at targets 4 and 5) were combined with the gas pressure histories for the bottom and top housings respectively to create total pressure versus time histories at those points. These files were then depopulated to generate input files of less than 20 pressure versus time pairs to be used as input to the sdof calculations described in the next section. 


\section{Loads Calculations: $125 \%$ Overcharge}

Analyze sample containment box for $1.25 \mathrm{x}$ the $3.5 \mathrm{gms}$ TNT, to increase the charge weight to:

Charge - 4.375 TNT:

1) Modelling the Containment

Liner:

Top inside diameter

Bottom inside diameter

Height inside

$$
\begin{array}{lll}
=5-.5 & = & 4.5 \mathrm{in} \\
=3.75-.5 & = & 3.25 \mathrm{in} \\
=2.01-.25 & = & 2.06 \mathrm{in}
\end{array}
$$

$$
\begin{array}{rlll}
\text { Volume } & =1 / 3 \pi \mathrm{h}\left(\mathrm{R}_{12}+\mathrm{R}_{22}+\mathrm{R}_{1} \mathrm{R}_{2}\right) \\
\mathrm{h} & =2.06 \mathrm{in} & \\
\mathrm{R}_{1} & =4.5 / 2=2.25 \mathrm{in} \\
\mathrm{R}_{2} & =3.5 / 2=1.625 \mathrm{in} \\
\mathrm{V}_{1} & =1 / 3 \pi(2.06)\left(2.25^{2}+1.625^{2}+2.25(1.625)\right) \\
& =24.50 \mathrm{in}^{3}= & .01418 \mathrm{ft}^{3}
\end{array}
$$

\section{Top Housing:}

Hemisphere with tapered base:

Hemisphere radius

$$
=2.00 \mathrm{in}
$$

Bottom radius

$$
=2.23 \mathrm{in} \quad=\quad .2027 \mathrm{ft} \text {. }
$$

Height

$$
=2.557-.125=2.432 \mathrm{in}
$$

Radius of taper top

$$
=\operatorname{Tan}\left(22^{\circ}\right) .25(2)+2.23=2.43 \text { in }
$$

Volume of trun. cone $=\mathrm{V}_{\mathrm{a}}=1 / 3 \pi(.25)\left(2.23^{2}+2^{2}+(2)(2.23)\right)$

$$
=3.52 \mathrm{in}^{3}
$$

Volume of hemisphere $=V_{b}=2 / 3 \pi R^{3}$

$$
\begin{aligned}
& =2 / 3 \pi(2)^{3}=16.75 \mathrm{in}^{3} \\
& \mathrm{~V}_{2}=16.75+3.52=20.28 \mathrm{in}^{3} \\
& =.01174 \mathrm{ft}^{3}
\end{aligned}
$$

An Equivalent Cylinder for Liner:

$$
\begin{array}{lll}
\text { Assume diameter } & =(4.5+3.25) / 2= & 3.875 \mathrm{in} .= \\
\text { Height } & =24.50 \mathrm{in}^{3} /\left(\pi(3.875)^{2} / 4\right) \\
& =2.077 \mathrm{in}= & \\
& &
\end{array}
$$


Vent opening between chambers:

$\begin{array}{lll}\text { Diameter } & =1.0 \mathrm{in} \\ \text { Area } & =.785 \mathrm{in}^{2} \quad=\quad .00545 \mathrm{ft}^{2}\end{array}$

Since BLASTX2 only treats shock propagation into parallelpipeds, the top housing will be modelled as a parallelpiped with a target located on the top surface@ 2.432 in.

Equivalent parallelpiped for top housing:

$$
\begin{array}{ll}
\frac{\text { Vol }}{\mathrm{Ht}} & =\text { Base Area } \\
\text { Base Area } & =\frac{20.28 \mathrm{in}^{3}}{2.432 \mathrm{in}} \\
& =8.33 \mathrm{in}^{2} \\
\text { If square, L } & =2.89^{\prime \prime}=\text { length of one side } \\
& =.2406 \mathrm{ft}
\end{array}
$$

2) Determining Loads

a) Airblast Only Results for Chamber 1:

\begin{tabular}{|c|c|c|c|c||}
\hline Target No. & $\mathbf{P}_{\mathbf{r}}$ & $\mathbf{i}_{\mathbf{r}}$ & $\mathbf{i}_{\mathbf{p r}}{ }^{* *}$ & multiplier \\
\hline 1 & $* 67,320 \mathrm{psi}$ & $1,428 \mathrm{psi}-\mathrm{ms}$ & $856 \mathrm{psi}-\mathrm{ms}$ & 1.67 \\
\hline 2 & $15,540 \mathrm{psi}$ & $228 \mathrm{psi}-\mathrm{ms}$ & $75 \mathrm{psi}-\mathrm{ms}$ & 3.0 \\
\hline $3 * * *$ & $8,973 \mathrm{psi}$ & $312 \mathrm{psi}-\mathrm{ms}$ & $104 \mathrm{psi}-\mathrm{ms}$ & 3.0 \\
\hline
\end{tabular}

* $\quad$ predicted reflected

** peak from CONWEP

*** at opening - incident

b) Peak pressure and impulse at device perimeter:

$\begin{array}{lll}\text { bottom: } & \mathrm{P}_{\mathrm{r}} & =67,320 \mathrm{psi} \\ & \dot{i}_{\mathrm{r}} & =855.7 \mathrm{psi}-\mathrm{ms} \\ \text { side: } & \mathrm{P}_{\mathrm{r}} & =23,840 \mathrm{psi} \\ & \dot{i}_{\mathrm{r}} & =154.0 \mathrm{psi}-\mathrm{ms}\end{array}$


( estimated device to be $2.5^{\prime \prime} \times 2.5^{\prime \prime} \times 1 "$ )

c) For shock attenuation in the filler:

$$
\mathrm{P}_{\mathrm{x}_{2}}=\mathrm{i}^{2} \alpha /\left[\rho_{\mathrm{oo}}\left\{\left[\frac{x_{2}^{2}}{2 x_{1}^{2}}+.5\right]\left[\left(x_{2}-x_{1}\right)+l\right]\right\}^{2}(\alpha-1)\right]
$$

where

$$
\begin{aligned}
& l=\text { wavelength } \\
& \alpha=\frac{\rho_{\text {solid }}}{\rho_{\text {foam }}}=\frac{\rho_{o}}{\rho_{o o}}
\end{aligned}
$$

We must include the wavelength in the equations:

$$
l=(2 \mathrm{i} / \rho) \mathrm{c} \quad=\quad \text { wavelength }
$$

To estimate vermiculite attenuation at targets 1 and 2:

Target 1:

There is no vermiculite between the charge and the liner bottom, $\therefore$ we will use the peak reflected pressure, and calculated "reflected up" impulse.

$$
\begin{aligned}
& P_{r_{1}}=67,320 \mathrm{psi} \\
& i_{r_{1}}=1,428 \mathrm{psi}-\mathrm{ms} \\
& t_{d}=.042 \mathrm{~ms}
\end{aligned}
$$

Target 2:

There is .6875 in of vermiculite between the fireset and the liner sidewall:

$$
\begin{array}{lll}
\alpha=3.24 & \mathrm{i}=.154 \mathrm{psi}-\mathrm{sec} \\
\mathrm{x}_{1}=1.25 \text { in } & \mathrm{x}_{2}=1.9375 \mathrm{in} \\
l & =2 \mathrm{j} / \rho(\mathrm{c}) & \left(\frac{2(.154)}{23,840}\right) 12,000=.155 \mathrm{in} \\
\rho & =.0000093 \mathrm{lb}-\mathrm{sec}^{2} / \mathrm{in}^{4}
\end{array}
$$




$$
\begin{aligned}
\mathrm{P}_{\mathrm{x}_{2}} & =3.24(.154)^{2} /\left\{(.0000093)\left[\left[\frac{1.9575^{2}}{2(1.25)^{2}}+.5\right][(1.9375-1.25)+1.55]\right]^{2}(3.24-1)\right\} \\
& =1795 \mathrm{psi} \\
& =\mathrm{i}_{\mathrm{x}_{2}} /\left(\frac{\mathrm{x}_{2}}{\mathrm{x}_{1}}\right)^{2} \\
& =.154 /\left(\frac{1.9375}{1.25}\right)^{2}=64 \text { psi-ms }
\end{aligned}
$$

If this is reflected up to account for reflections, according to the multiplier:

$$
\begin{aligned}
& P_{r_{2}}=\underline{1795} \mathrm{psi} \\
& i_{r}=64 \text { psi-ms (2) (3) = } 384 \text { psi-ms }
\end{aligned}
$$

\section{Target 3:}

The incident impulse at Target 3 will be applied to BLASTX2, Chamber 2 .

$$
\begin{aligned}
& \alpha=3.24 \\
& \mathrm{x}_{1}=.5 \mathrm{in} \\
& x_{2}=1.577 \text { in } \\
& \mathrm{i}=.856 \mathrm{psi}-\mathrm{sec} \\
& l=(2 \mathrm{i} / \rho) \mathrm{c}=\left(\frac{2(.856)}{67,320}\right) \quad(12,000)=.305 \text { in } \\
& \rho=.0000093 \mathrm{lb}-\mathrm{sec}^{2} / \mathrm{in}^{4} \\
& P_{x_{2}}=3.24(.856)^{2} /\left\{(.0000093)\left[\left[\frac{1.577^{2}}{2(.5)^{2}}+.5\right][(1.577-.5)+.305]\right]^{2}(3.24-1)\right\} \\
& =1991 \mathrm{psi}
\end{aligned}
$$




$$
\mathrm{i}_{\mathrm{x}_{2}}=.856 /\left(\frac{1.577}{.5}\right)^{2}=86 \mathrm{psi}-\mathrm{ms}
$$

This will not be reflected up by $2 \mathrm{x}$ but will be increased to account for other wall reflections.

$$
\begin{aligned}
\mathrm{P}_{\mathrm{r}_{3}=} & \underline{1991 \mathrm{psi}} \\
& 86(3)=\underline{258} \mathrm{psi}-\mathrm{ms} \\
\mathrm{t}_{\mathrm{d}}= & \underline{3} \mathrm{~ms}
\end{aligned}
$$

Plots of Targets 1 through 5 are attached. (Target 3 was at the opening.)

\begin{tabular}{||l|l|l||}
\hline Figure A6 & Target 1 & $\begin{array}{l}\text { 67,320 psi, 1428 psi-ms shock pulse } \\
\text { combined with gas (Chamber 1C) }\end{array}$ \\
\hline Figure A7 & Target 2 & $\begin{array}{l}\text { 1795 psi, 384 psi-ms shock pulse } \\
\text { combined with gas (Chamber 1C) }\end{array}$ \\
\hline Figure A8 & Target 4 & Target 4 combined with Chamber 2C gas pressure \\
\hline Figure A9 & Target 5 & Target 5 combined with Chamber $2 \mathrm{C}$ gas pressure \\
\hline
\end{tabular}

If the entire chamber is filled with vermiculite, the top housing loads can be calculated by first finding the shock history in air on the top housing, then calculating the attenuated shock through vermiculite and multiplying it by the "reflecting" factor plus $2 \mathrm{x}$ acoustic factor, and adding to the gas pulse for Chamber 2.

Shock attenuation (assuming retainer disk is not in place for vermiculite):

$$
\begin{aligned}
& \alpha=3.24 \\
& x_{1}=.5 \mathrm{in} \\
& \mathrm{x}_{2}=4 \mathrm{in} \\
& \mathrm{i}=.856 \mathrm{psi}-\mathrm{sec} \\
& 1=(2 \mathrm{i} / \rho) \mathrm{c}=\frac{2(.856)}{67,320}(12,000)=.305 \mathrm{in} \\
& \rho=.0000093 \mathrm{lb}-\mathrm{sec}^{2} / \mathrm{in}^{4}
\end{aligned}
$$




$$
\begin{aligned}
\mathrm{P}_{x_{2}} & =3.24(.856)^{2} /\left\{(.0000093)\left[\left[\frac{4^{2}}{2(.5)^{2}}+.5\right][(4-.5)+.305]\right]^{2}(3.24-1)\right\} \\
& =7.5 \mathrm{psi}
\end{aligned}
$$

The impulse from BLASTX2 is .308 psi-sec.

The impulse from CONWEP for $4^{\prime \prime}$ standoff is .025 psi-ms.

$$
\begin{gathered}
\text { Multiplier }=\frac{.308}{.025}=12.3 \\
\mathrm{i}_{x_{2}}=.856 / \frac{(4)^{2}}{(.5)^{2}}=.0134 \mathrm{psi}-\mathrm{sec} \\
\mathrm{i}_{\mathrm{r}_{\kappa_{2}}}=.0134(2)(12.3)=.329 \mathrm{psi}-\mathrm{sec}
\end{gathered}
$$




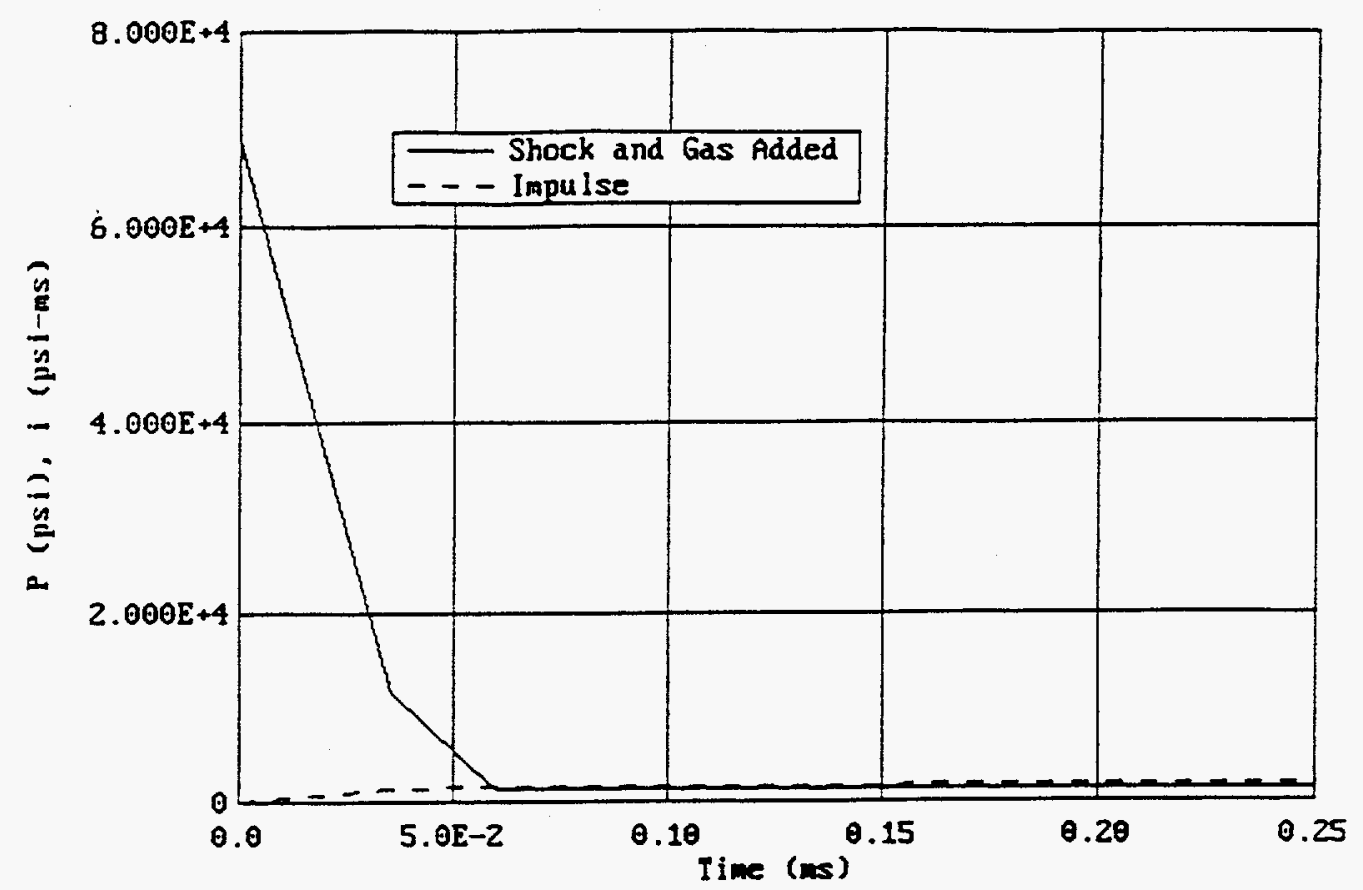

Figure A6. Target 1 Shock through Vermiculite, Gas Added

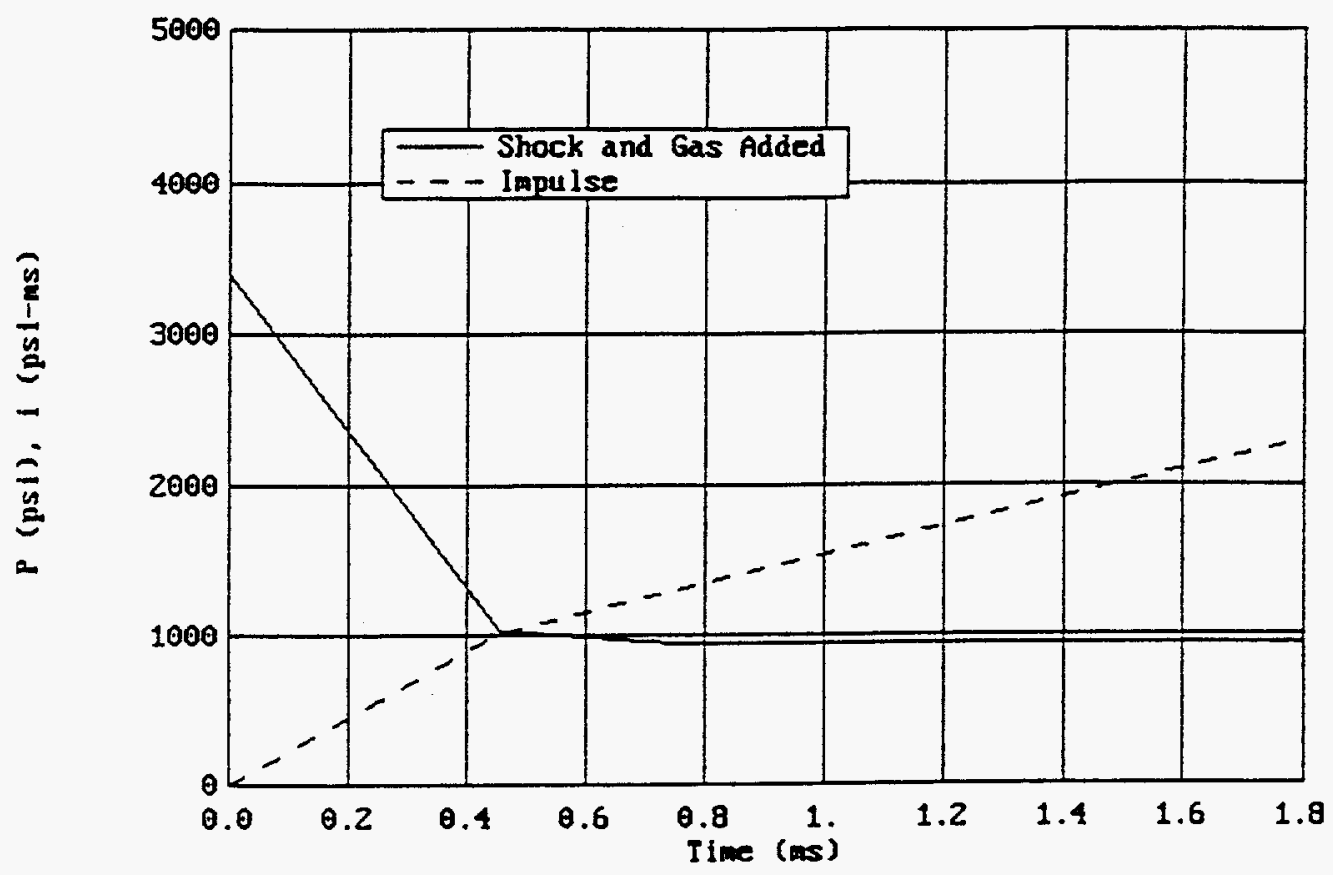

Figure A7. Target 2 Shock through Vermiculite, Gas Added 


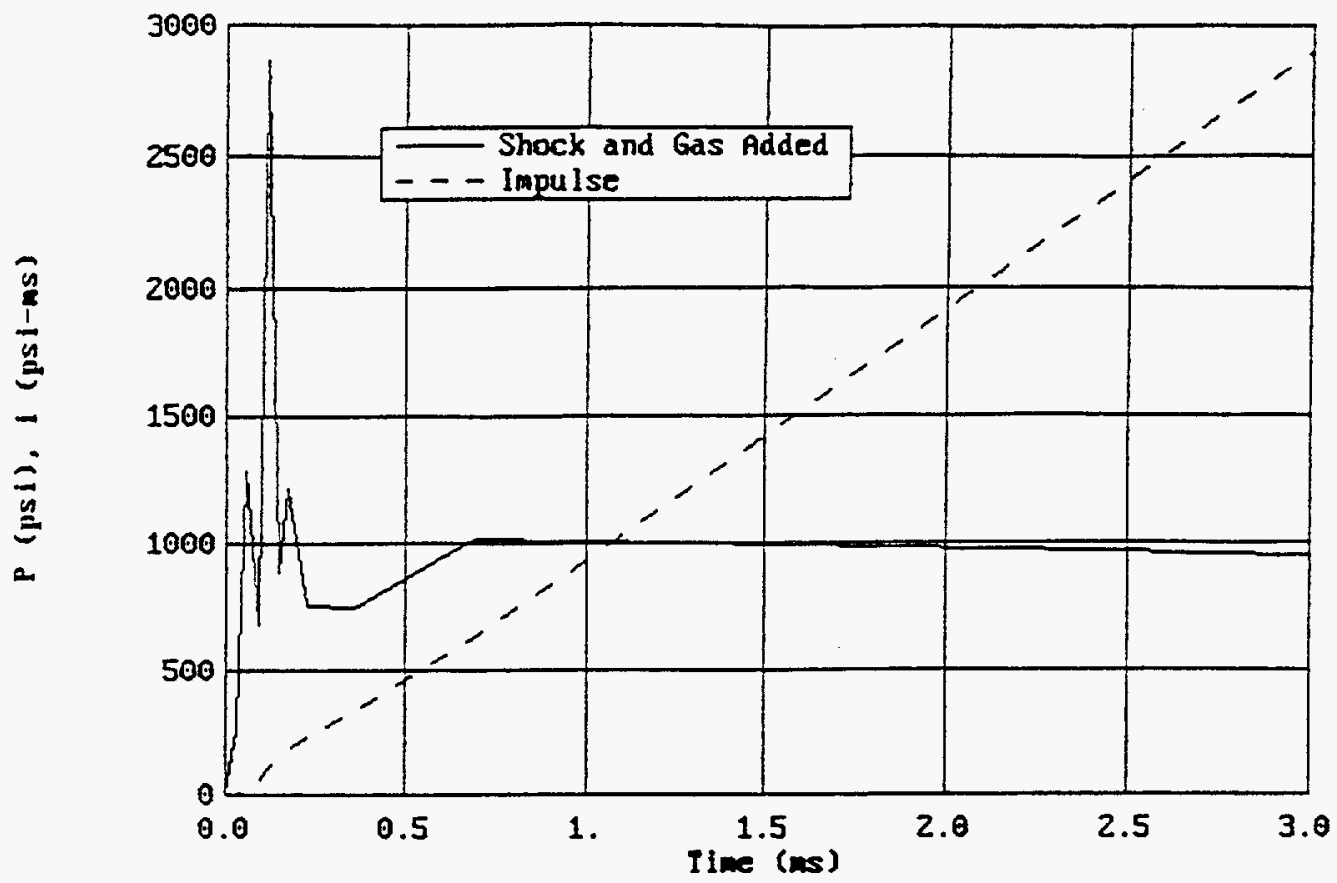

Figure A8. Target 4 Shock through Vermiculite, Gas Added

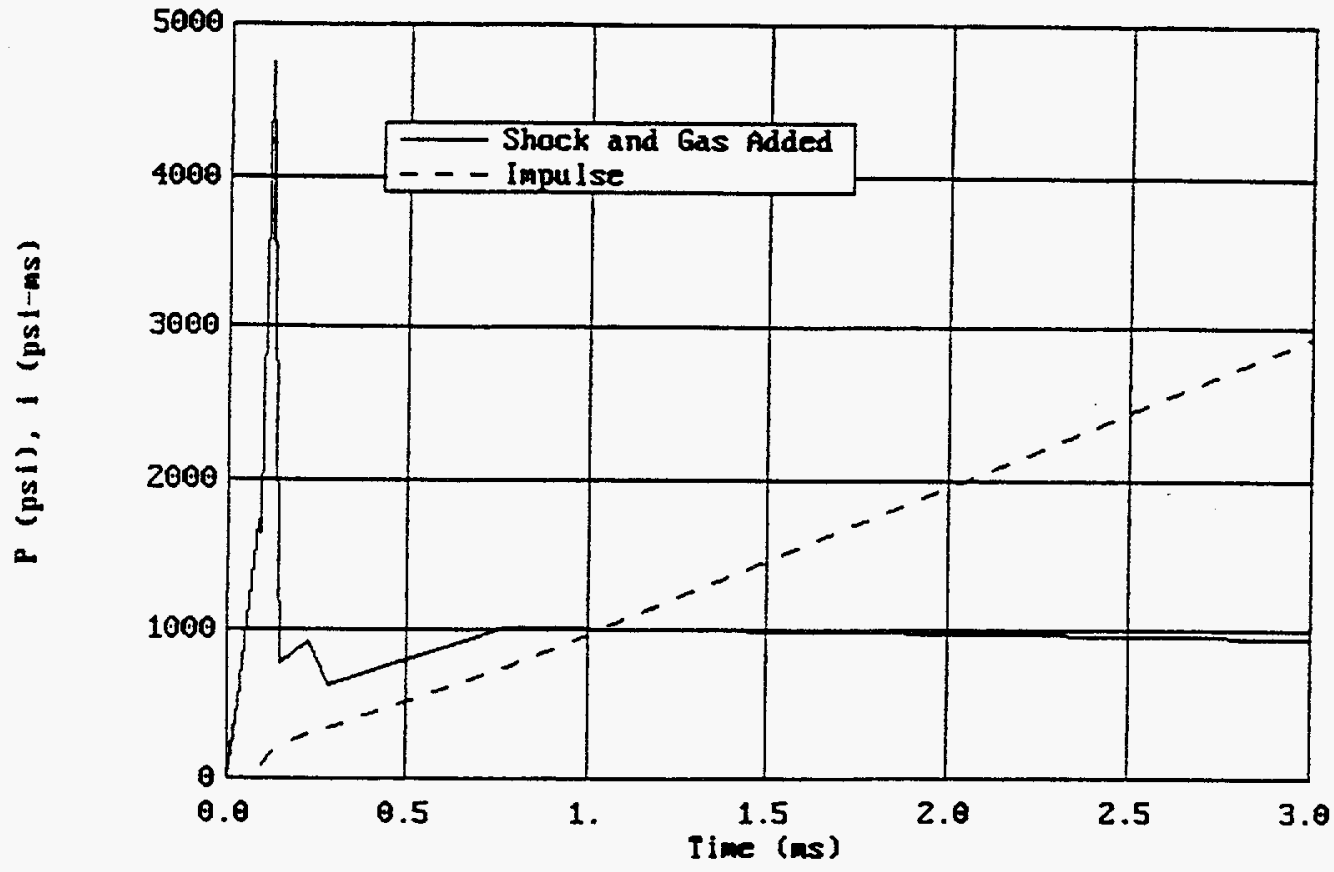

Figure A9. Target 5 Shock through Vermiculite, Gas Added 


\section{Appendix B. Response Calculations: Summary}

\section{Liner}

Since the bottom of the liner is cut away, the liner was checked only for radial expansion, disregarding reinforcement of the liner by the bottom housing. The maximum deflection, expressed as a ratio of the deflection at yield, $\mu$, was 0.37 . This low value of $\mu$ suggests that the thickness of the liner perhaps can be reduced.

\section{Bottom Housing}

Base--The base of the bottom housing was checked for bending from the loads produced by reflected pressure from the charge in the device. Because the sidewall of the housing is cut away over about $16 \%$ of the circumference, $16 \%$ of the base is unsupported and $84 \%$ is supported with a restraining moment between simply supported and fixed. Thus, a simply supported boundary condition was assumed for the base plate as a reasonable compromise. A more complex analysis is required to treat the actual geometry. An aluminum base is predicted to yield for all conditions evaluated at the design charge weight. When steel was substituted for aluminum in the bottom housing, the base reached yield, giving $\mu=1.01$. If steel is substituted for aluminum, some geometry changes can be made to minimize the weight increase.

Spirolox Retaining Groove--The Spirolox catalog gives an ultimate load for the ring, based on yielding of the groove, that is 2.2 times the maximum load on the ring; so the ring and retaining groove for the ring are adequate.

\section{Top Housing}

Dome--An analysis of the top housing as a hemisphere gave $\mu=0.35$, well short of yield for the material. The loads for this calculation were for air in the cavity between the top housing and the disk, the most severe case.

Sidewall--An analysis of sidewall response produced a $\mu=0.40$, again well short of yield for the material. The loads for this calculation were for air in the top housing, the most severe case.

Flange--A static analysis was performed to determine stresses and deflections in the flange for the maximum reaction produced by the response of the top housing as a hemisphere. The analysis treated rotation of the flange produced by the "couple" comprised of loads from the wall of the dome that pull up on the inside edge of the flange and loads from the Spirolox ring that restrain the outside edge of the flange. This analysis gave very high stresses in the flange when the cavity formed by the top housing and the disk is filled with air. When the cavity is filled with vermiculite, the shocks on the top housing are attenuated, and the stresses in the flange are 
reduced to acceptable levels. When the cavity is filled with vermiculite an effective ductility ratio is $\mu=0.70$, which is acceptable.

\section{Spirolox Retaining Ring}

The allowable load given in the Spirolox catalog for the ring chosen to restrain the top housing is 2.2 times the maximum load from the top housing when the cavity in the top housing is filled with air. The load is limited by yielding of the groove material. If the cavity is filled with vermiculite, the margin of safety is even higher. 


\section{Response Calculations: Design Charge Weight}

\section{Geometry}

Geometry of the sample containment is shown in Figure 1 of the Guide. The containment is generally axisymmetric. Its bottom housing is a truncated cone and the top housing is a flanged dome. The top housing sits inside the bottom housing and is retained by a Spirolox ring that engages the flange and a slot in the bottom housing. Two chambers are formed by a thin disk that is placed between the top and bottom housings. The disk has a small central hole, initially sealed with tape. With the hole taped closed the disk retains a filler material in the bottom chamber where the explosive device is located. The tape is designed to fail at low pressure when the device functions, permitting pressure in the lower chamber to "bleed" into the top chamber. The disk could also fail, permitting a faster release of pressure from the lower chamber. A steel liner reinforces the sides of the aluminum bottom housing.

\section{Loads}

Loads calculated for the design charge weight (125\% over-charge), are given in Appendix A. They were provided as input to the response predictions as pressure-time pairs, up to a maximum of twenty pairs. Therefore, "unit values" of the transformed properties are used in the response calculations.

\section{Response Modes}

Liner--The liner will undergo uniform radial expansion for the combined shock and quasistatic pressures. If liner strength is inadequate, consider reinforcement of the liner by the bottom housing.

Bottom Housing--The base of the bottom housing will respond as a circular plate in bending to the shock and quasistatic pressures. It will be modelled as a S.S. plate under uniform loading. A groove in the bottom housing must withstand loads from the Spirolox ring.

Top Housing--Response of the top housing will be (approximately) uniform radial expansion. It will be modelled as a hemisphere. Radial expansion of the sidewall, represented as a cylinder, will also be checked. Rotation of the flange, for the maximum reaction from the "dome" response calculation, will be calculated for its restraint by the Spirolox retaining ring.

Spirolox Retaining Ring--Vendor supplied data will be relied upon to determine the adequacy of the ring assembly. 


\section{Liner Analysis}

Liner geometry is given in Figure A3. The material is stainless steel, Type 17-4Ph per AMS 55604, heat treated to condition H1075 per MIL-H-6875. Properties, as given in MILHDBK-5, are:

$$
\begin{aligned}
& \mathrm{F}_{\mathrm{TU}}=145,000 \mathrm{psi} \\
& \mathrm{F}_{\mathrm{TY}}=125,000 \mathrm{psi} \\
& \mathrm{e}=13 \% \quad v=\frac{E}{2 G}=.272 \\
& \mathrm{E}=28.5 \times 10^{6} \mathrm{psi} \\
& \mathrm{G}=11.2 \times 10^{6} \mathrm{psi} \\
& \rho \quad=.282 \mathrm{lb} / \mathrm{in}^{3}
\end{aligned}
$$

Mass

Because the liner is tapered let:

$$
\begin{gathered}
\bar{D}_{o}=\frac{1}{2}\left[5.006+5.006-\frac{1}{2.312}(5.006-3.767)\right]=4.74 \text { in } \\
\bar{D}_{i}=\bar{D}_{o}-2\left(.25 / \cos 15^{\circ}\right)=4.74-\frac{.5}{\cos 15^{\circ}}=4.222 \mathrm{in}
\end{gathered}
$$

Using Equation (9) in the Guide and the properties of the liner, the mass, for a unit length of the liner, is:

$$
M=\frac{\pi}{4}\left(4.74^{2}-4.22^{2}\right)(1) \frac{.282}{386}=0.002673 \mathrm{lb} \mathrm{sec}^{2} / \text { in }
$$


Per unit of internal area, the mass becomes:

$$
\begin{aligned}
\mathrm{m} & =\frac{\mathrm{M}}{\mathrm{A}}=\frac{0.002673 \mathrm{lb} \mathrm{sec}{ }^{2} / \mathrm{in}}{\pi D_{i}(1)}=\frac{.002673}{\pi(4.22)(1)} \\
& =2.016 \times 10^{-4} \mathrm{psi} \mathrm{sec}^{2} / \mathrm{in}
\end{aligned}
$$

\section{Resistance}

Resistance is found from Equation (10) in the Guide. Dividing by the internal area, the unit resistance is:

$$
\begin{gathered}
R_{m}^{\circ}=\frac{2 F_{T Y} t}{D_{i}} \\
R_{m}^{0}=\frac{2(125,000)(.259)}{4.22}=15,344 \mathrm{psi}
\end{gathered}
$$

\section{Stiffness}

Equation (11) gives the stiffness of a cylinder of length L. Dividing by the internal area, the unit stiffness for elastic behavior is:

$$
K_{e}=\frac{4(.259)\left(28.5 \times 10^{6}\right)}{(4.22)^{2}}=1.658 \times 10^{6} \mathrm{psi} / \text { in }
$$

For uniform radial expansion of a thin-wall cylinder

$$
\mathrm{K}_{\mathrm{L}}=\mathrm{K}_{\mathrm{M}}=\mathrm{K}_{\mathrm{LM}}=1.0
$$

and work hardening of the liner is neglected so that $\mathrm{K}_{\mathrm{p}}^{\circ}=0$. 
Values for $m, R_{m}{ }^{\circ}, K_{e}{ }^{\circ}, K_{p}{ }^{\circ}$ and $K_{L M}$ were substituted into the Bigg's program, with the loading history on the liner wall, to determine the radial response of the liner alone, that is, neglecting any influence from the bottom housing. The loading history is given in Figure B1, and the radial response of the liner in Figure B2. Peak displacement is about 37\% of the displacement required to yield the liner $(\mu=0.37)$. Thus, the liner is well within the elastic region, and is quite adequate without considering the influence of the bottom housing on liner response.

\section{Bottom Housing}

The base of the housing (Figures A1 and B3) is loaded by overpressures from the explosion. These pressures will act over an area equal to the opening in the liner. For simplicity we will assume that pressures are uniform over the full area of the base.

The base plate will be modelled as a circular plate that is simply supported. In fact, the plate has moment restraint over about $84 \%$ of its circumference and is free over $16 \%$. Because the moment restraint provided by the sidewalls of the bottom housing is less than full fixity, the assumption of simple support is a reasonable, and probably conservative, assumption.

For circular plates, transformation factors can be found in Table $\mathrm{C} 8$ of the Guide. For the base of the housing:

Load Mass Factor

$$
\mathrm{K}_{\mathrm{LM}}=0.65 \text { (elastic) }=0.52 \text { (plastic) }
$$

\section{Resistance}

$$
\begin{aligned}
& \mathrm{R}_{\mathrm{M}} \quad=18.8 \mathrm{M}_{\mathrm{pc}} \\
& \mathrm{M}_{\mathrm{pc}}=\text { fully plastic moment at the plate center (in-lb/in) } \\
& =F_{T Y} \cdot Z_{p}=F_{T Y} \cdot \frac{1}{4} h^{2} \\
& \mathrm{R}_{\mathrm{M}}=18.8(52,000) 1 / 4(.479)^{2}=56,075 \mathrm{lb} \\
& \text { per unit area } \mathrm{R}_{\mathrm{M}}^{0}=\frac{56,075}{\frac{\pi}{4}(3.767)^{2}}=5,031 \mathrm{psi}
\end{aligned}
$$


Mass

$$
m=\frac{\rho t}{g_{o}}=\frac{.101(.479)}{386}=1.253 \times 10^{-4} \mathrm{psi} \frac{\sec ^{2}}{\mathrm{in}}
$$

Stiffness - elastic

$$
\begin{aligned}
& \mathrm{K}_{e}=\frac{216 E I}{a^{2}} \\
& \mathrm{I} \quad=\frac{1}{12} h^{3}=\frac{1}{12}(.479)^{3}=.0096 \mathrm{in}^{3} \\
& \mathrm{~K}_{\mathrm{e}}=\frac{216\left(10.3 \times 10^{6} \mathrm{psi}\right)\left(.00196 \mathrm{in}^{3}\right)}{(3.767)^{2}}=1.436 \times 10^{6} \mathrm{lb} / \mathrm{in} \\
& \text { per unit area } \mathrm{K}_{e}^{\circ}=\frac{K_{e}}{\frac{\pi}{4} D_{i}^{2}}=128,838 \mathrm{psi} / \mathrm{in}
\end{aligned}
$$

Stiffness - plastic

$\mathrm{K}_{\mathrm{p}}=0$

Dynamic Shear Reactions

$\begin{array}{ll}\text { elastic: } & .28 \mathrm{~F}+.72 \mathrm{R} \\ \text { plastic: } & .36 \mathrm{~F}+.64 \mathrm{R}\end{array}$

$\therefore$ conservatively use $V=.36 \mathrm{~F}+.72 \mathrm{R}$

These unit transformation factors were entered into the Biggs Computer program along with the loading history at the center of the base on the bottom housing, to compute the transient response of the base plate. The loading history is given in Figure B4, and the displacement, in Figure B5. Results show that the base of the bottom housing yields, with $\mu=8.24$ for this case. Several things can be done to remove some conservatism from the present analysis.

1) Reduce the loaded area to better represent the area loaded by the shock pressures. This requires derivations of new load-mass factors, as explained by Biggs ${ }^{[11]}$.

2) Account for bending stiffness and a mass of the FS mount plate \#397287. 
These steps were performed in the analysis of the base plate and together they did not prevent yielding of the base plate at the design charge weight. Thus, it appears that the bottom housing should be made of steel as is the liner. To check the effect of changing materials, the sdof parameters are recomputed for steel, using the appropriate ratios of the material properties for steel and aluminum. The new values are:

\section{Resistance}

$$
R_{M}^{o}=5031 \frac{\left(F_{T Y}\right)^{S T L}}{\left(F_{T Y}\right)^{A L}}=5031 \frac{125,000}{52,000}=12,094 \mathrm{psi}
$$

Stiffness

$$
K_{e}^{0}=128,838 \times \frac{(E)^{S T L}}{(E)^{A L}}=128,838 \times \frac{28.5 \times 10^{6}}{10.1 \times 10^{6}}=363,553 \mathrm{psi} / \mathrm{in}
$$

Mass

$$
M=M \frac{(\rho)^{S T L}}{(\rho)^{A L}}=1,253 \times 10^{-4} \frac{.282}{.101}=3.50 \times 10^{-4} \mathrm{psi} \frac{\mathrm{sec}^{2}}{\text { in }}
$$

Substituting into the Biggs program (with the same loadings in Figure B4) we obtain the results in Figure B6 which show that a steel base just reaches the yield stress. Other options could be examined, such as increasing the thickness of the base of the aluminum bottom housing, increasing the thickness of the FS mounting plate, or extending the liner to cover the bottom, as well as the sides, of the bottom housing. Shear stresses in a steel base would be approximately the maximum reaction divided by the shear area or

$$
\sigma_{s}=\text { Max Resistance from Figure B6 } \times \frac{\left(\frac{\pi D^{2}}{4}\right)}{.84 \pi D t}
$$




$$
=\frac{\text { Max Shear A from Figure B6 } \times \mathrm{D}}{(.84) 4 t}
$$

$$
\sigma_{s}=\frac{(14,030)(3.767)}{(4) .84(.479)}=32,838 \mathrm{psi}
$$

where the 0.84 factor accounts for the free edges and the geometry has been taken from Figure B3. The shear stress is low relative to a yield of

$$
F_{\text {sy }} \approx 0.6 F_{\text {ty }}=(0.6)(125,000 \mathrm{psi})=75,000 \mathrm{psi}
$$

\section{Top Housing}

The round end of the top housing (Figure A2) is spherical and will be assumed to respond as though it were a complete sphere or hemisphere. The lower portion is conical and has a tapered thickness. It will be approximated as a cylinder with an effective radius and effective thickness. Reinforcement of the sidewall by the flange will be ignored. The flange will then be checked for rotations based upon reactions from the "dome". The top housing is fabricated from the same material as the liner.

Dome Analysis--Equations (13) through (15) in the Guide are divided by the internal area to obtain "unit" values for a sphere that are equally applicable to a hemisphere.

Mass

$$
\begin{aligned}
& \mathrm{t}_{\min }=2.120-2.005=0.115 \mathrm{in} \\
& \mathrm{m}=\frac{\rho t}{g_{o}}=\frac{\left(.282{\left.\mathrm{lb} / \mathrm{in}^{3}\right)(.115)}_{386}=8.4 \times 10^{-5} \mathrm{psi} \frac{\mathrm{sec}^{2}}{\text { in }}\right.}{}
\end{aligned}
$$




$$
\begin{aligned}
& R_{m}^{\circ}=\frac{\left(D_{o}^{2}-D_{i}^{2}\right) \sigma_{y}}{D_{i}^{2}}=\frac{\left[(4.240)^{2}-(4.010)^{2}\right](125,000 \mathrm{psi})}{(4.010)^{2}} \\
= & 14,109 \mathrm{psi}
\end{aligned}
$$

\section{Stiffness}

$$
\begin{aligned}
& K_{e}^{\circ}=\frac{2 E\left(D_{o}^{2}-D_{i t}^{2}\right)}{(1-v) D_{i}^{3}}=\frac{2\left(28.5 \times 10^{6}\right)\left[(4.24)^{2}-(4.01)^{2}\right]}{(1-.3)(4.010)^{3}} \\
& =\quad 2.40 \times 10^{6} \mathrm{psi} / \mathrm{in}
\end{aligned}
$$

Load-Mass Factors, $\mathrm{K}_{\mathrm{LM}}=1.0$, and the reactions are equal to $R$.

These transformation factors, and the loading predicted for the top chamber, were substituted into the Bigg's program. Results, given in Figures B7 and B8, show that the dome is well short of yield with $\mu=.35$, and is therefore adequate for the design charge.

Sidewall Analysis--The lower 1.05 inches of the top housing will be approximated as a cylinder, without the flange. If this is too conservative, the flange will be added. First, calculate an average wall thickness:

$$
\begin{aligned}
\bar{R}_{i} & =1 / 2\left(2.005 \cos 18^{\circ}+2.235\right)=2.071 \text { in } \\
\bar{R}_{o} & =1 / 2\left(2.120 \cos 22^{\circ}+.18 \tan 22^{\circ}+2.120\left(\cos 22^{\circ}+1.23 \tan 22^{\circ}\right)\right. \\
& =1 / 2(2.038+2.463)=2.250 \mathrm{in} \\
\bar{t} & =\bar{R}_{o}-\bar{R}_{i}=0.179 \mathrm{in}
\end{aligned}
$$


Using Equations (9) through (11) in the Guide, we find:

Mass

$$
m=\frac{\frac{\rho}{g_{o}}\left(\bar{R}_{o}^{2}-\bar{R}_{i}^{2}\right)}{R_{i}^{2}}=\frac{.282 \frac{\mathrm{lb}}{\mathrm{in}}\left(2.25^{2}-2.071^{2}\right)}{(386)(2.071)^{2}}=1.317 \times 10^{-4} \frac{\mathrm{psi}-\mathrm{sec}^{2}}{\text { in }}
$$

Resistance

$$
\mathrm{R}_{\mathrm{m}}^{\circ}=\frac{2 \mathrm{~F}_{\mathrm{ty}} \mathrm{t}}{\mathrm{D}_{\mathrm{i}}}=\frac{\mathrm{F}_{\mathrm{ty}} \mathrm{t}}{\mathrm{R}_{\mathrm{i}}}=\frac{(145,000)(.179 \mathrm{in})}{2.071 \mathrm{in}}=12,533 \mathrm{psi}
$$

Stiffness

$$
\begin{gathered}
\mathrm{K}_{\mathrm{e}}{ }^{0}=\frac{4 \mathrm{tE}}{\mathrm{D}_{\mathrm{i}}{ }^{2}}=\frac{\mathrm{tE}}{\mathrm{R}_{\mathrm{i}}{ }^{2}}=\frac{(.179 \mathrm{in})\left(28.5 \times 10^{6} \mathrm{psi}\right)}{(2.071 \mathrm{in})^{2}}=1.189 \times 10^{6} \frac{\mathrm{psi}}{\mathrm{in}} \\
\mathrm{K}_{\mathrm{p}}{ }^{\circ}=0 \\
\mathrm{~K}_{\mathrm{LM}}=1.0
\end{gathered}
$$

Substituting these values into the Bigg's program, along with the loading determined in Appendix A, the results in Figures B9 and B10 are obtained. They show that the sidewall is adequate, with $\mu=0.40$.

Flange Rotation--The maximum reaction at the base of the dome must be reacted by the flange.

From Figure B8 the maximum resistance is:

$$
\mathrm{R}_{\mathrm{m}}^{0}=5815 \mathrm{psi}
$$

The maximum reaction at the flange is:

$$
\mathrm{R}=(5815 \mathrm{psi})(\pi)(2.235 \mathrm{in})^{2}=91,254 \mathrm{lb}
$$


Per unit length the reaction is:

$$
N_{\max }=\frac{R}{\pi(2.73)}=\frac{91,254 \mathrm{lb}}{8.576 \mathrm{in}}=10,640 \mathrm{lb} / \mathrm{in}
$$

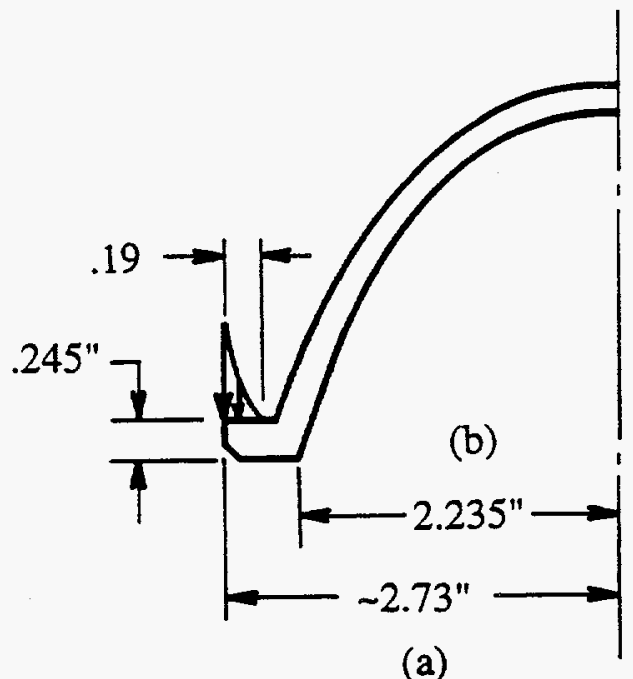

contact width, flange to Spirolox ring

$\approx 0.1 \mathrm{~g} "$ $\mathrm{r}_{\mathrm{o}}=\mathrm{a}-.1 \mathrm{~g}=2.73-.1 \mathrm{~g}=2.54^{\prime \prime}$

(a)

A solution will be developed using equations in Roark ${ }^{[6]}$ for the following conditions:

Parabolic pressure distribution assumed between Flange and Spirolox ring

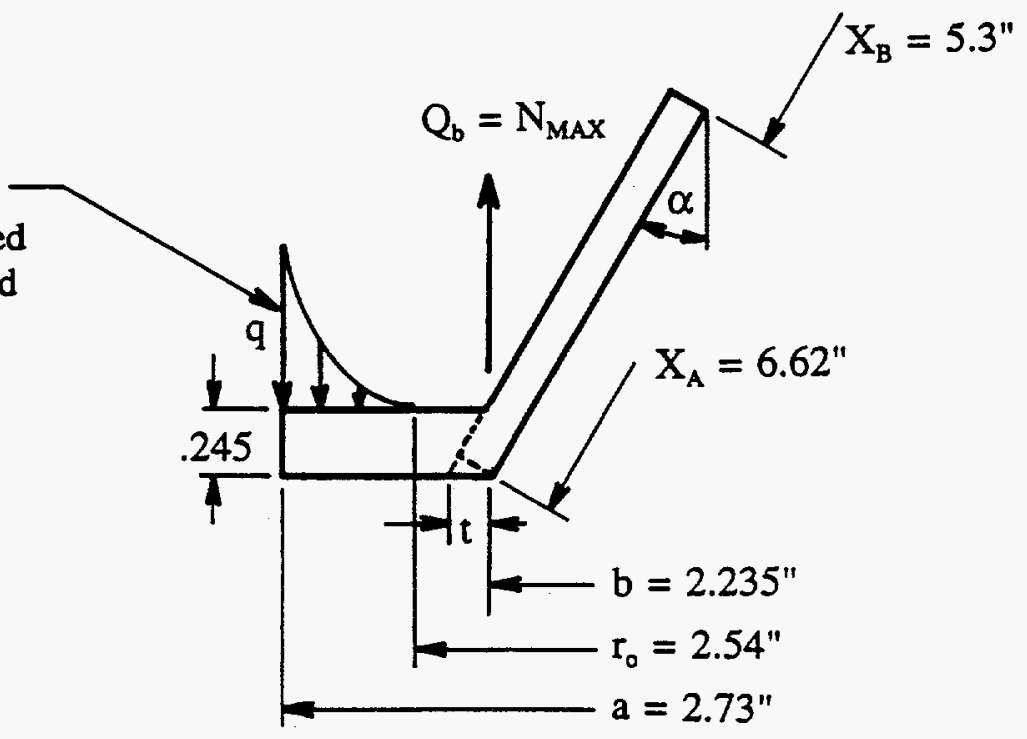

$$
\begin{aligned}
\alpha & =22^{\circ} \\
t & =.179^{\prime \prime}
\end{aligned}
$$

Moment continuity is maintained at the junction of the truncated cone and the flange. The following cases from Roark are used: 
Case 4k, Table 24:

$$
\begin{aligned}
Q_{b} & =\frac{q}{12 b}\left(3 a^{2}-2 a r_{o}-r_{o}^{2}\right) \\
\theta_{b} & =\frac{-q a^{3}}{D C_{7}}\left[\frac{C q}{12 a b}\left(3 a^{2}-2 a r_{o}-r_{o}^{2}\right)-L_{19}\right]
\end{aligned}
$$

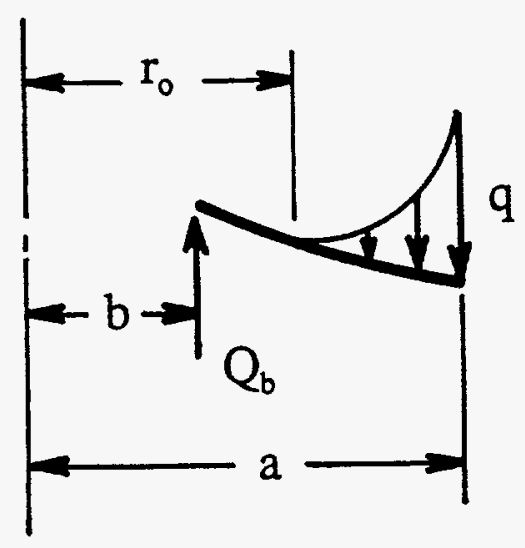

$$
D=\frac{E t^{3}}{12\left(1-v^{2}\right)} ; \quad C_{7}=\frac{1}{2}\left(1-v^{2}\right)\left(\frac{a}{b}-\frac{b}{a}\right)
$$

$$
C q=\frac{b}{a}\left\{\frac{1+v}{2} \ln \frac{a}{b}+\frac{1-v}{4}\left[1-\left(\frac{b}{a}\right)^{2}\right]\right\}
$$

$$
L_{19}=\frac{a^{2}}{1440\left(a-r_{o}\right)^{2}}\left[15(5+v)-64 \frac{r_{o}}{a}(4+v)+90\left(\frac{r_{o}}{a}\right)^{2}(3+v)-5\left(\frac{r_{o}}{a}\right)^{4}(1 g+7 v)\right.
$$

$$
\left.+6\left(\frac{r_{o}}{a}\right)^{6}(1-v)-60\left(\frac{r_{0}}{a}\right)^{4}(1+v) \ln \frac{a}{r_{o}}\right]
$$


Substituting $\mathrm{D}$ and $\mathrm{C}_{7}$

$$
\theta_{b}=\frac{-249 a^{3}}{E t^{3}\left(\frac{a}{b}-\frac{b}{a}\right)}\left[\frac{C q}{12 a b}\left(3 a^{2}-2 a r_{o}-r_{o}^{2}\right)-L_{19}\right]
$$

Case 5a, Table 24:

$$
\theta_{b}=\frac{-M_{o} a}{D C_{7}} L_{8}
$$

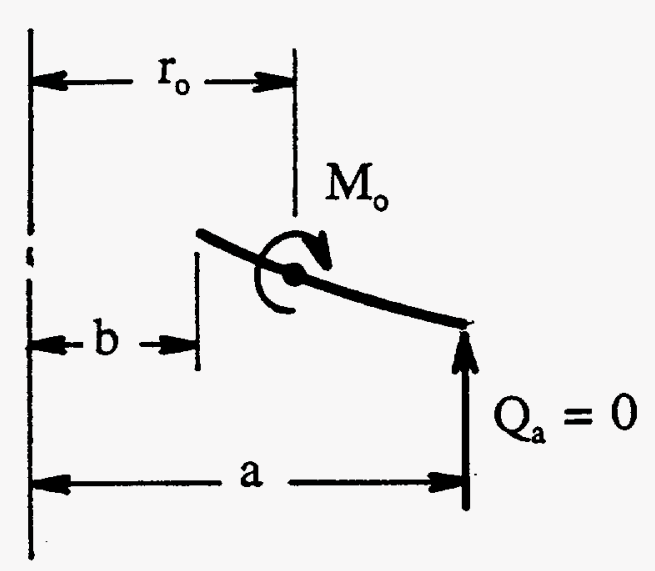

$\mathrm{D}$ and $\mathrm{C}_{7}$ are given above

$$
L_{8}=\frac{1}{2}\left[1+v+(1-v)\left(\frac{r_{o}}{a}\right)^{2}\right]
$$

for $r_{o}=a$ (this case only) $M_{o}=M_{b}$

$$
\theta_{b}=\frac{24 M_{b} a}{E t^{3}\left(\frac{a}{b}-\frac{b}{a}\right)} \frac{1}{2}[1+v+(1-v)(1)]=-\frac{24 M_{b} a}{E t^{3}\left(\frac{a}{b}-\frac{b}{a}\right)}
$$

$\mathrm{M}_{\mathrm{b}}$ is created by the rotations in the sidewall of the dome, approximated by the truncated cone. 
Case 6b, Table 31:

$$
k=2\left[\frac{12\left(1-v^{2}\right) x^{2}}{t^{2} \tan ^{2} \alpha}\right]^{\frac{1}{4}}
$$

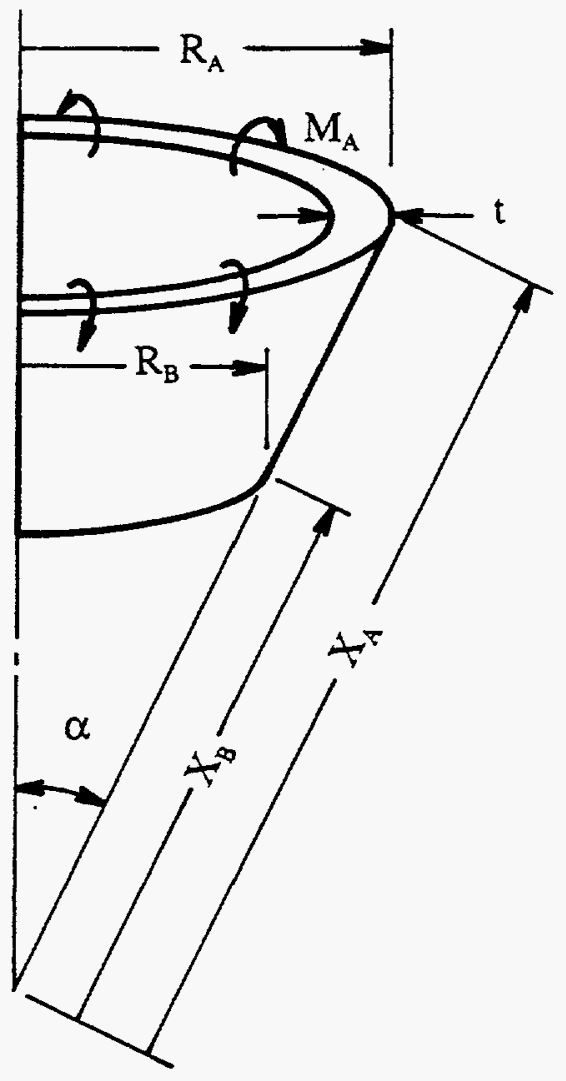

$k_{A}=2\left[\frac{12\left(1-.272^{2}\right)(6.62)^{2}}{(.179)^{2}\left(\tan 22^{\circ}\right)^{2}}\right]^{\frac{1}{4}}=35.233$

$$
k_{B}=2\left[\frac{12\left(1-2.72^{2}\right)(5.3)^{2}}{\left(.179 \tan 22^{\circ}\right)^{2}}\right]^{\frac{1}{4}}=31.260
$$

$$
\mu_{b}=\frac{k_{A}-k_{B}}{\sqrt{2}}=2.8094
$$

$$
\Omega=\frac{\mathrm{x}_{\mathrm{A}}-\mathrm{X}}{\mathrm{x}_{\mathrm{A}}-\mathrm{x}_{\mathrm{B}}}=0 \text { at } x=x_{\mathrm{A}}
$$

$$
\beta=\sqrt{12\left(1-v^{2}\right)}=3.3335
$$


Rotation @ $\mathrm{x}=\mathrm{x}_{\mathrm{A}}$ is given by

$$
\Psi_{A}=M_{A} \frac{2 \sqrt{2} \beta^{2} x_{A}}{E t^{3} k_{a}} K_{\psi}
$$

$\mathrm{K}_{\Psi}$ is given in Table 31 as $\mathrm{f}\left(\mathrm{k}_{\mathrm{A}}, \mu_{0}, \Omega\right)$ :

$$
k_{A}=20, \quad K_{\psi}=1.392+\frac{.983-1.392}{1.6}(2.8094-1.6)=1.083
$$

$$
k_{A}=40, \quad K_{\psi}=1.419+\frac{.994-1.419}{1.6}(2.8094-1.6)=1.0978
$$

$$
@ k_{A}=35.233, \quad K_{\psi}=1.083+\frac{1.0978-1.083}{20}(35.233-20)=1.0943
$$

Now

$$
\begin{aligned}
\Psi_{A} & =M_{A} \frac{2 \sqrt{2}(3.3335)^{2}(6.62)}{\left(28.5 \times 10^{6}\right)(.179)^{3}(35.233)}(1.0943) \\
& =3.9535 \times 10^{-5} \mathrm{M}_{\mathrm{A}} \\
\mathrm{M}_{\mathrm{A}} & =25,294 \Psi_{\mathrm{A}}
\end{aligned}
$$


In terms of the flange on page B-13

$$
\mathrm{M}_{\mathrm{A}}=-\mathrm{M}_{\mathrm{b}} \quad \psi_{\mathrm{A}}=\theta_{\mathrm{b}}
$$

Substituting:

$$
M_{b}=-25,294 \theta_{b}
$$

Now, solving for $\theta_{\mathrm{b}}$ we find:

$$
\begin{gathered}
\theta_{b}=\theta_{b_{q}}+\theta_{b_{m}}=\theta_{b_{q}}+\frac{-24 M_{b} a}{E t^{3}\left(\frac{a}{b}-\frac{b}{a}\right)} \\
=\theta_{b_{q}}+\frac{-24\left(-25,294 \theta_{b}\right) a}{E t^{3}\left(\frac{a}{b}-\frac{b}{a}\right)}=\theta_{b_{q}}+\frac{607,065 a}{E t^{3}\left(\frac{a}{b}-\frac{b}{a}\right)} \theta_{b} \\
\theta_{b}\left[1-\frac{607,065 a}{E t^{3}\left(\frac{a}{b}-\frac{b}{a}\right)}\right]=\theta_{b_{a}}
\end{gathered}
$$




$$
\theta_{b}=\frac{\theta_{b_{a}}}{1-\frac{607,065 a}{E T^{3}\left(\frac{a}{b}-\frac{b}{a}\right)}}
$$

From $\theta_{b}, M_{b}$ is calculated, and the radial bending stress is given by:

$$
\sigma_{r_{b}}=\frac{6 M_{b}}{t^{2}}
$$

The equations were solved in EXCEL to obtain the results in Table B1. Bending stresses reach $496 \mathrm{ksi}$ at the juncture of the flange and sidewall. Pressures between the flange and Spirolox reach a peak of $140 \mathrm{ksi}$. The bending stress is about four times the yield stress of $125 \mathrm{ksi}$ for the $17-4 \mathrm{ph}$ stainless steel of the top housing.

These results are based on the peak reaction at the base of the top housing given in Figure B8. It will be reduced if the shock loads are attenuated in the top cavity. This can be achieved by filling the top, as well as the bottom cavity, with vermiculite. This was done, and the calculations in Figure B8 were repeated with the new loads. Results, in Figures B11 and $B 12$, show that the response is essentially quasistatic with very little amplification. The peak resistance is reduced from

$$
\mathrm{R}_{\mathrm{MAX}}=5815 \text { psi (Figure B8) }
$$

to

$$
\mathrm{R}_{\mathrm{MAX}}=1029 \text { psi (Figure B12) }
$$

This reduction, by almost a factor of 6 , reduces the flange bending stress in Table B1 to:

$$
\sigma_{b_{f}}=496 \mathrm{ksi} \times \frac{1029}{5815}=88 \mathrm{ksi}
$$

which is well below the yield stress of $125 \mathrm{ksi}$. In terms of a ductility ratio: $\mu=88 / 125=0.70$. 
Therefore, the Top Housing looks adequate if it is filled with vermiculite -- inadequate because of flange bending, if filled with air. Still to be checked is the Spirolox ring and the groove in the bottom housing.

\section{Spirolox Ring}

The Spirolox catalog gives the following allowable loads for the chosen ring and the specified geometry.

Allowable Thrust Load:

$\begin{array}{lll}\text { Ring shear } & 87,780 \mathrm{lb} & \mathrm{SF}=3 \\ \text { Groove yield } & 74,355 & \mathrm{SF}=2 \text { for } \mathrm{F}_{\mathrm{TY}}=45 \mathrm{ksi}\end{array}$

Max reaction, page B-12 is $91,254 \mathrm{lb}$. This load is well within the ultimate carrying capacity of the Spirolox ring which is about:

$$
\text { Ultimate thrust load }=2 \times 74,355 \times \frac{52}{45}=171,843 \mathrm{lb}
$$

based on groove yield stress of $52 \mathrm{ksi}$ (Figure B-3). This is $\frac{171,843}{78,276}=1.88$ times the load on the ring. In terms of the ductility ratio we have: $\mu=1 / 1.88=0.53$.

If the Top Housing is filled with vermiculite, the max-reaction reduces to

$$
\text { Max Reaction }=91,254 \times \frac{1029}{5815}=16,147 \mathrm{lb}
$$

An effective ductility ratio for this load is:

$$
\mu=\frac{16,147}{171,843}=0.09
$$




\section{Response Predictions: $200 \%$ Overcharge}

Calculations for the sample containment were repeated with loads for a $200 \%$ overcharge. Because only the loads changed, determination of the sdof equivalent systems is the same as for the design charge (125\% overcharge) and will not be repeated.

The new loading and the structural response predictions are given in Figures B17 through B20. Results are summarized and compared to results for the design charge in Table B2. Calculations for the Top Housing at a $200 \%$ overcharge were performed for vermiculite in the top chamber. This was done because of the excessive stress in the flange at the design change. Only the flange yields at the $200 \%$ overcharge. The predicted stress is $106 \%$ of the yield stress for an "effective" ductility ratio of 1.06. Because a dynamic calculation is not performed for the flange we cannot predict the amount of yielding that may occur. Relative to the ultimate strength of the material $(145,000 \mathrm{psi})$ the flange stress at $200 \%$ overcharge is $91 \%$. Thus, the flange is believed to be adequate for the overcharge, as are all other components. 
Equiv. Elastic Displac. $=1.074 E-62$

Max Displacement $=3.997 \mathrm{E}-03$

Min Displacement $=-8.452 E-04$

Time of Max Displacement $=3.340 \mathrm{E}-65$

Time of Min Displacement $=2.698 \mathrm{E}-04$

$\mathrm{MU}=3.723 \mathrm{E}-01$

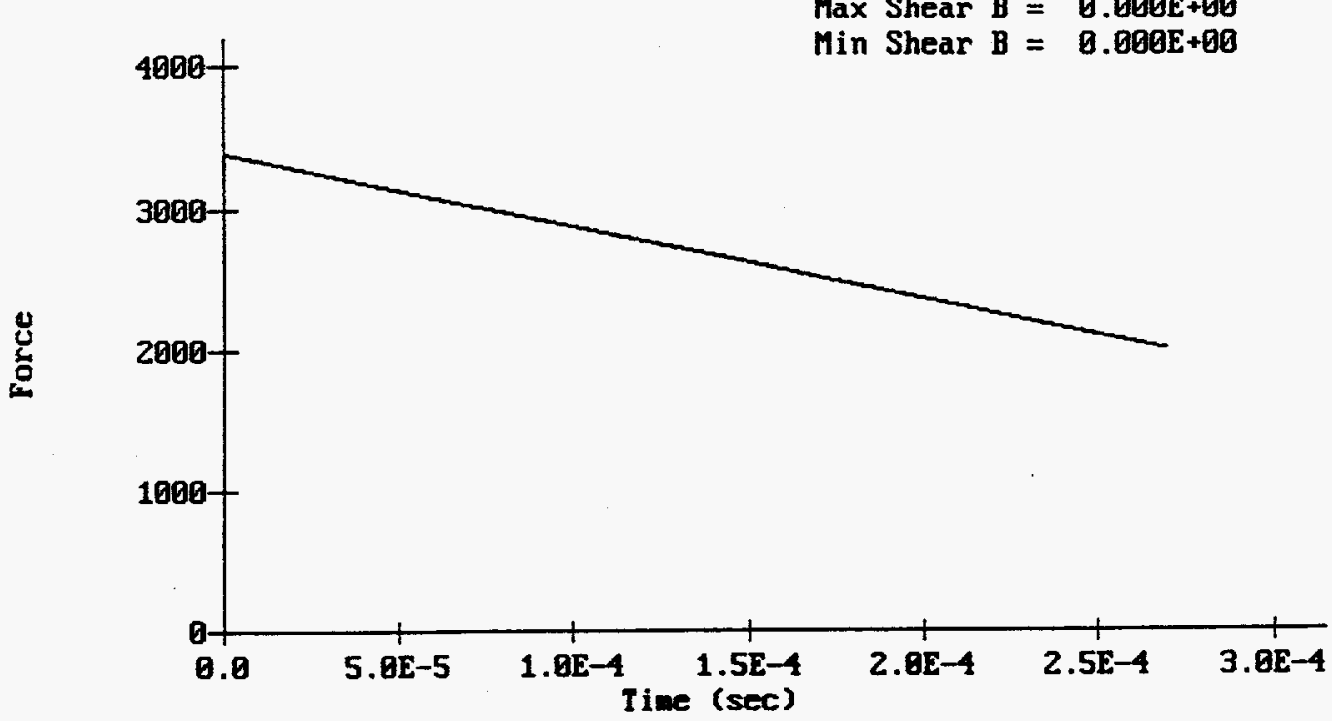

Max Force $=3.480 \mathrm{E}+03$

Min Force $=1.999 \mathrm{E}+03$

Max Resistance $=6.627 \mathrm{E}+83$

Min Resistance $=-1.401 \mathrm{E}+63$

Max Shear $A=0.000 \mathrm{E}+00$

Min Shear $A=0.000 E+B 0$

Max Shear $B=0.000 E+00$

$\operatorname{Min}$ Shear $B=8.000 \mathrm{E}+08$

Figure B1. Force (Pressure) on the Liner

Radial Expan. of Liner, corr. Ids

83-88-1994

Equiu. Elastic Displac. = 1.074E-02

Max $D$ isplacement $=3.997 E-03$

Min Disp lacement $=-8.452 \mathrm{E}-04$

Time of Max Displacenent $=3.340 E-85$

Time of Min Displacenent $=2.698 \mathrm{E}-04$

$M U=3.723 E-01$

葛

$M U=3.7235-81$
Max Force $=3.480 \mathrm{E}+03$

Min Force $=1.999 E+03$

Max Resistance $=6.627 \mathrm{E}+03$

Min Resistance $=-1.401 E+03$

Max Shear $A=0.0 B 0 E+B 0$

$\operatorname{Min}$ Shear $A=0.00 B E+B B$

Max Shear $B=0.000 E+B 0$

Min Shear $B=0.000 E+00$

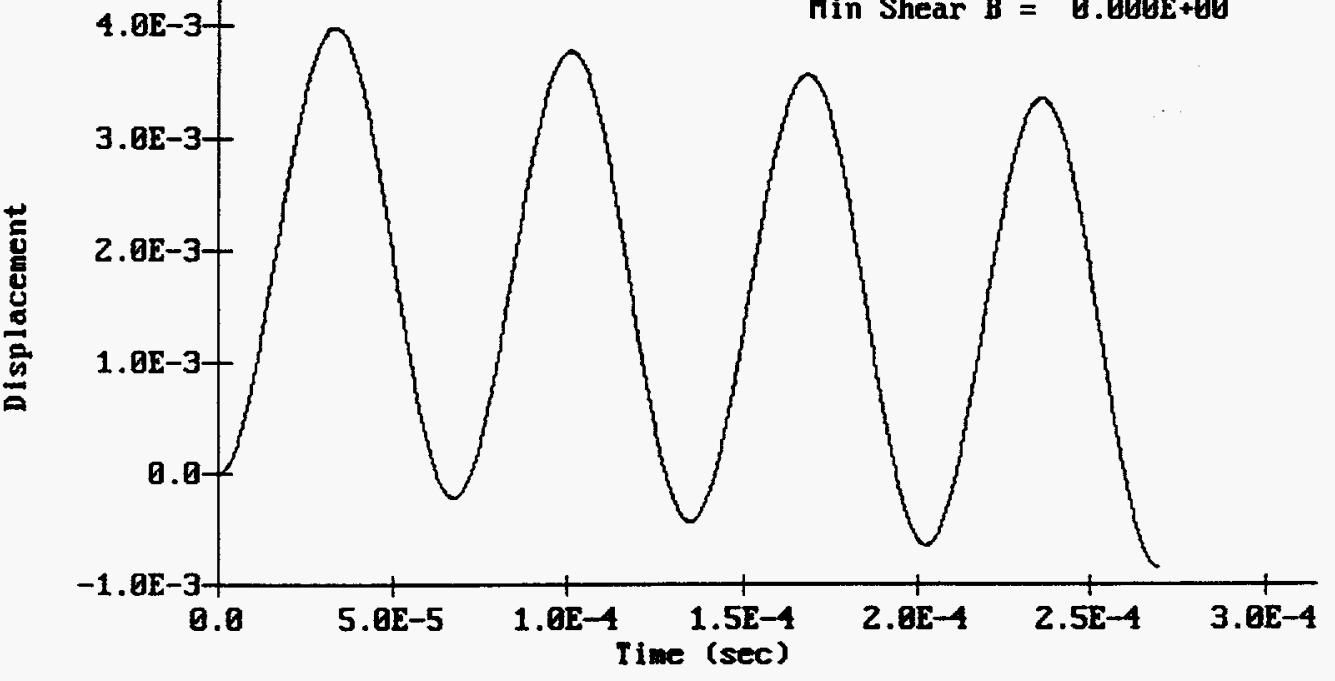

Figure B2. Radial Response of the Liner 

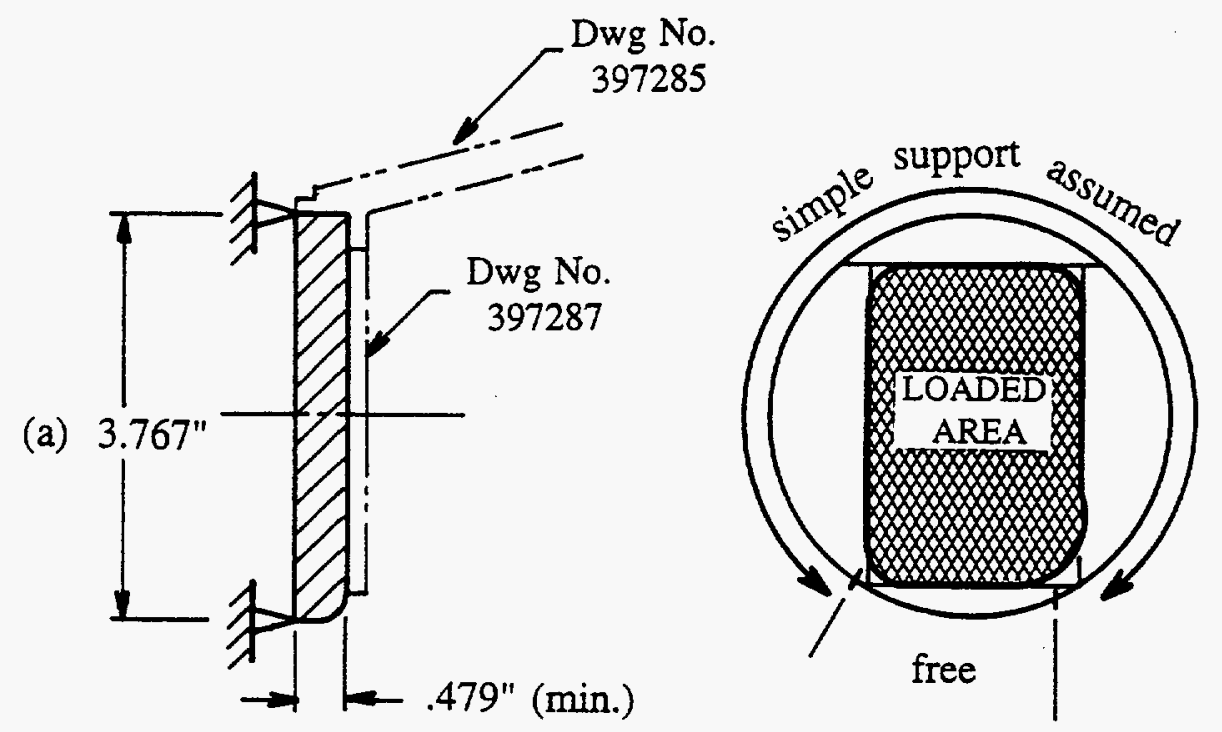

Matl $=7075-\mathrm{T} 651$

$\mathrm{F}_{\mathrm{TU}}=64 \mathrm{ksi}(\mathrm{ST}) *$

$\mathrm{F}_{\mathrm{TY}}=52 \mathrm{ksi}$ "

$E=10.3 \times 10^{6} \mathrm{psi}$

$v=.33$

$\rho=.101 \mathrm{lb} / \mathrm{in}^{3} / \mathrm{g}_{\mathrm{o}}$

* short transverse direction

(h)

Figure B3. Base Plate of Bottom Housing

Base of aluminum Bottom Housing

83-38-1994

Equiv. Elastic Displac. $=3.996 E-02$

Max Displacement $=3.218 E-01$

Min Displacement $=4.927 \mathrm{E}-68$

Time of Max Displacement $=1.518 \mathrm{E}-04$

Time of Min Displacement $=1.000 \mathrm{E}-6 \mathrm{7}$

$M U=8.237 \mathrm{E}+80$

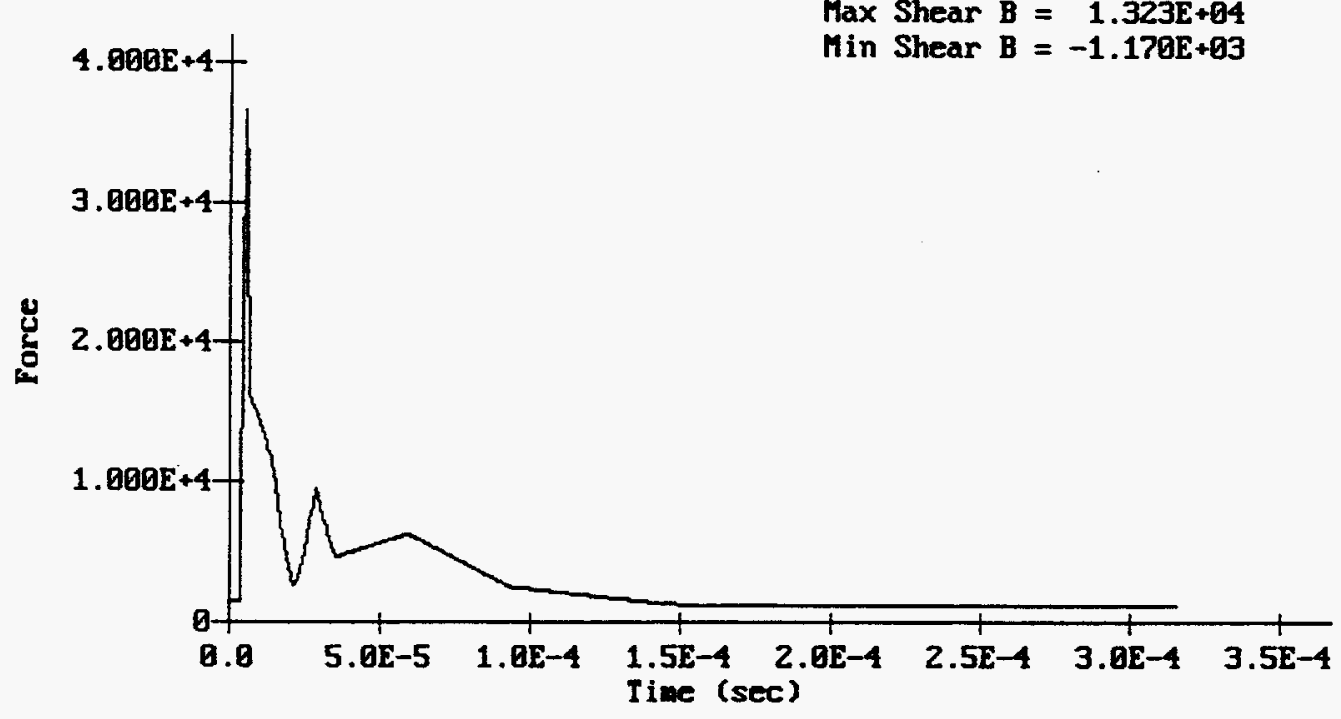

$\operatorname{Max}$ Force $=3.668 \mathrm{E}+04$

Min Force $=1.261 \mathrm{E}+03$

Max Resistance $=5.031 \mathrm{E}+63$

Min Resistance $=-2.292 \mathrm{E}+03$

Max Shear $A=1.323 \mathrm{E}+04$

Min Shear $A=-1.170 E+03$

Max Shear $B=1.323 \mathrm{E}+04$

$M$ Min Shear $B=-1.170 E+03$

Figure B4. Loads (Pressure) on the Base Plate 
Equiv. Elastic Displac. = 3.906E-02

Max Displacement $=3.218 E-01$

Min Displacement $=4.927 \mathrm{E}-68$

Time of Max Displacement $=1.518 E-04$

Time of Min Displacement $=1.000 E-B 7$

$\mathrm{MU}=\mathbf{8} \cdot 237 \mathrm{E}+00$

蒈

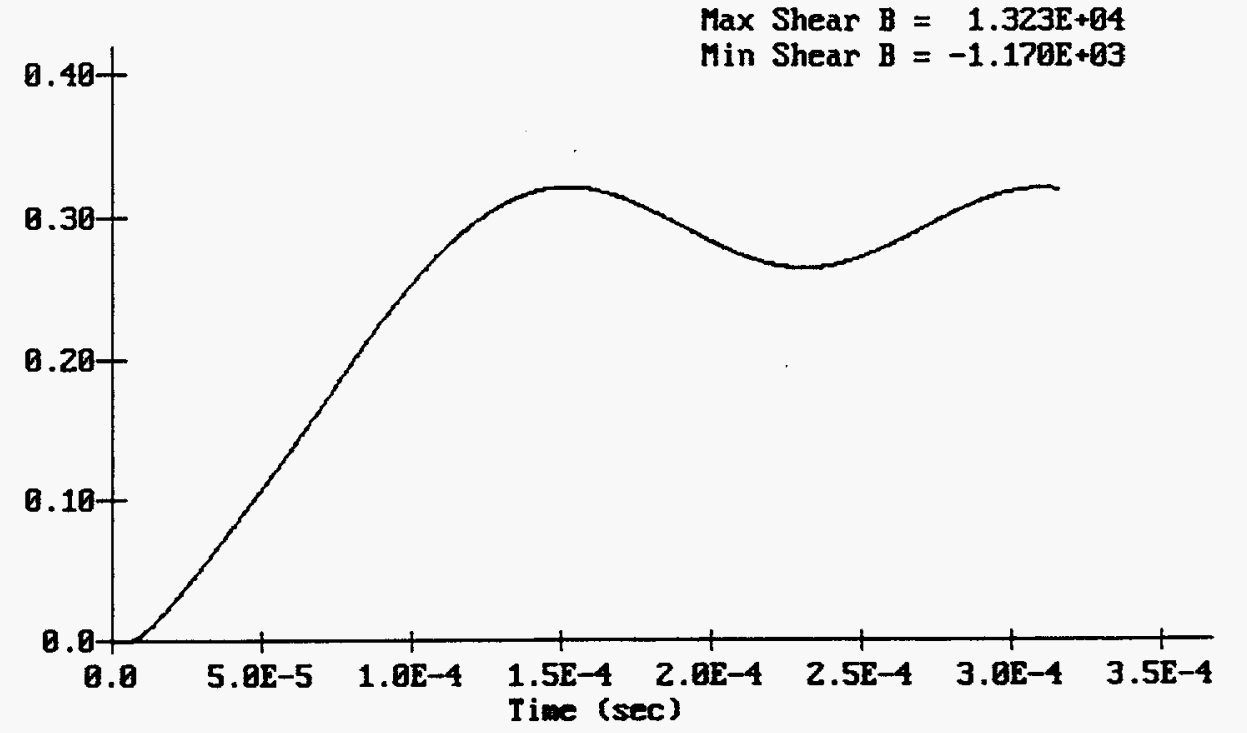

Max Force $=3.668 \mathrm{E}+94$

Min Force $=1.261 \mathrm{E}+03$

Max Resistance $=5.031 E+03$

Min Resistance $=-2.292 \mathrm{E}+03$

Max Shear $A=1.323 E+B 4$

Min Shear $A=-1 \cdot 170 E+B 3$

Max Shear $B=1.323 E+04$

Min Shear $B=-1.170 E+83$

Figure B5. Response of the Aluminum Base Plate

$$
\text { Base, Bot. Hsing, st 1, 125\% chg }
$$

Equiv. Elastic Displac. = 3.859E-82

Max Displacement $=3.884 \mathrm{E}-\mathrm{B2}$

Min Displacement $=-2.514 \mathrm{E}-02$

Time of Max Displacement $=6.620 \mathrm{E}-05$

Time of Min Displacement $=3.076 \mathrm{E}-04$

$M U=1.007 E+b 0$

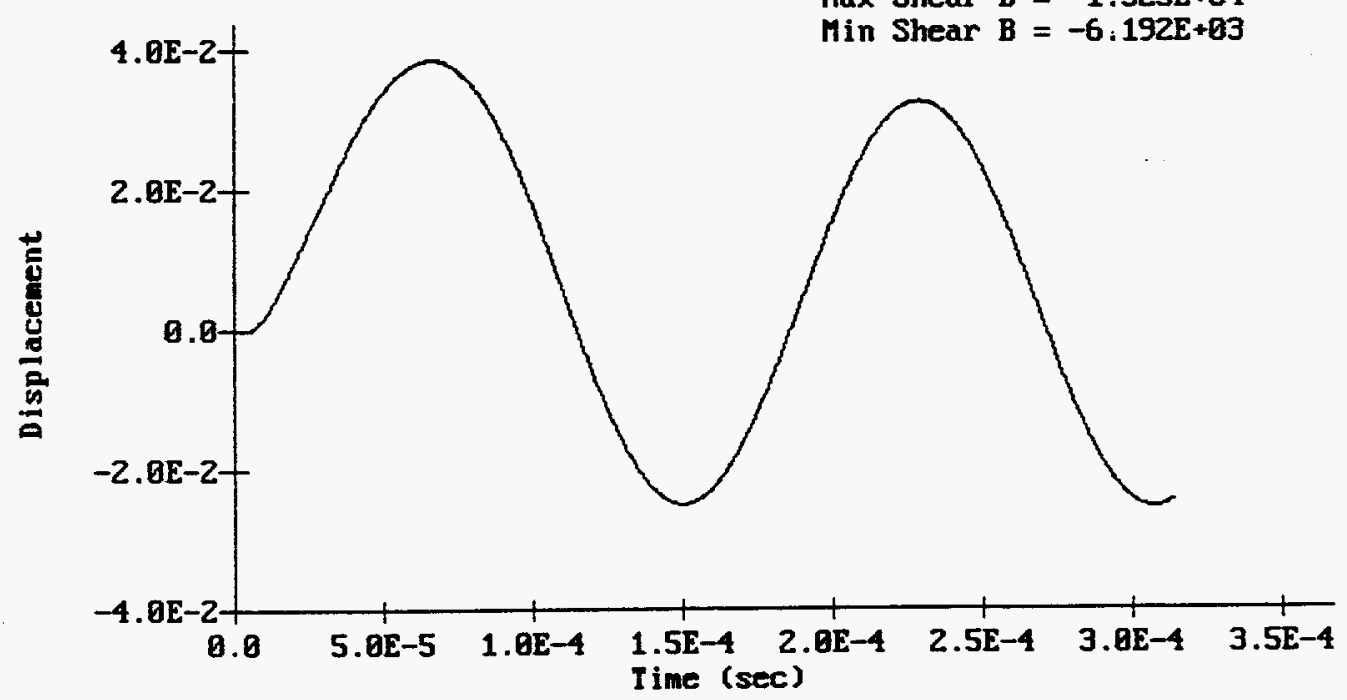

Max Force $=3.668 \mathrm{E}+04$

$\operatorname{Min}$ Force $=1.262 \mathrm{E}+03$

Max Resistance $=1.403 E+04$

Min Resistance $=-9 \cdot 233 E+03$

Max Shear $A=1.323 E+04$

Min Shear $A=-6.192 E+03$

Max Shear $B=1.323 \mathrm{E}+04$

Min Shear $B=-6: 192 E+63$

Figure B6. Response of the Base Plate for a Steel Bottom Housing 
Equiu. Elastic Displac. $=7.4242-63$

Max Displacement $=2.596 \mathrm{E}-83$

Min Displacement $=-8.212 \mathrm{E}-84$

Time of $\operatorname{Max} D$ isplacement $=1.256 \mathrm{E}-84$

Time of Min Displacement $=3.037 \mathrm{E}-04$

$M U=3.496 \mathrm{E}-01$

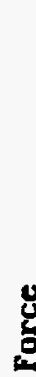

ํํㅁ

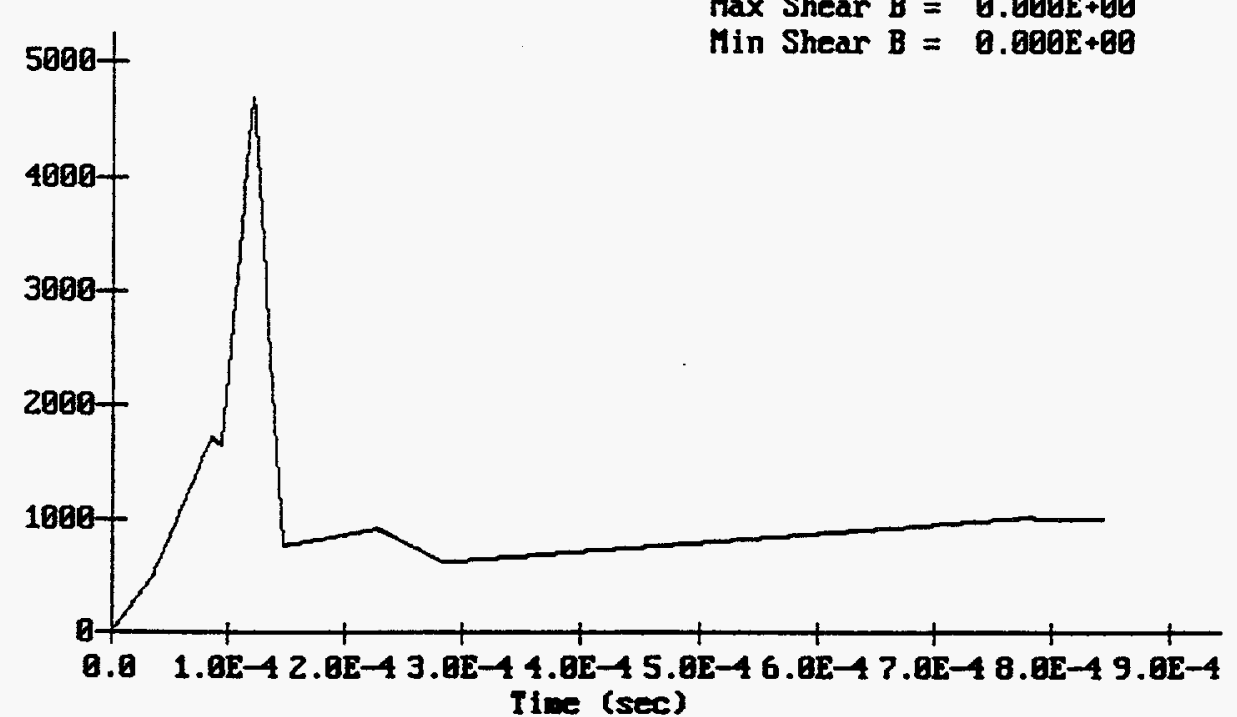

Max Force $=4.745 E+63$

Min Force $=1.447 \mathrm{E}+00$

Max Resistance $=5.815 \mathrm{E}+03$

Min Resistance $=-1.839 E+03$

Max Shear $A=0.0 B Q E+Q B$

Min Shear $A=0.000 E+B 0$

Max Shear $B=0.008 E+B B$

Min Shear $B=0.000 E+B B$

Figure B7. Force (Pressure) Acting on the Dome of the Top Housing

Response of the Iop Housing Dowe

11-88-1993

Equiv. Elastic Displac. = $7.424 E-83$

Max Displacement $=2.596 \mathrm{E}-03$

Min Displacenent $=-8.212 \mathrm{E}-64$

Time of Max Displacement $=1.256 \mathrm{E}-04$

Time of Min Displacement $=3.037 \mathrm{E}-04$

MU $=3.496 E-01$

Max Force $=4.745 E+03$

Min Force $=1.447 E+60$

Max Resistance $=5.815 E+\theta 3$

Min Resistance $=-1.839 \mathrm{E}+03$

Max Shear $A=0.080 E+8 B$

Min Shear $A=0.008 E+B \theta$

Max Shear $B=0.000 \mathrm{E}+00$

Min Shear $B=0.999 E+80$

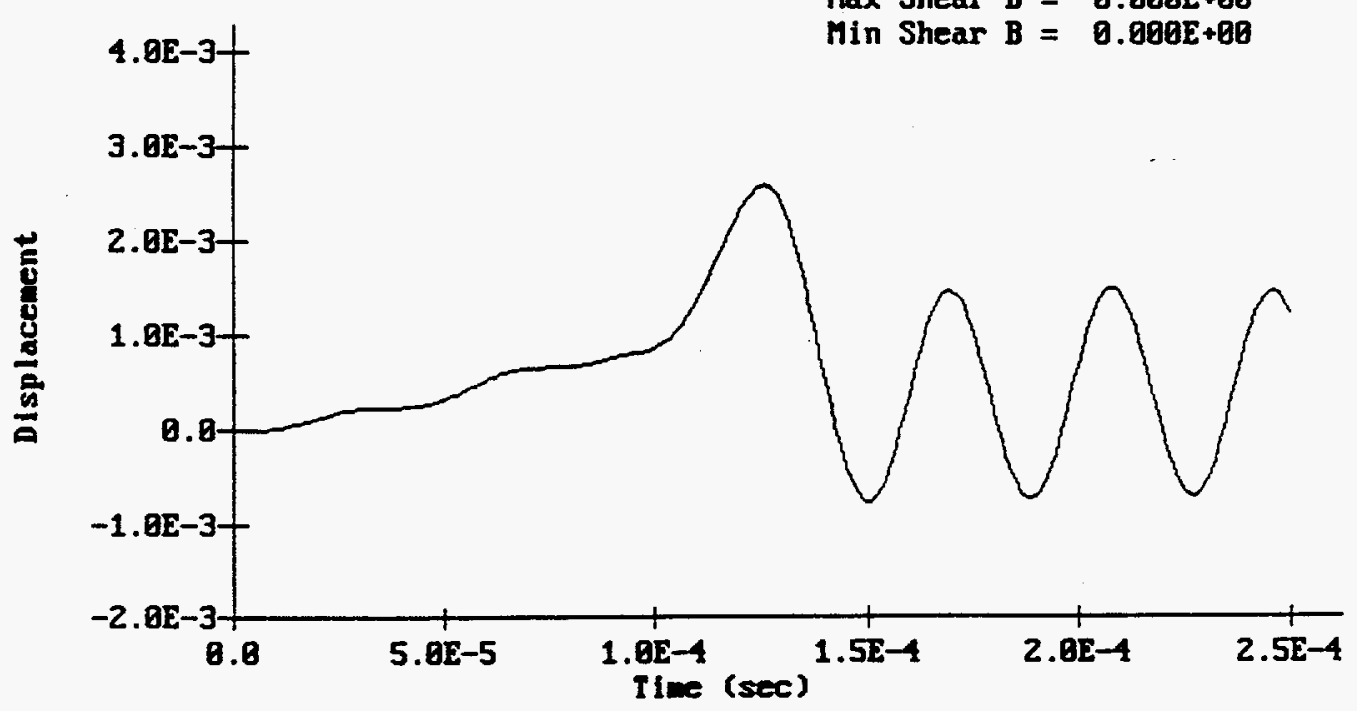

Figure B8. Response of the Dome in the Top Housing 
Equiv. Elastic Displac. $=1.854 E-82$

Max Displacement $=4.195 \mathrm{E}-83$

Min Displacement $=-2.717 \mathrm{E}-03$

Time of Max Displacement $=$ ?.349E-64

Time of Min Displacement $=3.700 \mathrm{E}-64$

$M U=3.981 E-81$

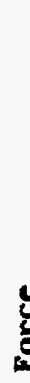

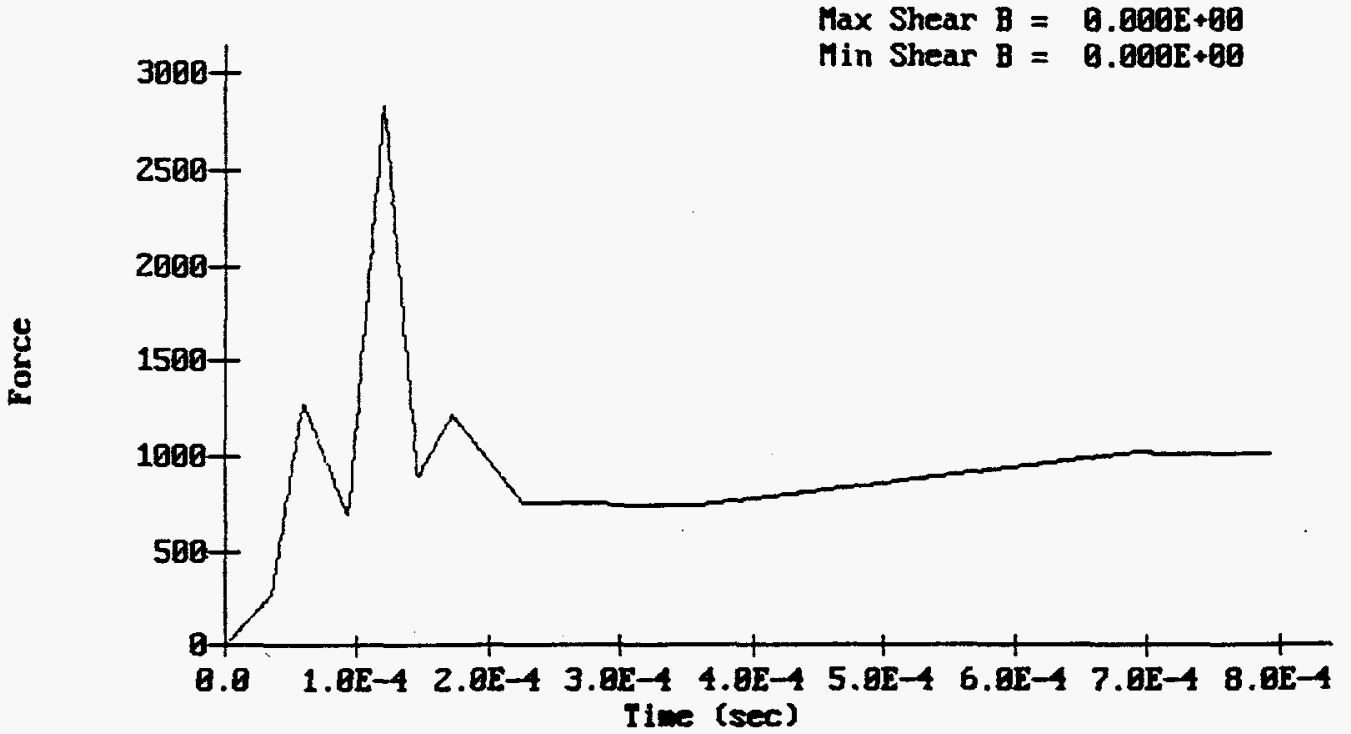

Figure B9. Force (Pressure) on the Sidewall of the Top Housing

Top Housing Side Wall

Equiv. Elastic Displac. $=1.854 \mathrm{E}-\mathrm{BZ}$

Max Displacement $=4.195 \mathrm{E}-83$

Min Displacenent $=-2.717 \mathrm{E}-03$

Time of Max Displacement $=7.340 \mathrm{E}-04$

Time of Min Displacement $=3.700 \mathrm{E}-04$

$M U=3.981 E-81$

造

\section{$6.8 E-3-$}

Max Force $=2.845 E+\theta 3$

Min Force $=7.591 \mathrm{E}+\mathrm{BO}$

Max Resistance $=4.988 \mathrm{E}+03$

Min Resistance $=-3.231 E+83$

Max Shear $A=0.080 E+80$

Min Shear $A=0.000 E+\theta 0$

Max Shear $B=0.000 \mathrm{E}+08$

Min Shear $B=0.000 E+B 0$
Max Force $=2.845 E+83$

Min Force $=7.591 \mathrm{E}+00$

Max Resistance $=4.988 \mathrm{E}+83$

Min Resistance $=-3.231 E+83$

Max Shear $A=0.000 E+B 0$

Min Shear $A=0.000 E+B 0$

Max Shear $B=0.000 E+B 0$

Min Shear $B=0.008 E+80$

11-88-1993

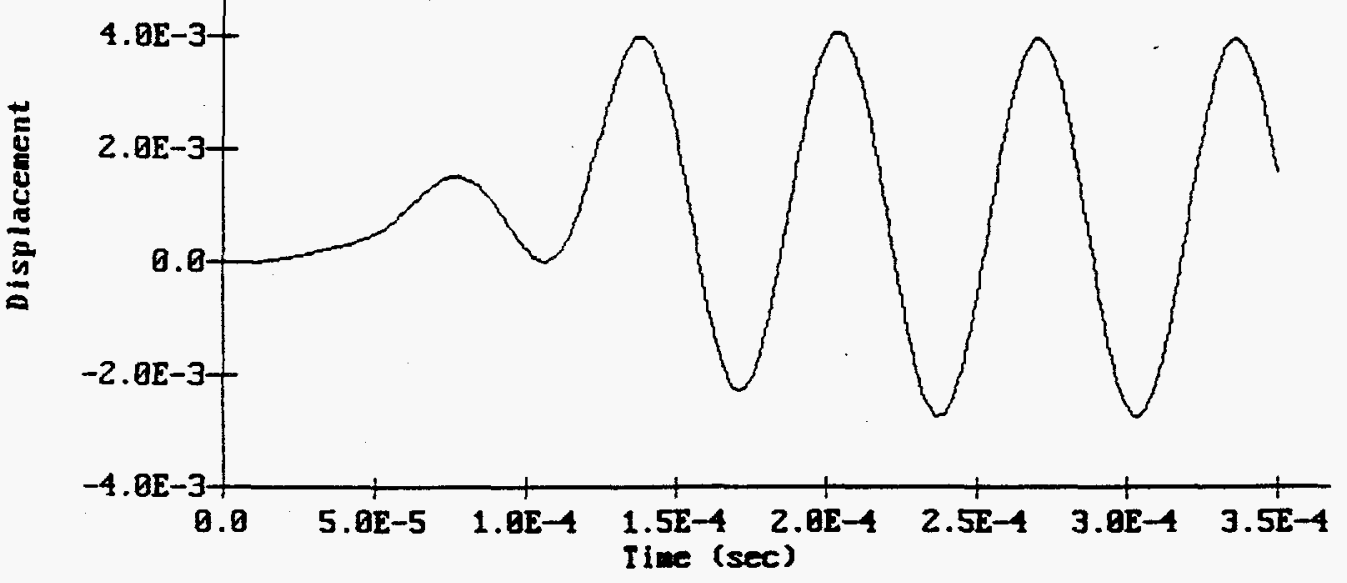

Figure B10. Response of the Sidewall of the Top Housing 
Equiv. Elastic Displac. = 8.314E-03

Max Displacement $=5.787 E-04$

Min Displacement $=2.096 E-08$

Time of Max Displacement $=1.023 \mathrm{E}-03$

Time of Min Displacement $=1.000 \mathrm{E}-06$

$\mathrm{MU}=6.864 \mathrm{E}-62$

แู

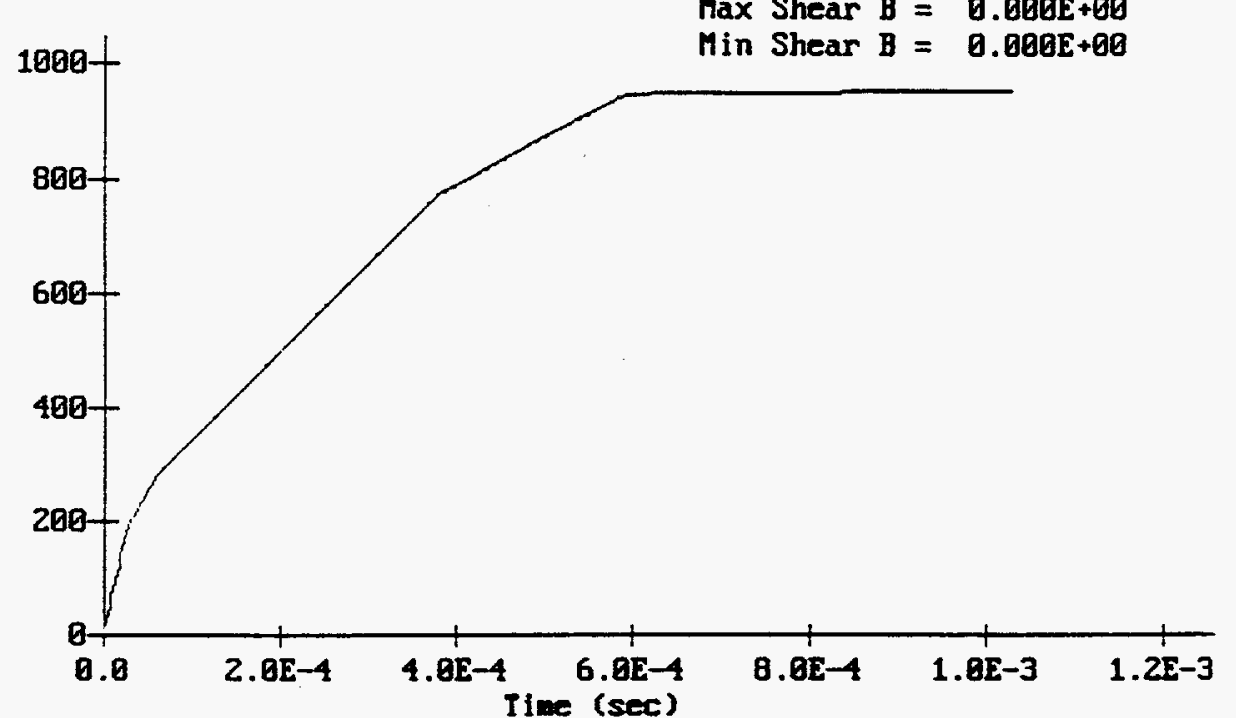

Max Force $=9.562 E+\theta 2$

$\operatorname{Min}$ Force $=7.843 \mathrm{E}+00$

Max Resistance $=1.029 E+\theta 3$

Min Resistance $=3.780 \mathrm{E}-02$

Max Shear $A=0.000 E+B 0$

Min Shear $A=0$. BOBE+BO

Max Shear $B=0.080 E+\theta 0$

Min Shear B $=0.000 E+00$

Figure B11. Force (Pressure) on the Dome of the Top Housing with

Vermiculite in the Upper Chamber

IH Dome wrmax. radius a vermicul

11-11-1993

Equiv. Elastic Displac. = 8.314E-83

Max Displacement $=5.707 \mathrm{E}-04$

Min Displacement $=2.896 \mathrm{E}-08$

Iime of Max Displacement $=1.023 E-63$

Time of Min Displacement $=1.000 E-86$

$M U=6.864 E-B 2$

Max Force $=9.562 \mathrm{E}+82$

Min Force $=7.043 E+80$

Max Resistance $=1.029 \mathrm{E}+03$

Min Resistance $=3.780 \mathrm{E}-02$

Max Shear $A=0.000 E+\theta 0$

Min Shear $A=0.000 E+\theta 0$

Max Shear $B=0.000 E+00$

Min Shear $B=0.000 E+00$

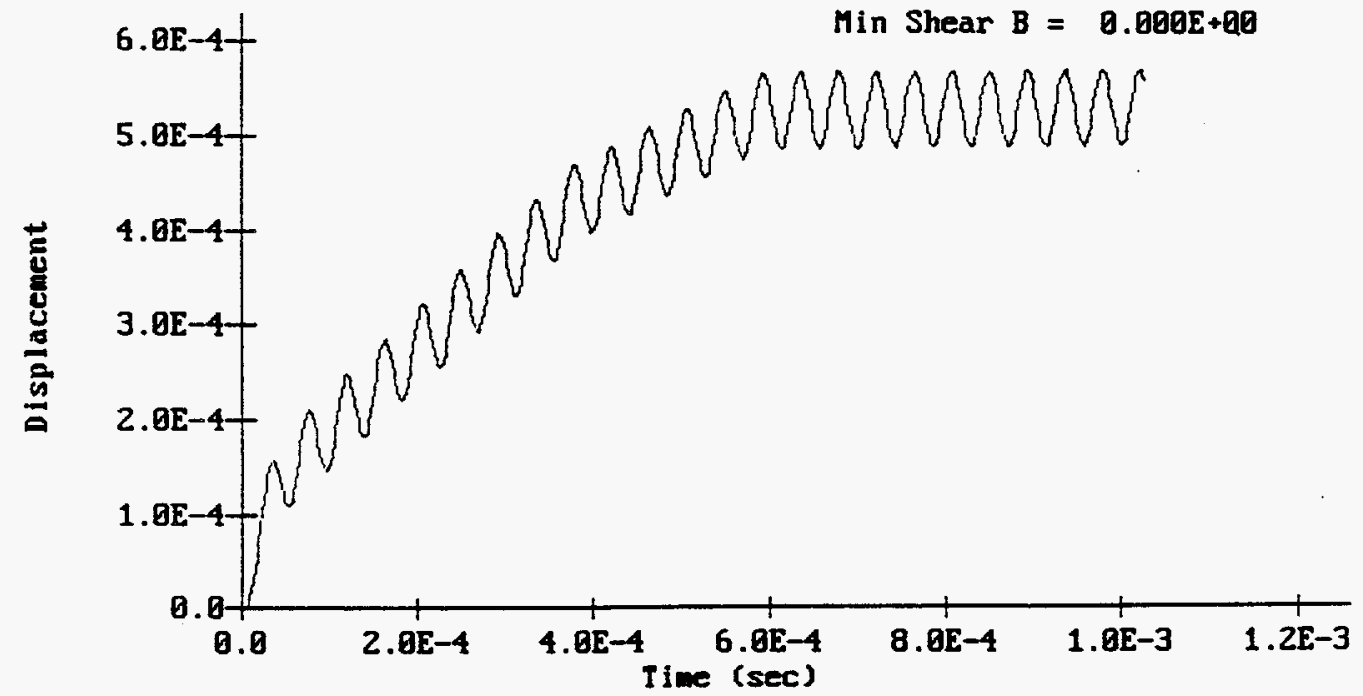

Figure B12. Response of the Dome in the Top Housing with Vermiculite in the Top Chamber 
Equiv. Elastic Displac. = 1.874E-62

Max Displacement $=7.391 \mathrm{E}-\mathrm{B3}$

Min Displacement $=-2.461 E-03$

Time of Max Displacement $=3.320 \mathrm{E}-05$

Time of Min Displacement $=2.698 \mathrm{E}-04$

$M U=6.884 E-01$

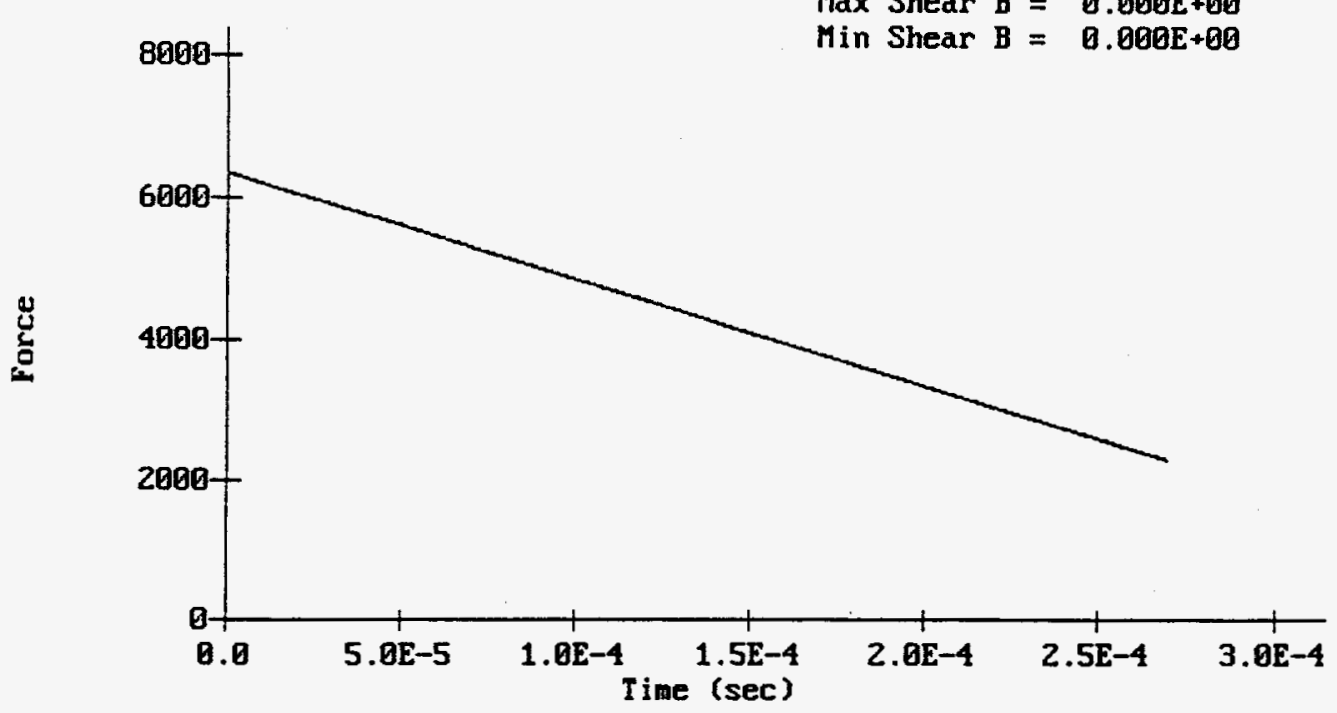

Max Force $=6.377 \mathrm{E}+03$

Min Force $=2.298 E+03$

Max Resistance $=1.225 E+04$

Min Resistance $=-4.081 E+03$

Max Shear $A=0.000 E+00$

Min Shear $A=0.000 E+B 0$

Max Shear $\mathrm{B}=0.0 \mathrm{BOE}+00$

$M$ in Shear $B=0.080 E+00$

Figure B13. Force (Pressure) on the Liner: 200\% Overcharge

Radial Expansion of Liner, 200\% Ids

03-68-1994

Equiu. Elastic Displac. = 1.074E-02

Max Displacement $=$ ?.391E-03

Min Displacement $=-2.461 \mathrm{E}-03$

Time of Max Displacement $=3.32 \mathrm{BE}-05$

Time of Min Displacement $=2.698 \mathrm{E}-04$

$M U=6.884 \mathrm{E}-81$

Max Force $=6.377 \mathrm{E}+63$

Min Force $=2.298 \mathrm{E}+03$

Max Resistance $=1.225 \mathrm{E}+84$

Min Resistance $=-4.681 \mathrm{E}+03$

Max Shear $A=0.000 E+00$

Min Shear $A=0.000 E+00$

Max Shear $B=0.000 \mathrm{E}+00$

Min Shear $B=0.080 E+80$

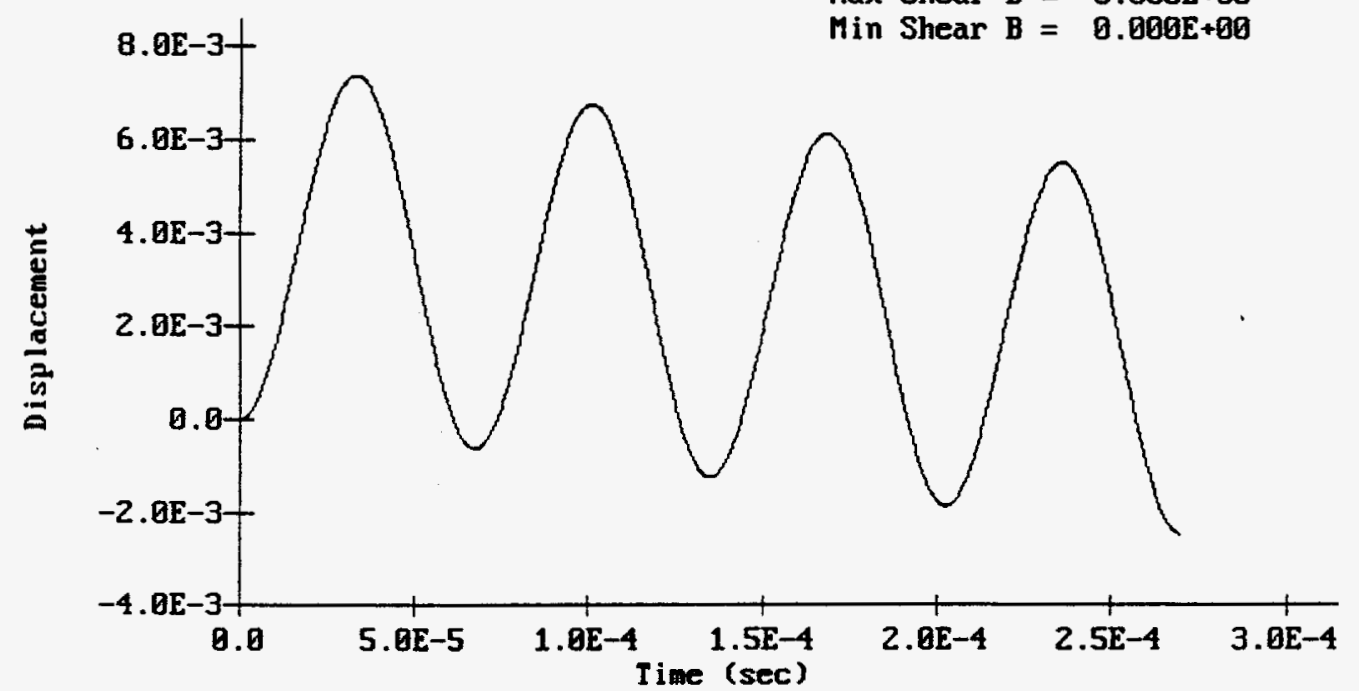

Figure B14. Radial Response of the Liner: $200 \%$ Overcharge 
Equiu. Elastic Displac. = 3.859E-62

Max Displacement $=5.369 E-02$

Min Displacement $=-8.384 E-03$

Time of Max Displacement $=7.480 E-65$

Time of Min Displacement $=3.143 \mathrm{E}-04$

$\mathrm{MU}=1.392 \mathrm{E}+80$

¿ّ

$5.600 \mathrm{E}+4+$

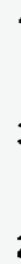

3. $000 \mathrm{E}+4$

$2.000 \mathrm{E}+4-1$

$1.0 B 0 E+4-$

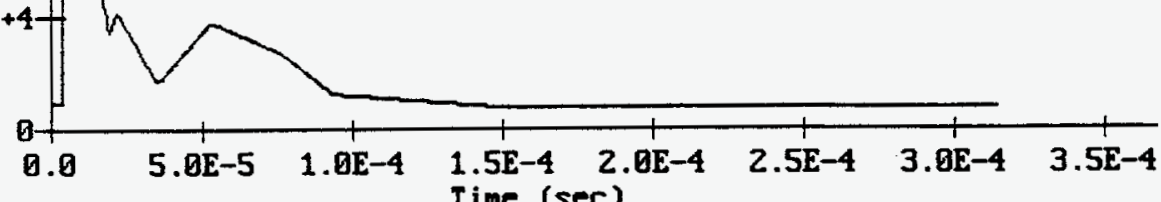

Figure B15. Force (Pressure) on the Base Plate: $200 \%$ Overcharge

Base, Bot. Hsing, st1, 290\% chg

Equiu. Elastic Displac. = 3.859E-62

Max Displacement $=5.369 E-62$

Min Displacenent $=-8.384 E-63$

Time of Max Displacement $=7.480 \mathrm{E}-05$

Time of Min Displacement $=3.143 \mathrm{E}-64$

$\mathrm{MU}=1.392 \mathrm{E}+\mathrm{BB}$

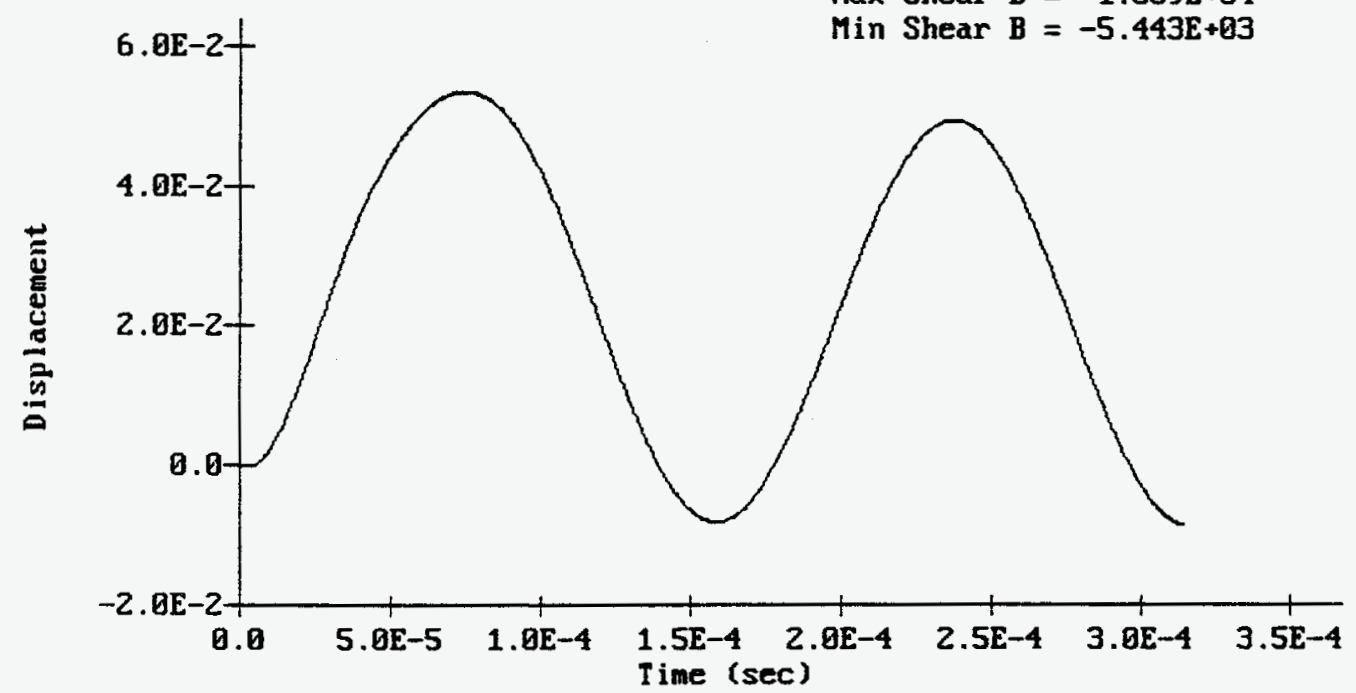

Figure B16. Response of the Steel Base Plate: 200\% Overcharge

Max Force $=4.626 \mathrm{E}+04$

Min Force $=1.962 E+03$

Max Resistance $=1.403 \mathrm{E}+04$

Min Resistance $=-8.542 \mathrm{E}+83$

Max Shear $A=1.669 E+B 4$

Min Shear $A=-5.443 E+03$

Max Shear $B=1.669 E+04$

Min Shear $B=-5.443 E+03$ 
Equiv. Elastic Displac. = $7.424 \mathrm{E}-03$

Max Displacement $=6.938 \mathrm{E}-04$

Min Displacement $=5.893 \mathrm{E}-10$

Time of Max Displacement $=7.587 \mathrm{E}-04$

Time of Min Displacement $=1.8 B 0 E-07$

MU $=9.345 E-02$

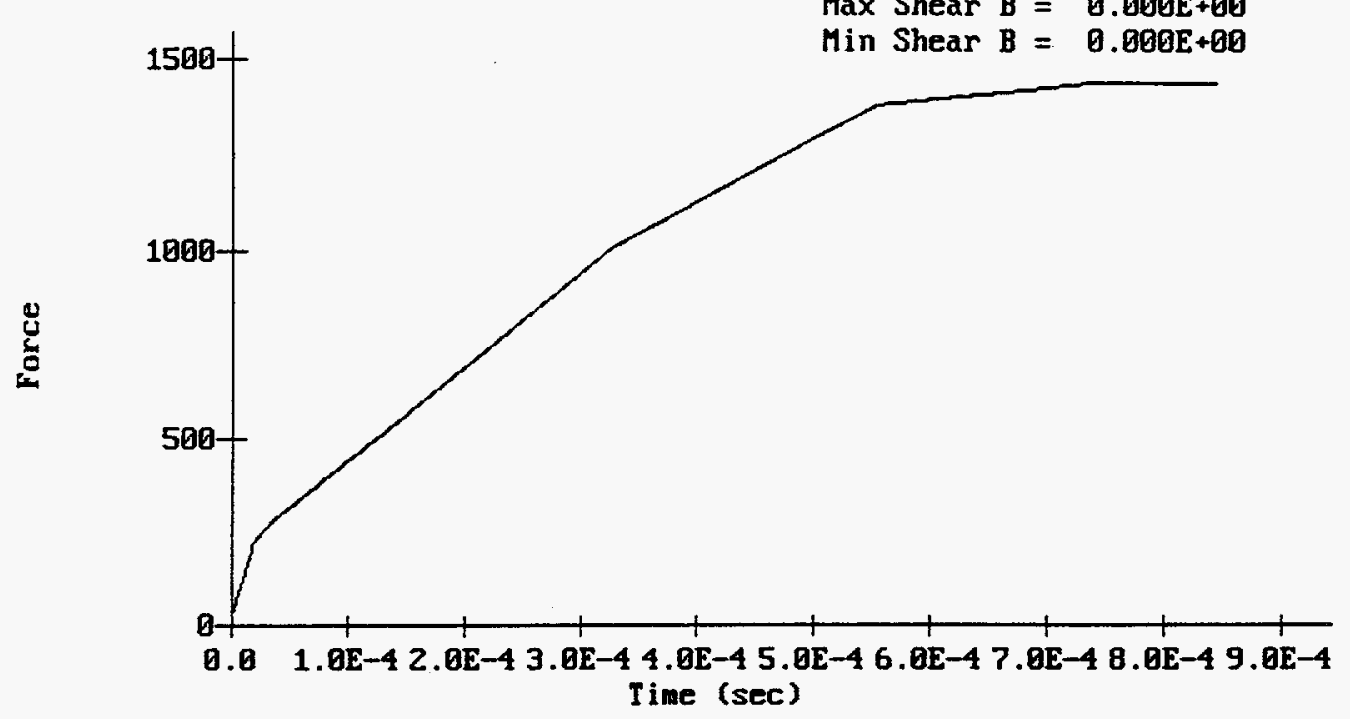

Max Force $=1.440 \mathrm{E}+83$

Min Force $=1.980 \mathrm{E}+\mathrm{B1}$

Max Resistance $=1.554 \mathrm{E}+03$

Min Resistance $=1.320 \mathrm{E}-03$

Max Shear $A=0.000 E+\theta 0$

Min Shear $A=0.000 E+00$

Max Shear $B=0.000 E+00$

Min Shear $B=0.000 E+B D$

Figure B17. Force (Pressure) on the Top Housing Dome: 200\% Overcharge

Response of Dome, 200\% Id

Equiv. Elastic Displac. $=7.424 E-03$

Max Displacement $=6.938 E-04$

Min Displacement $=5.893 E-10$

Time of Max Displacement $=7.587 \mathrm{E}-04$

Time of Min Displacement $=1.000 \mathrm{E}-0$ ?

$\mathrm{MU}=9.345 \mathrm{E}-02$

要
Max Force $=1.440 \mathrm{E}+03$

$\operatorname{Min}$ Force $=1.980 \mathrm{E}+01$

Max Resistance $=1.554 E+63$

Min Resistance $=1.320 \mathrm{E}-03$

Max Shear $A=0.0 B \theta E+B B$

Min Shear $A=B .000 E+B \theta$

Max Shear $B=0.000 E+00$

Min Shear $B=0.000 E+00$

03-07-1994

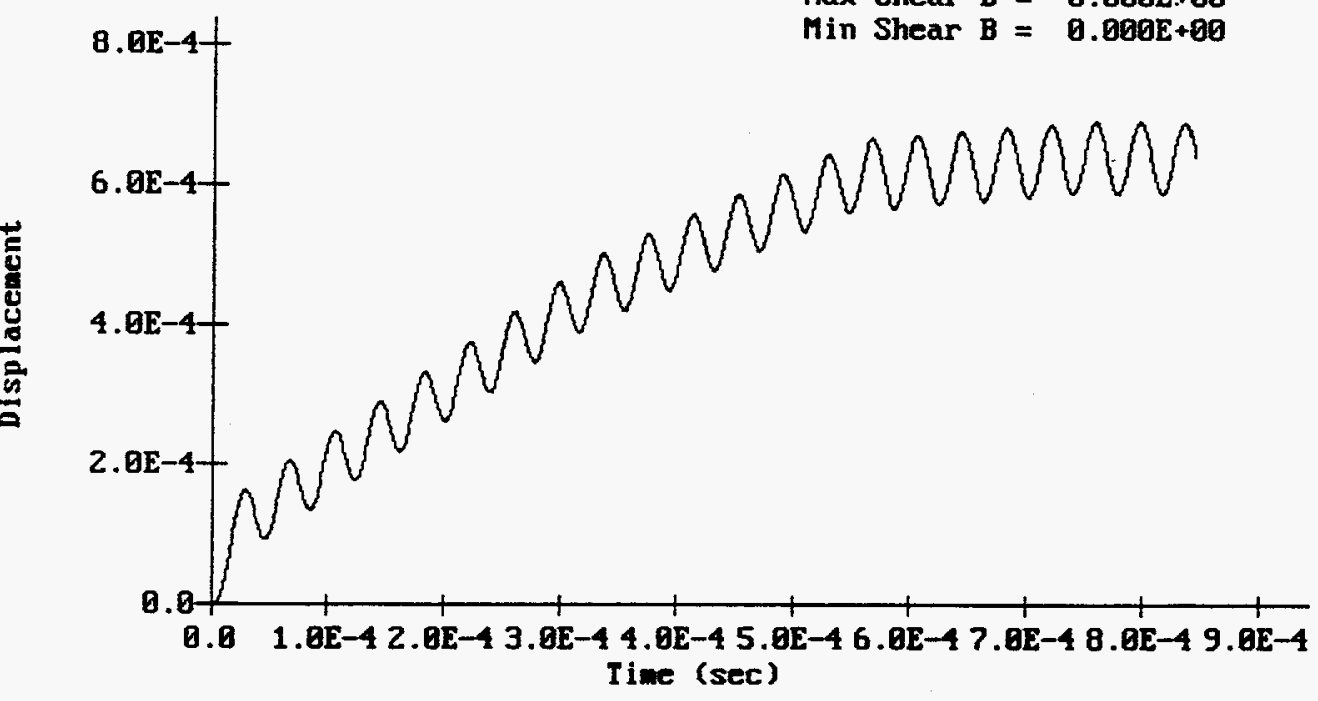

Figure B18. Response of the Top Housing Dome: $200 \%$ Overcharge 
Equiu. Elastic Displac. = 1.054E-82

Max Displacement $=1.396 \mathrm{E}-03$

Min Displacement $=9.491 \mathrm{E}-10$

Time of Max Displacement $=7.694 \mathrm{E}-04$

Time of Min Displacement $=1.000 \mathrm{E}-07$

$\mathrm{MU}=1.324 \mathrm{E}-\mathrm{B1}$

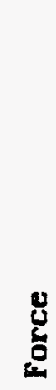

Max Force $=1.468 E+03$

Min Force $=5.000 \mathrm{E}+01$

Max Resistance $=1.659 E+03$

Min Resistance $=1.129 \mathrm{E}-03$

Max Shear $A=0.000 E+00$

Min Shear $A=0.000 E+B 0$

Max Shear $\mathrm{B}=0.800 \mathrm{E}+00$

Min Shear $B=0.000 E+00$

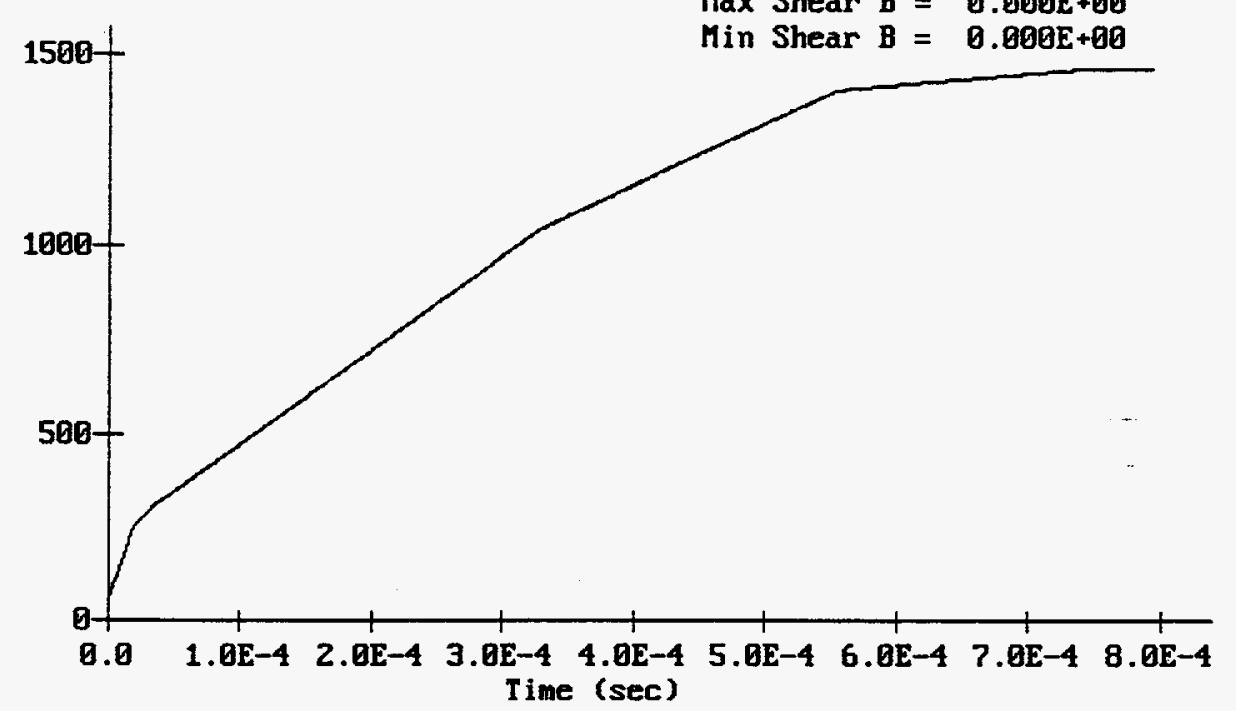

Figure B19. Force (Pressure) on the Top Housing Sidewall: 200\% Overcharge

Top Housing Side Wall, 200\% Id

Equiv. Elastic Displac. = 1.054E-82

Max Displacement $=1.396 \mathrm{E}-03$

Min Displacement $=9.491 \mathrm{E}-10$

Time of Max Displacement $=7.694 \mathrm{E}-04$

Time of Min Displacement $=1.000 \mathrm{E}-07$

$M U=1.324 \mathrm{E}-01$

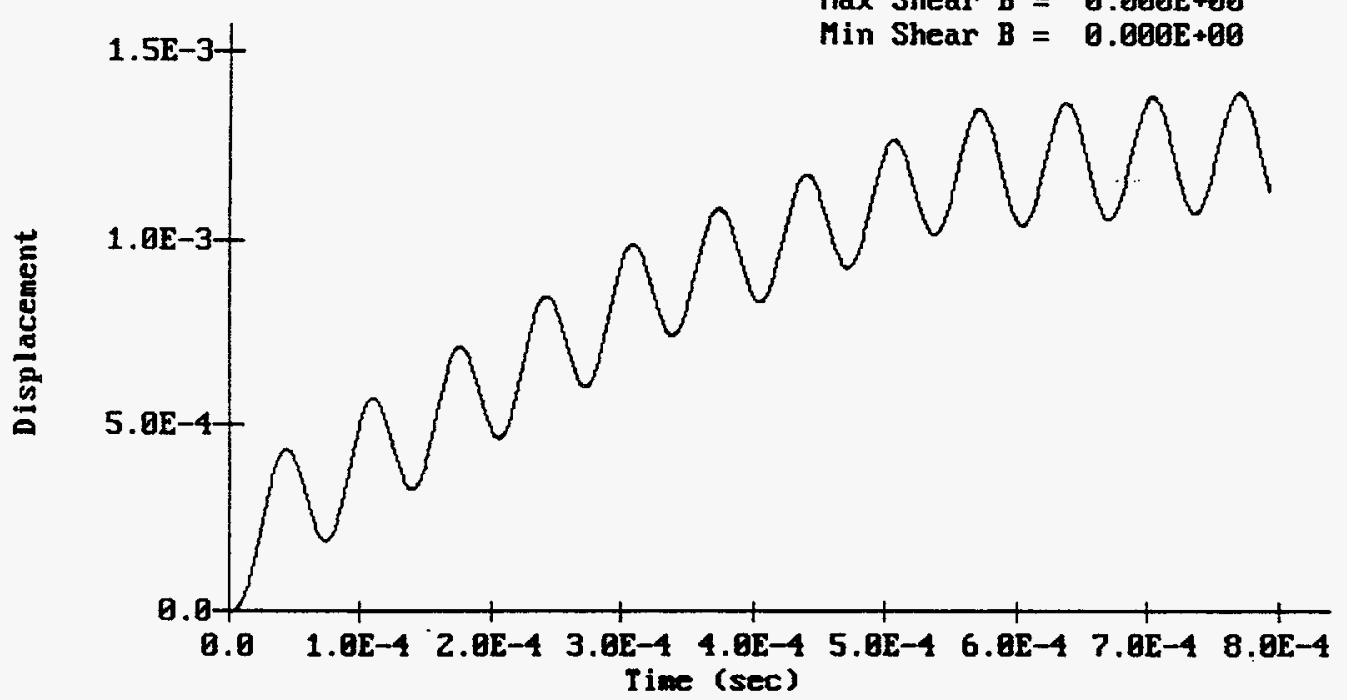

Max Force $=1.468 E+03$

Min Force $=5.080 E+01$

Max Resistance $=1.659 \mathrm{E}+03$

Min Resistance $=1.129 \mathrm{E}-03$

Max Shear $A=0.000 E+\theta 0$

Min Shear $A=0.000 E+00$

Max Shear $B=0$. BQDE + Bg

Min Shear $B=0.000 E+\theta 0$

$03-07-1994$

Figure B20. Response of the Top Housing Sidewall: 200\% Overcharge 
Table B1. Domed Cover with Spirolox Closure

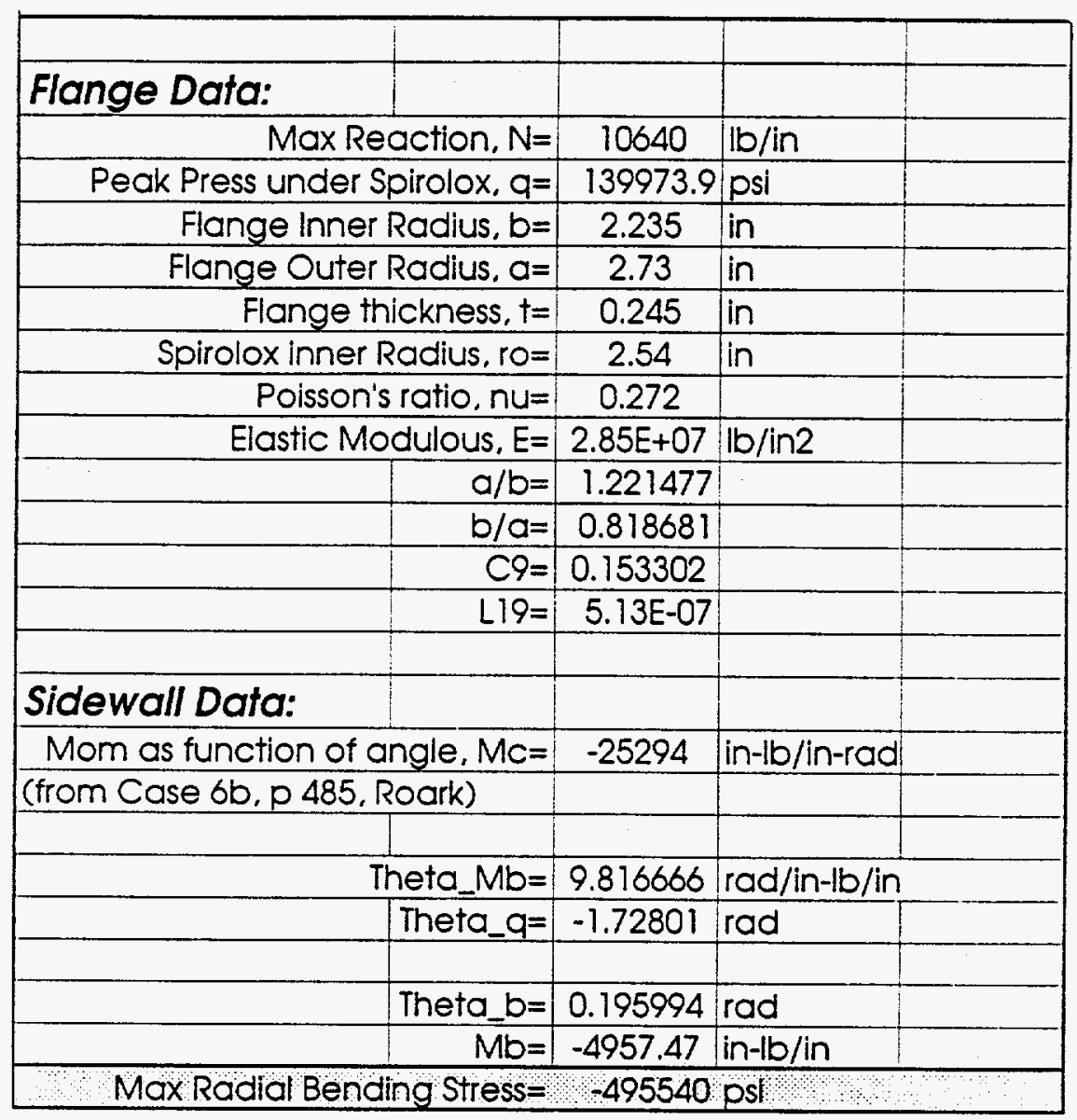


Table B2. Summary of Results for the Sample Containment

\begin{tabular}{|c|c|c|c|c|c|c|c|}
\hline \multirow[b]{2}{*}{ Component } & \multicolumn{3}{|c|}{ Design Charge } & \multicolumn{3}{|c|}{$200 \%$ Overcharge } & \multirow[b]{2}{*}{ Comments } \\
\hline & Figure & $\mu$ & Max Resistance & Figure & $\mu$ & Max Resistance & \\
\hline Liner & B4 & 0.37 & 6,627 & B18 & 0.69 & 12,250 & Acceptable \\
\hline \multicolumn{8}{|l|}{ Bottom Housing } \\
\hline Base Plate (al) & B8 & 8.24 & 5,031 & - & - & - & Unacceptable \\
\hline Base Plate (stl) & B9 & 1.01 & 14,030 & $\mathrm{~B} 20$ & 1.39 & 14,030 & $\begin{array}{l}\text { Marginal at Design } \\
\text { Charge }\end{array}$ \\
\hline \multicolumn{8}{|l|}{ Top Housing (Air) } \\
\hline Dome & $\mathrm{B} 12$ & 0.35 & 5,815 & - & - & - & \multirow{3}{*}{$\begin{array}{l}\text { Top housing is } \\
\text { inadequate when air } \\
\text { is in the top chamber } \\
\text { because of excessive } \\
\text { flange stress }\end{array}$} \\
\hline Sidewall & B14 & 0.40 & 4,988 & - & - & - & \\
\hline Flange & - & $\gg 1.0$ & - & - & - & - & \\
\hline Spirolox Ring (Air) & - & 0.45 & - & - & - & - & \\
\hline \multicolumn{8}{|l|}{$\begin{array}{l}\text { Top Housing } \\
\text { (Vermiculite) }\end{array}$} \\
\hline Dome & B16 & 0.07 & 1,029 & B22 & 0.09 & 1,554 & \multirow{3}{*}{$\begin{array}{l}\text { Top Housing } \\
\text { acceptable for } \\
\text { vermiculite fill in top }\end{array}$} \\
\hline Sidewall & - & - & - & B24 & 0.13 & 1.659 & \\
\hline Flange & - & 0.70 & - & - & 1.06 & - & \\
\hline $\begin{array}{l}\text { Spirolox Ring } \\
\text { (Vermiculite) }\end{array}$ & - & 0.09 & - & - & 0.14 & - & Acceptable \\
\hline
\end{tabular}

Appendix B - Figures and Tables 
Appendix C

Transformation Factors for Beams and Plates 


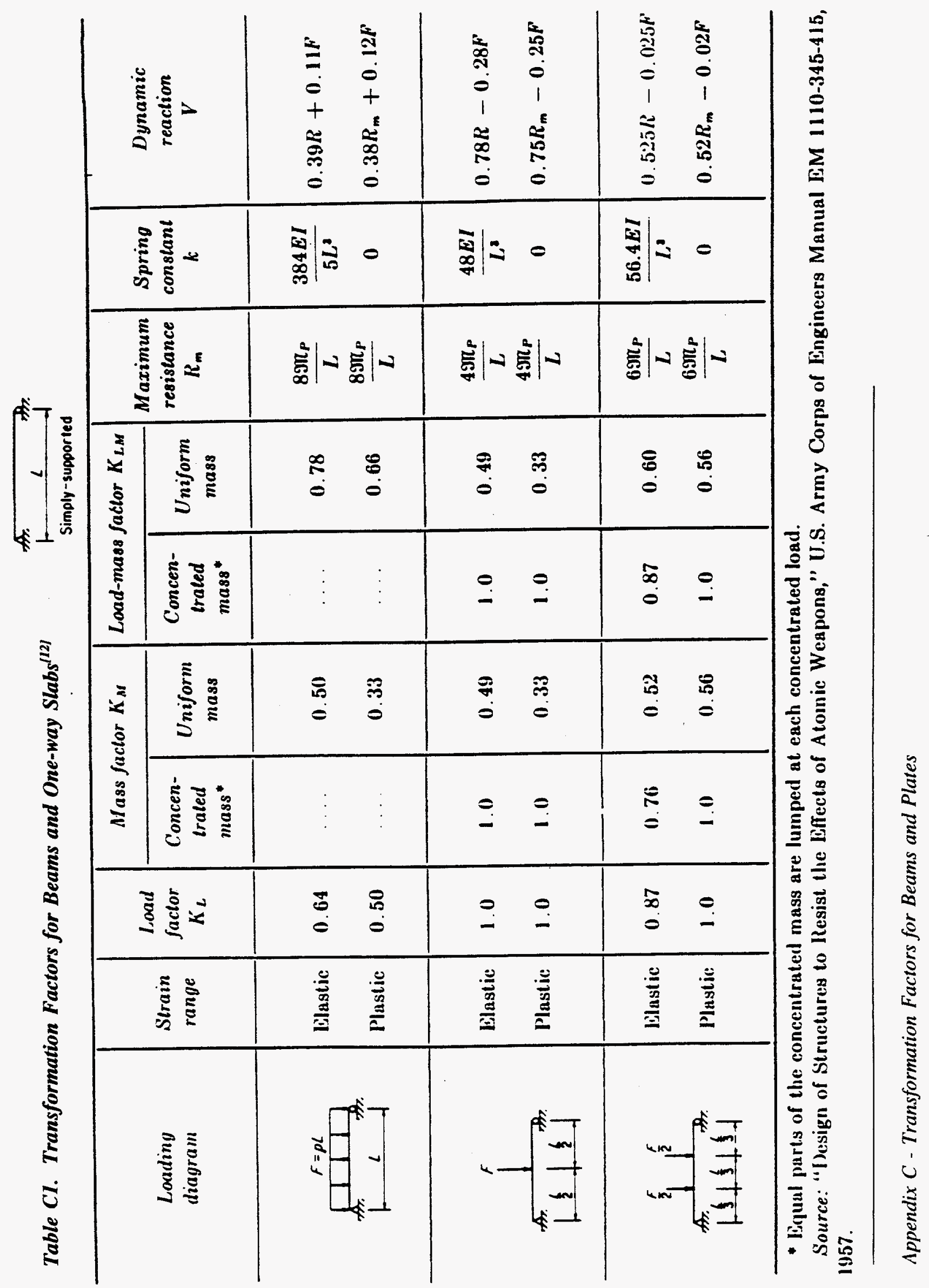


Table C2. Transformation Factors for Beams and One-way Slabs ${ }^{[12]}$

IIIP, = ultimate moment capacity at aupport

Jll $P_{m}=$ ultimate moment capacity at midanan

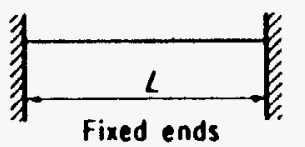

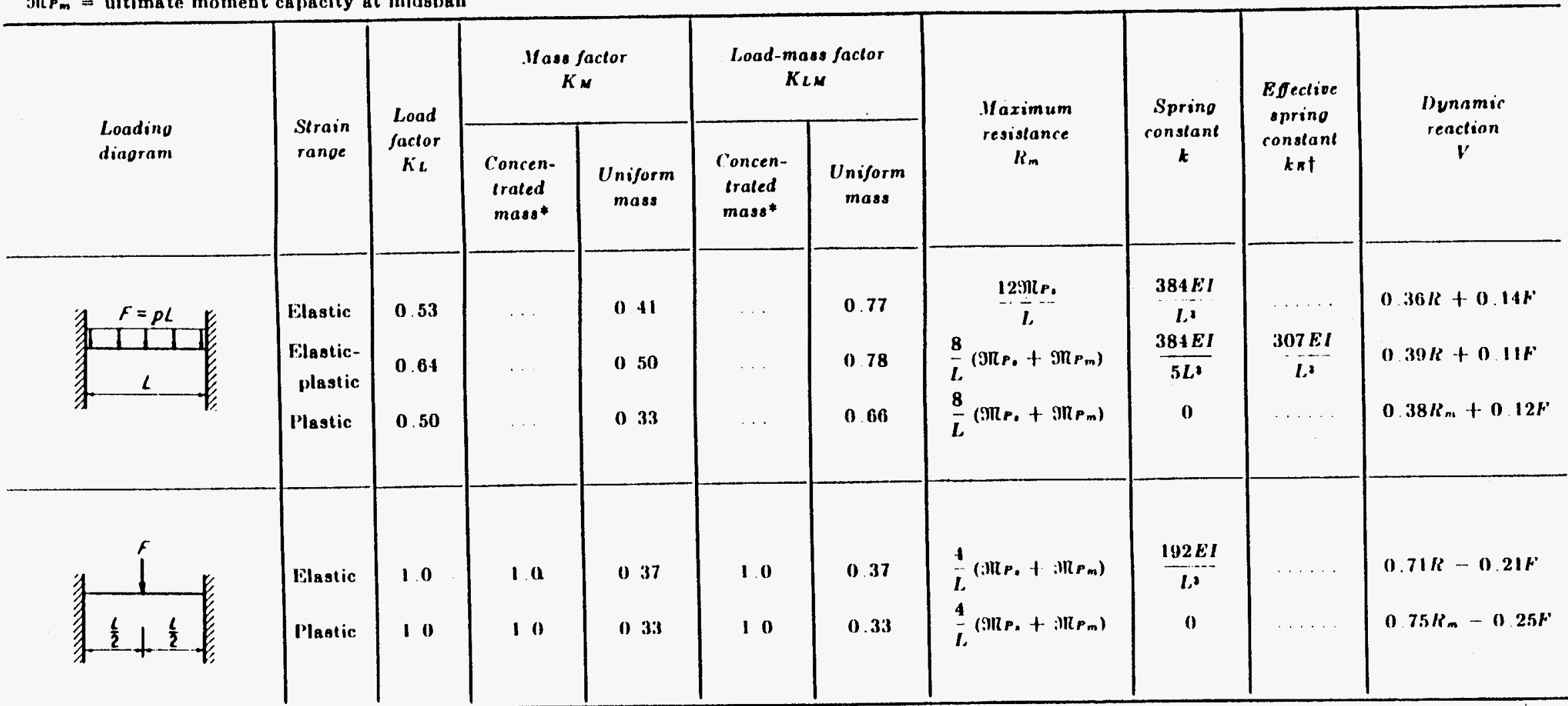

- Concentrated mags is lumped al tho concentrated loal.

t See Fig. 5.4.

Source: "Degign of Structures to Regist the Effects of Atomic Weapons." U.S. Irmy Corpa of lingineers Manual EM $1110-345-415.1957$. 
\& Table C3. Transformation Factors for Beams and One-way Slabs ${ }^{[12]}$

Ml $P_{0}=$ ultimale bending capacity at aupport.

MRP $=$ ultimate poaitive bending capacity

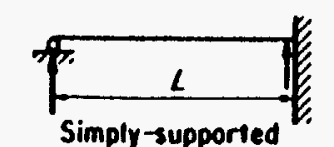

and fixed

\begin{tabular}{|c|c|c|c|c|c|c|c|c|c|c|}
\hline \multirow{2}{*}{$\begin{array}{l}\text { Loadino } \\
\text { diaoram }\end{array}$} & \multirow{2}{*}{$\begin{array}{l}\text { Strain } \\
\text { ranoc }\end{array}$} & \multirow{2}{*}{$\begin{array}{c}\text { Load } \\
\text { faclor } \\
K_{L}\end{array}$} & \multicolumn{2}{|c|}{$\begin{array}{c}\text { Mase faclor } \\
K_{M}\end{array}$} & \multicolumn{2}{|c|}{$\begin{array}{l}\text { Load-mase } \\
\text { factor } \\
\text { KLA }\end{array}$} & \multirow{2}{*}{$\begin{array}{c}\text { Maximum } \\
\text { resiolance } \\
R_{m}\end{array}$} & \multirow{2}{*}{$\begin{array}{c}\text { Spring } \\
\text { contant } \\
\boldsymbol{t}\end{array}$} & \multirow{2}{*}{$\begin{array}{c}\text { EDective } \\
\text { opring } \\
\text { conetant } \\
\text { Ext }\end{array}$} & \multirow{2}{*}{$\begin{array}{c}\text { Dynamic } \\
\text { reaction } \\
V\end{array}$} \\
\hline & & & $\begin{array}{l}\text { Con- } \\
\text { cen- } \\
\text { traled } \\
\text { mace* }\end{array}$ & $\begin{array}{l}\text { Uni- } \\
\text { form } \\
\text { mase }\end{array}$ & $\begin{array}{l}\text { Con- } \\
\text { cen- } \\
\text { trated } \\
\text { mase* }\end{array}$ & $\begin{array}{l}\text { Uni- } \\
\text { form } \\
\text { mase }\end{array}$ & & & & \\
\hline $\begin{array}{l}F=\rho l \\
I I 1 \\
F_{V_{1}}, V_{2}\end{array}$ & $\begin{array}{l}\text { Elastic } \\
\text { Elastic- } \\
\text { plastic } \\
\text { Plastic }\end{array}$ & $\begin{array}{l}0.58 \\
0.64 \\
0.50\end{array}$ & $\ldots$ & $\begin{array}{l}0.45 \\
0.50 \\
0.33\end{array}$ & $\ldots$ & $\begin{array}{l}0.78 \\
0.78 \\
0.66\end{array}$ & 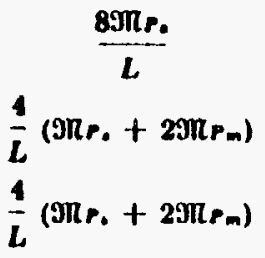 & $\begin{array}{c}\frac{185 E I}{L '} \\
\frac{384 E I}{5 L^{\prime}} \\
0\end{array}$ & $\frac{160 E I}{L}$ & $\begin{array}{l}V_{1}=0.26 R+0.12 F \\
V_{2}=0.43 R+0.19 F \\
V=0.39 R+0.11 F \pm M_{r_{0} / L} \\
V=0.38 R_{m}+0.12 F \pm M_{r_{0} / L}\end{array}$ \\
\hline$v_{2}$ & $\begin{array}{l}\text { Elastic } \\
\text { Elastic- } \\
\text { plastic } \\
\text { Plastic }\end{array}$ & $\begin{array}{l}10 \\
10 \\
10\end{array}$ & $\begin{array}{l}1.0 \\
1.0 \\
1.0\end{array}$ & $\begin{array}{l}0.43 \\
0.49 \\
0.33\end{array}$ & $\begin{array}{l}1.0 \\
1.0 \\
10\end{array}$ & $\begin{array}{l}0.43 \\
0.49 \\
\text { 0.33 }\end{array}$ & $\begin{array}{l}\frac{16 M P_{1}}{3 L} \\
\frac{2}{L}\left(9 R_{r_{1}}+2 M r_{m}\right) \\
\frac{2}{L}\left(M r_{r_{1}}+2 M r_{m}\right)\end{array}$ & $\begin{array}{l}\frac{107 E I}{L 2} \\
\frac{48 E I}{L !} \\
0\end{array}$ & $\frac{106 E I}{L^{\circ}}$ & $\begin{aligned} V_{1} & =0.25 R+0.07 F \\
V_{2} & =0.54 R+0.14 F^{\prime} \\
V & =0.78 R-0.28 F \pm 9 r_{\cdot} / L \\
V & =0.75 R_{m}-0.25 F \pm M_{r_{.} / L}\end{aligned}$ \\
\hline$\frac{1^{\frac{5}{2}}}{16 ! t}$ & $\begin{array}{l}\text { Elastic } \\
\text { Elastic- } \\
\text { plastic } \\
\text { Plastic }\end{array}$ & $\begin{array}{l}0.81 \\
0.87 \\
1.0\end{array}$ & $\begin{array}{l}0.67 \\
0.76 \\
1.0\end{array}$ & $\begin{array}{l}\text { 0. } 45 \\
\text { 0. } 52 \\
\text { 0. } 56\end{array}$ & $\begin{array}{l}0.83 \\
0.87 \\
1.0\end{array}$ & $\begin{array}{l}\text { 0.55 } \\
\text { 0.60 } \\
\text { 0.56 }\end{array}$ & $\begin{array}{l}\frac{6 M r_{1}}{L} \\
\frac{2}{L}\left(\mathfrak{M} r_{r_{1}}+3 M r_{m}\right) \\
\frac{2}{L}\left(\mathfrak{M} r_{p_{1}}+3 M r_{m}\right)\end{array}$ & $\begin{array}{l}\frac{132 B I}{L I} \\
\frac{56 B I}{L I}\end{array}$ & $\frac{122 E I}{L^{*}}$ & $\begin{aligned} V_{1} & =0.17 R+0.17 F \\
V_{2} & =0.33 R+0.33 F \\
V & =0.525 R-0.025 F+9 \pi_{P_{1} / L} \\
V & =0.52 R_{m}-0.02 F \pm M_{r_{d} / L}\end{aligned}$ \\
\hline
\end{tabular}

- Equal parts of the concentrated mases are lumped at encli concentraled load.

t See Fig. 5.4.

Source: "Design of Structurea to Resiat the Effects of Alomic Weapone," U.8. Army Corpa of Engineero Manual EM $1110-345-116$, 1957.

Appendix C - Transformation Factors for Beams and Plates 
Table C4. Transformation Factors for Two-way Slabs: Simple Supports - Four Sides, Uniform Load ${ }^{[12]}$

$r_{A}=$ total dynamic reaction along short edge; $V_{B}=$ total dynamic reaction along long edge.

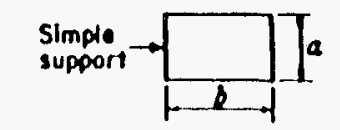

\begin{tabular}{|c|c|c|c|c|c|c|c|c|}
\hline \multirow{2}{*}{$\begin{array}{l}\text { Slrain } \\
\text { range }\end{array}$} & \multirow{2}{*}{$a / b$} & \multirow{2}{*}{$\begin{array}{c}\text { Load } \\
\text { faclor } \\
K_{L} \\
\end{array}$} & \multirow{2}{*}{$\begin{array}{l}\text { Mass } \\
\text { factor } \\
K_{M}\end{array}$} & \multirow{2}{*}{$\begin{array}{c}\text { Load-mass } \\
\text { factor } \\
K_{L M} \\
\end{array}$} & \multirow{2}{*}{$\begin{array}{l}\text { Maximum } \\
\text { resislance }\end{array}$} & \multirow{2}{*}{$\begin{array}{c}\begin{array}{c}\text { Spring } \\
\text { conslant } \\
k\end{array} \\
\end{array}$} & \multicolumn{2}{|c|}{ Dynamic reaclions } \\
\hline & & & & & & & $V_{A}$ & $V_{B}$ \\
\hline \multirow{6}{*}{ Slastic } & 1.0 & 0.46 & 0.31 & 0.67 & $\frac{12}{a}\left(\mathfrak{M}_{P / \bullet}+\mathfrak{M}_{P / b}\right)$ & $\frac{252 E I_{a}}{a^{2}}$ & $0.07 F+0.18 R$ & $0.07 F+0.18 R$ \\
\hline & 0.0 & 0.47 & 0.33 & 0.70 & $\frac{1}{a}\left(12 M_{P / a}+11 M_{P / b}\right)$ & $\frac{230 E I_{0}}{a^{2}}$ & $0.06 F+0.16 R$ & $0.08 F+0.20 R$ \\
\hline & 0.8 & 0.40 & 0.35 & 0.71 & $\frac{1}{a}\left(129 M_{P / a}+10.39 M_{P / b}\right)$ & $\frac{212 E I}{a^{2}}$ & $0.06 F+0.14 R$ & $0.08 F+0.22 R$ \\
\hline & 0.7 & 0.51 & 0.37 & 0.73 & $\frac{1}{a}\left(12 \mathfrak{M}_{P / a}+9.8 \mathfrak{M}_{P / b}\right)$ & $\frac{201 E I_{a}}{a^{2}}$ & $0.05 F+0.13 R$ & $0.08 F+0.24 R$ \\
\hline & 0.6 & 0.53 & $0.39^{\circ}$ & 0.74 & $\frac{1}{a}\left(12 \mathbb{M}_{P / a}+9.3 \mathfrak{M}_{P / b}\right)$ & $\frac{197 E I_{a}}{a^{2}}$ & $0.04 F+0.11 R$ & $0.09 F+0.26 R$ \\
\hline & 0.5 & 0.55 & 0.41 & 0.75 & $\frac{1}{a}\left(129 M_{P / a}+9.09 M_{P / b}\right)$ & $\frac{201 E I_{a}}{a^{2}}$ & $0.04 F+0.00 R$ & $0.09 F+0.28 R$ \\
\hline \multirow{6}{*}{ Plastic } & 1.0 & 0.33 & 0.17 & 0.51 & $\frac{12}{a}\left(\mathfrak{M}_{P / a}+\mathfrak{M}_{P / b}\right)$ & $\mathbf{0}$ & $0.09 F+0.16 R_{m}$ & $0.09 F+0.16 R_{m}$ \\
\hline & 0.0 & 0.35 & 0.18 & 0.51 & $\frac{1}{a}\left(12 M_{P / a}+11 M_{P / b}\right)$ & 0 & $0.08 F+0.15 R_{m}$ & $0.09 F^{\circ}+0.18 R_{m}$ \\
\hline & 0.8 & 0.37 & 0.20 & 0.54 & $\frac{1}{a}\left(129 \pi_{P / a}+10.39 \pi_{P / b}\right)$ & $\mathbf{0}$ & $0.07 F+0.13 R_{m}$ & $0.10 F+0.20 R_{m}$ \\
\hline & 0.7 & 0.38 & 0.22 & 0.58 & $\frac{1}{a}\left(12 \mathfrak{M}_{P / a}+9.8 \mathfrak{M}_{P / b}\right)$ & 0 & $0.06 F+0.12 R_{m}$ & $0.10 F+0.22 R_{m}$ \\
\hline & 0.6 & 0.40 & 0.23 & 0.58 & $\frac{1}{a}\left(12 \mathfrak{M}_{P / a}+9.3 \mathbb{M}_{P / b}\right)$ & 0 & $0.05 F+0.10 R_{m}$ & $0.10 F+0.25 R_{m}$ \\
\hline & 0.5 & 0.42 & 0.25 & 0.59 & $\frac{1}{a}\left(12 M_{P / \bullet}+9.09 M_{P / b}\right)$ & $\mathbf{0}$ & $0.04 F+0.08 R_{m}$ & $0.11 F+0.27 R_{m}$ \\
\hline
\end{tabular}

Source: "Jesign of Structures to Resist the Effects of Atomic Weapong," U.S. Army Corpe of Engineers Manual EM 1110-345-415, 1957.

$O$

Appendix C - Transformation Factors for Beams and Plates 
Table C5. Transformation Factors for Two-way Slabs: Fixed Four Sides, Uniform Load ${ }^{[2]}$

$V_{A}=$ total dynamic reaction along short edge; $V_{A}=$ total dyamic reaction along long edge.

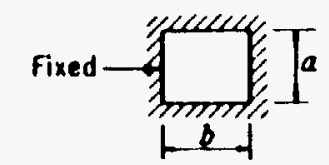

\begin{tabular}{|c|c|c|c|c|c|c|c|c|}
\hline & & & & Load-mane & & Spr & \multicolumn{2}{|c|}{ Dynamic reaclions } \\
\hline Plantic & $\begin{array}{l}1.0 \\
0.0 \\
0.8 \\
0.7 \\
0.6 \\
0.5\end{array}$ & $\begin{array}{l}\text { 0.33 } \\
\text { 0.34 } \\
\text { 0.36 } \\
\text { 0.38 } \\
\text { 0.41 } \\
\text { 0.43 }\end{array}$ & $\begin{array}{l}0.21 \\
0.23 \\
0.25 \\
0.27 \\
0.29 \\
0.31\end{array}$ & $\begin{array}{l}0.63 \\
0.68 \\
0.69 \\
0.71 \\
0.71 \\
0.72\end{array}$ & 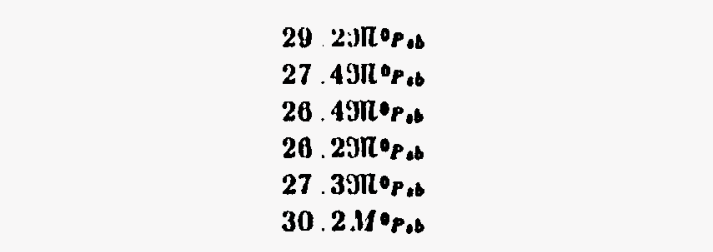 & $\begin{array}{l}810 E I_{a} / a^{2} \\
742 E I_{a} / a^{2} \\
705 E I_{a} / a^{2} \\
602 E I_{a} / a^{2} \\
724 E I_{a} / a^{2} \\
806 E I_{a} / a^{2}\end{array}$ & $\begin{array}{l}0.10 F+0.15 R \\
0.00 F+0.14 R \\
0.08 F+0.12 R \\
0.07 F+0.11 R \\
0.06 F+0.09 R \\
0.05 F+0.08 R\end{array}$ & $\begin{array}{l}0.10 F+0.15 R \\
0.10 F+0.17 K \\
0.11 F+0.19 R \\
0.11 F+0.21 R \\
0.12 F+0.23 R \\
0.12 F+0.25 K\end{array}$ \\
\hline $\begin{array}{l}\text { Pilaatic- } \\
\text { plastic }\end{array}$ & $\begin{array}{l}1.0 \\
0.0 \\
0.8 \\
0.7 \\
0.6 \\
0.5\end{array}$ & $\begin{array}{l}0.46 \\
0.47 \\
0.49 \\
0.51 \\
0.53 \\
0.55\end{array}$ & $\begin{array}{l}\mathbf{0 . 3 1} \\
\mathbf{0 . 3 3} \\
\mathbf{0 . 3 5} \\
\mathbf{0 . 3 7} \\
\mathbf{0 . 3 0} \\
\mathbf{0 . 4 1}\end{array}$ & $\begin{array}{l}0.67 \\
0.70 \\
0.71 \\
0.73 \\
0.74 \\
0.75\end{array}$ & 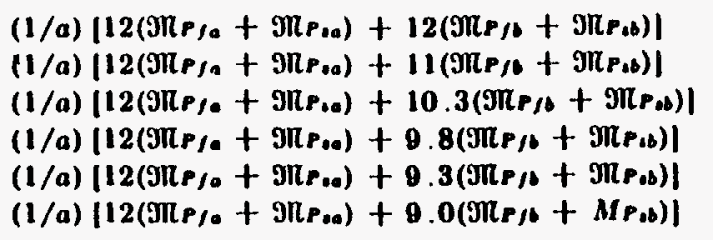 & $\begin{array}{l}252 E I_{a} / a^{2} \\
230 E I_{a} / a^{2} \\
212 E I_{a} / a^{2} \\
201 E I_{a} / a^{2} \\
197 E I_{a} / a^{2} \\
201 E I_{a} / a^{2}\end{array}$ & $\begin{array}{l}0.07 F+0.18 R \\
0.06 F+0.16 R \\
0.00 F+0.14 R \\
0.05 F+0.13 R \\
0.04 F+0.11 R \\
0.04 F+0.09 R\end{array}$ & $\begin{array}{l}0.07 F+0.18 k \\
0.08 F+0.20 k \\
0.08 F+0.22 k \\
0.08 k+0.24 R \\
0.09 k+0.26 R \\
0.09 F+0.28 K\end{array}$ \\
\hline I'lastire & $\begin{array}{l}1.0 \\
0.0 \\
0.8 \\
0.7 \\
0.6 \\
0.5\end{array}$ & $\begin{array}{l}0.33 \\
0.35 \\
0.37 \\
0.38 \\
0.40 \\
0.12\end{array}$ & $\begin{array}{l}0.17 \\
0.18 \\
0.20 \\
0.22 \\
0.23 \\
0.25\end{array}$ & $\begin{array}{l}0.51 \\
0.51 \\
0.54 \\
0.58 \\
0.58 \\
0.59\end{array}$ & 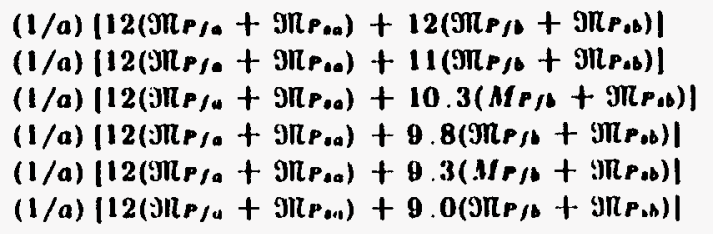 & $\begin{array}{l}0 \\
0 \\
0 \\
0 \\
0 \\
0\end{array}$ & $\begin{array}{l}0.09 F+0.16 R_{m} \\
0.08 F+0.15 R_{m} \\
0.07 F+0.13 R_{m} \\
0.06 F+0.12 R_{m} \\
0.05 F+0.10 R_{m} \\
0.01 F+0.08 R_{m}\end{array}$ & $\begin{array}{l}0.00 F+0.16 R_{\mathrm{m}} \\
0.00 F+0.18 R_{\mathrm{m}} \\
0.10 F+0.20 R_{\mathrm{m}} \\
0.10 F+0.22 R_{\mathrm{m}} \\
0.10 F+0.25 R_{\mathrm{m}} \\
0.11 F+0.27 R_{\mathrm{m}}\end{array}$ \\
\hline
\end{tabular}

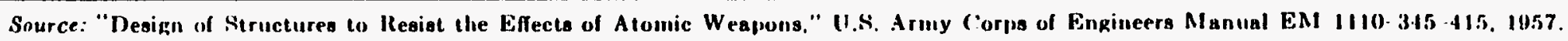

Appendix C - Transformation Factors for Beams and Plates 
Table C6. Transformation Factors for Two-way Slabs:

Short Edges Fixed - Long Edges Simply Supported;

for Poisson's Ratio $=0.3$

[U.S. Army Corps of Engineering Manual $\left.(1975)^{[12]}\right]$

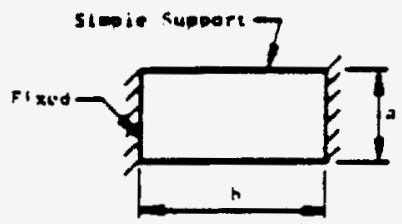

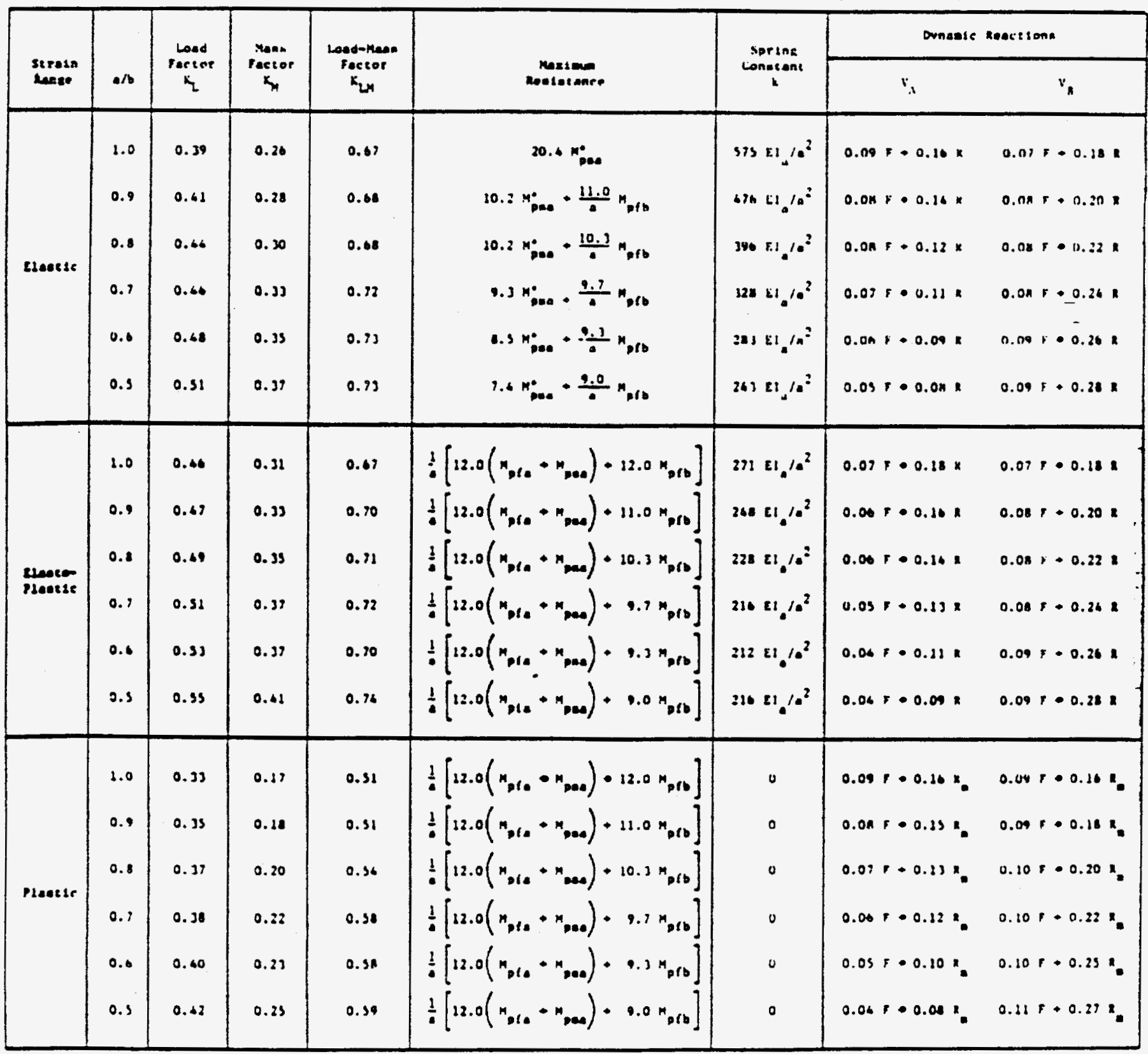

Appendix C - Transformation Factors for Beams and Plates 
Table C7. Transformation Factors for Two-way Slabs:

Short Sides Simply Supported - Long Sides Fixed;

$$
\text { for Poisson's Ratio = } 0.3
$$

[U.S. Army Corps of Engineering Manual $\left.(1975)^{[12]}\right]$

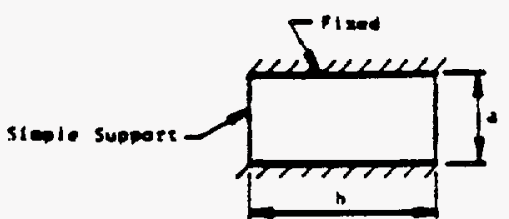

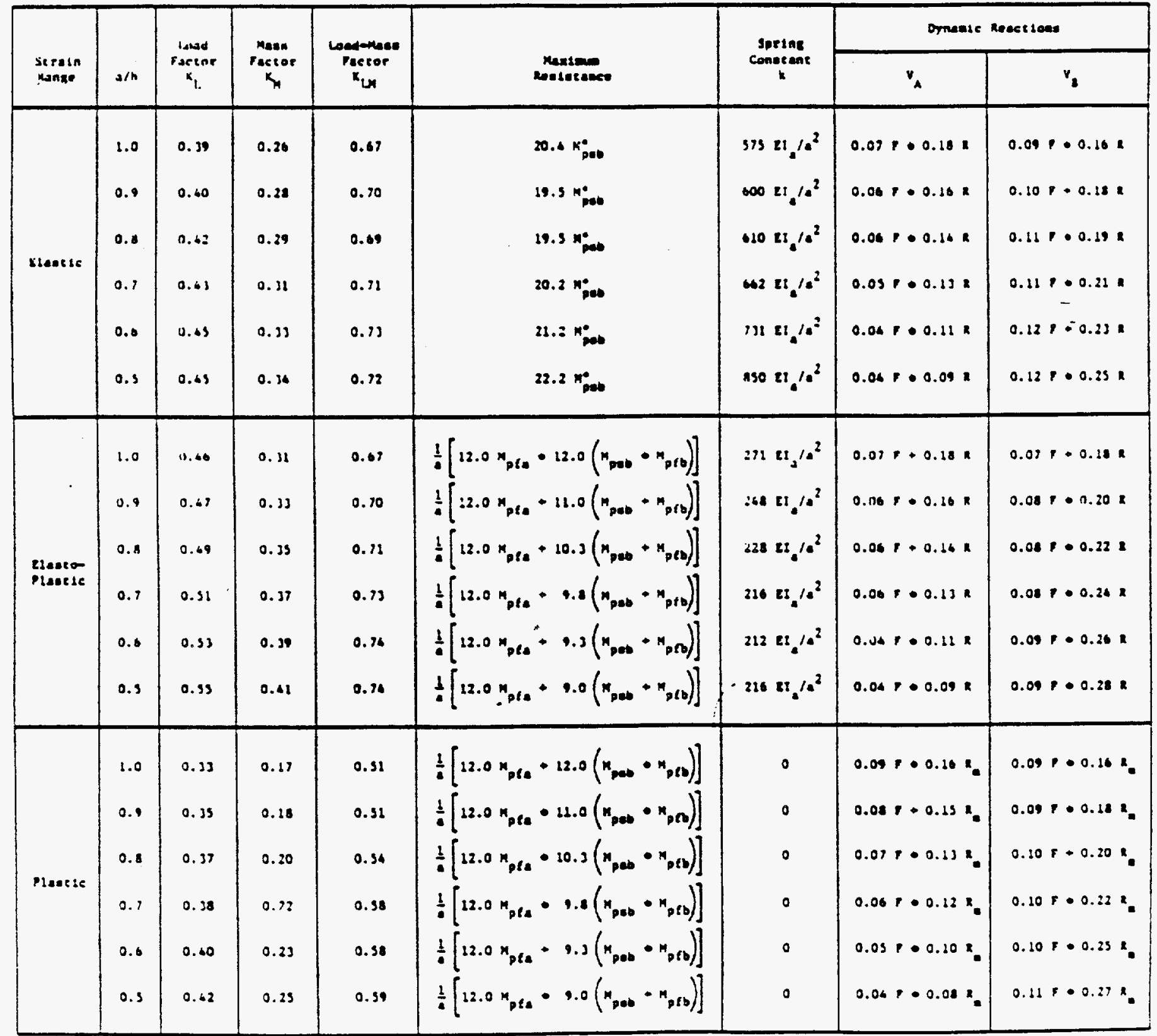


Table C8. Transformation Factors for Circular Slabs; for Poisson's Ratio $=0.3$

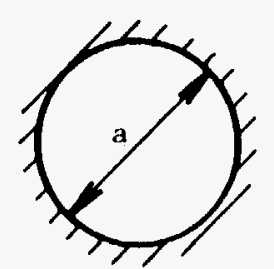

Fixed Edges [U.S. Army Corps of Engineering Manual $\left.(1975)^{(12]}\right]$

\begin{tabular}{|c|c|c|c|c|c|c|c|}
\hline $\begin{array}{c}\text { Edge } \\
\text { Condition }\end{array}$ & $\begin{array}{l}\text { Strain } \\
\text { Range }\end{array}$ & $\begin{array}{c}\text { Load } \\
\text { Factor } \\
K_{L}\end{array}$ & $\begin{array}{c}\text { Mass } \\
\text { Factor } \\
K_{M}\end{array}$ & $\begin{array}{c}\text { Load-Mass } \\
\text { Factor } \\
\text { K }\end{array}$ & $\begin{array}{c}\text { Maximum } \\
\text { Resistance }\end{array}$ & $\begin{array}{c}\text { Spring } \\
\text { Constant }\end{array}$ & $\begin{array}{l}\text { Dynamic } \\
\text { Reaction }\end{array}$ \\
\hline \multirow{2}{*}{$\begin{array}{l}\text { Simple } \\
\text { Supports }\end{array}$} & Elastic & 0.46 & 0.30 & 0.65 & $18.8 \mathrm{M}_{\mathrm{pc}}$ & $216 \mathrm{EI} / \mathrm{a}^{2}$ & $0.28 F+0.72 R$ \\
\hline & Plastic & 0.33 & 0.17 & 0.52 & $18.8 \mathrm{M}_{\mathrm{pc}}$ & 0 & $0.36 \mathrm{~F}+0.64 \mathrm{R}_{\mathrm{m}}$ \\
\hline \multirow{3}{*}{$\begin{array}{l}\text { Fixed } \\
\text { Supports }\end{array}$} & Elastic & 0.33 & 0.20 & 0.61 & $25.1 \mathrm{M}_{\mathrm{ps}}$ & $880 \mathrm{EI} / \mathrm{a}^{2}$ & $0.40 F+0.60 R$ \\
\hline & $\begin{array}{l}\text { Elasto- } \\
\text { Plastic }\end{array}$ & 0.46 & 0.30 & 0.65 & $18.8\left(M_{p c}+M_{p s}\right)$ & $216 \mathrm{EI} / \mathrm{a}^{2}$ & $0.28 F+0.72 R$ \\
\hline & Plast 1c & 0.33 & 0.17 & 0.52 & $18.8\left(M_{p c}+M_{p s}\right)$ & 0 & $0.36 \mathrm{~F}+0.64 \mathrm{R}_{\mathrm{m}}$ \\
\hline
\end{tabular}

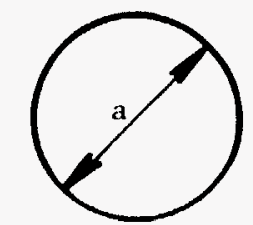

Simple Supports

Appendix C - Transformation Factors for Beams and Plates 


\section{Table C9. Explanation of Terms}

$\mathrm{M}_{\mathrm{p}} \quad=\quad$ fully plastic moment $=\alpha_{\mathrm{y}} \mathrm{Z}_{\mathrm{p}}$

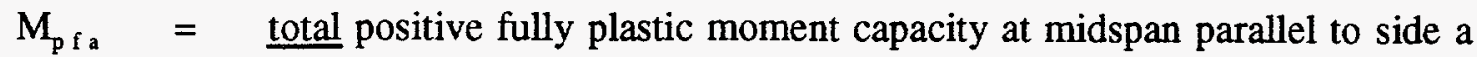

$\mathrm{M}_{\mathrm{psa}} \quad=\quad$ total negative fully plastic moment capacity alongside $\mathrm{a}$

$\mathrm{M}_{\mathrm{psb}}=$ unit negative fully plastic moment capacity alongside $\mathrm{b}$

$\mathrm{I}_{\mathrm{a}} \quad=\quad$ unit area moment of inertia for section cut parallel to side $\mathrm{b}$

$=\quad \frac{1}{12} t^{3}$ for homogeneous section

$\mathrm{Z}_{\mathrm{p}} \quad=\quad$ plastic section modulus

$=\frac{1}{4} b t^{2}$ for a rectangular section 


\section{Appendix D. THOR Equations}

\section{Penetration in Miscellaneous Materials}

The equations that are presented in this section have been constructed empirically. They are based on the assumption that the resistance of a material to perforation by steel fragments can be related to the losses in weight and velocity sustained by the fragment during penetration. The data base used in developing these equations was limited to cases where perforation was achieved, and the residual velocity and residual weight were recorded. These measurements refer to the largest piece of original fragment which perforates the target material.

The empirical THOR equations, based on a large series of tests performed over 30 years ago, were presented for metallic target materials in 1961 (Reference 14) and for nonmetallic materials in 1963. The most extensively used of the THOR equations are those for ballistic limit velocity, residual velocity, and residual mass. The ballistic limit velocity, $\mathrm{V}_{\mathrm{i}}$, is the minimum velocity that a fragment must have to perforate a target plate of given material and thickness. The THOR equation given for ballistic velocity is as follows:

$$
V_{l}=10^{C_{1}}(h A)^{\alpha_{1}}\left(7000 W_{s}\right)^{\beta_{1}}(\sec \theta)^{\gamma_{1}}
$$

$$
\text { where } \quad \begin{aligned}
\mathrm{V}_{l} & =\text { ballistic limit velocity (ft/sec) } \\
\mathrm{h} & =\text { target plate thickness (inches) } \\
\mathrm{A} & =\text { average impact area of the fragment }\left(\mathrm{in}^{2}\right) \\
\mathrm{W}_{\mathrm{s}}= & \text { weight of the original fragment }(\mathrm{lb}) \\
\theta= & \text { angle between the trajectory of the fragment and the normal to the target } \\
\mathrm{C}_{1}, \alpha_{1}, \beta_{1}, \gamma_{1}= & \text { empirical constants which are dependent on the plate material to be perforated } \\
& \text { (see Table D1) }
\end{aligned}
$$

The THOR equation for residual velocity is

$$
V_{r}=V_{s}-10^{c}(h A)^{\alpha}\left(7000 W_{s}\right)^{\beta}(\sec \theta)^{\gamma} V_{s}^{\lambda}
$$

where $\quad V_{r}=$ residual velocity of the fragment $(\mathrm{ft} / \mathrm{sec})$ after perforation of the target occurs

$\mathrm{V}_{\mathrm{s}}=$ initial velocity of the fragment before perforating the target $(\mathrm{ft} / \mathrm{sec})$

$\mathrm{t}, \mathrm{A}, \mathrm{W}_{s}, \theta=$ parameters given above

$c, \alpha, \beta, \gamma, \lambda=$ empirical constants similar to those defined for ballistic limit velocity (see 
The THOR equation for residual weight is

$$
\left(7000 W_{r}\right)=\left(7000 W_{s}\right)-10^{C_{2}}(H A)^{\alpha_{2}}\left(7000 W_{s}\right)^{\beta_{2}}(\sec \theta)^{\gamma_{2}} V_{s}^{\lambda_{2}}
$$

where $\left(7000 \mathrm{~W}_{\mathrm{r}}\right)=$ residual weight of the largest piece of fragment (grains) after perforation of the target occurs

$\mathrm{t}, \mathrm{A}, \mathrm{W}_{\mathrm{s}}, \theta, \mathrm{V}_{\mathrm{s}}=$ parameters given above

$C_{2}, \alpha_{2}, \beta_{2}, \gamma_{2}=$ empirical constants similar to those defined for ballistic and residual velocity (see Table D1)

The values of the constants in Equations (D.1), (D.2), and (D.3) are given in Table D1. The ranges of variables for each material is given in Table D2. The constants which appear in Table D1 are for no particular fragment shape. 
Table D1. THOR Constants

\begin{tabular}{|c|c|c|c|c|c|c|c|c|c|c|c|c|c|c|}
\hline & C & $\alpha$ & $\beta$ & $\boldsymbol{x}$ & $\lambda$ & $C_{1}$ & $\alpha_{1}$ & $\beta_{1}$ & $\underline{x}_{1}$ & $\mathrm{C}_{2}$ & $\alpha_{2}$ & $\boldsymbol{B}_{2}$ & $\gamma_{2}$ & $\lambda_{2}$ \\
\hline Magnesium & 6.904 & 1.092 & -1.170 & 1.050 & -0.087 & 6.349 & 1.004 & -1.076 & 0.966 & -5.945 & 0.285 & 0.803 & -0.172 & 1.519 \\
\hline $\begin{array}{l}\text { Aluminum } \\
(2024 \mathrm{~T}-3)\end{array}$ & 7.047 & 1.029 & -1.072 & 1.251 & -0.139 & 6.185 & 0.903 & -0.941 & 1.098 & -6.663 & 0.227 & 0.694 & -0.361 & 1.901 \\
\hline Cast Iron & 4.840 & 1.042 & -1.051 & 1.028 & 0.523 & 10.153 & 2.186 & -2.204 & 2.156 & -9.703 & 0.162 & 0.673 & 2.091 & 2.710 \\
\hline Titanium & 6.292 & 1.103 & -1.095 & 1.369 & 0.167 & 7.552 & 1.325 & -1.314 & 1.643 & -2.318 & 1.086 & 0.748 & 1.327 & 0.459 \\
\hline Face Hard. Steel & 4.356 & 0.674 & -0.791 & 0.989 & 0.434 & 7.694 & 1.191 & -1.397 & 1.747 & -1.195 & 0.234 & 0.744 & 0.469 & 0.483 \\
\hline $\begin{array}{l}\text { Mild Homog. } \\
\text { Steel }\end{array}$ & 6.399 & 0.889 & -0.945 & 1.262 & 0.019 & 6.523 & 0.906 & -0.963 & 1.286 & -2.507 & 0.138 & 0.835 & 0.143 & 0.761 \\
\hline $\begin{array}{l}\text { Hard Homog. } \\
\text { Steel }\end{array}$ & 6.475 & 0.889 & -0.945 & 1.262 & 0.019 & 6.601 & 0.906 & -0.963 & 1.286 & -2.264 & 0.346 & 0.629 & 0.327 & 0.880 \\
\hline Copper & 2.785 & 0.678 & -0.730 & 0.846 & 0.802 & 14.065 & 3.476 & -3.687 & 4.270 & -5.489 & 0.340 & 0.568 & 1.422 & 1.650 \\
\hline Lead & 1.999 & 0.499 & -0.502 & 0.655 & 0.818 & 10.955 & 2.735 & -2.753 & 3.590 & -1.856 & 0.506 & 0.350 & 0.777 & 0.934 \\
\hline Tuballoy & 2.537 & 0.583 & -0.603 & 0.865 & 0.828 & 14.773 & 3.393 & -3.510 & 5.037 & -3.379 & 0.560 & 0.447 & 0.640 & 1.381 \\
\hline Unbonded Nylon & 5.816 & 0.835 & -0.654 & 0.990 & -0.162 & 5.006 & 0.719 & -0.563 & -.852 & -7.538 & -0.067 & 0.903 & -0.351 & 1.717 \\
\hline Bonded Nylon & 4.672 & 1.144 & -0.968 & 0.743 & 0.392 & 7.689 & 1.883 & -1.593 & 1.222 & -13.601 & 0.035 & 0.775 & 0.045 & 3.451 \\
\hline Lexan & 2.908 & 0.720 & -0.657 & 0.773 & 0.603 & 7.329 & 1.814 & -1.652 & 1.948 & -6.275 & 0.480 & 0.465 & 1.171 & 1.765 \\
\hline Plexiglas as Cast & 5.243 & 1.044 & -1.035 & 1.073 & 0.242 & 6.913 & 1.377 & -1.364 & 1.415 & -2.342 & 1.402 & -0.137 & 0.674 & 1.324 \\
\hline $\begin{array}{l}\text { Stretched } \\
\text { Plexiglas } \\
\end{array}$ & 3.605 & 1.112 & -0.903 & 0.715 & 0.686 & 11.468 & 3.537 & -2.871 & 2.274 & -5.344 & 0.437 & 0.169 & 0.620 & 1.683 \\
\hline Doron & 7.600 & 1.021 & -1.014 & 0.917 & -0.362 & 5.581 & 0.750 & -0.745 & 0.673 & -10.404 & 0.215 & 0.343 & 0.706 & 2.906 \\
\hline $\begin{array}{l}\text { Bullet Resistant } \\
\text { Glass }\end{array}$ & 3.743 & 0.705 & -0.723 & 0.690 & 0.465 & 6.991 & 1.316 & -1.351 & 1.289 & -5.926 & 0.305 & 0.429 & 0.747 & 1.819 \\
\hline
\end{tabular}


Table D2. Range of Variables in Equations (D.1) (D.2) (D.3)

\begin{tabular}{|c|c|c|c|c|c|}
\hline Target Material & $\begin{array}{c}\text { Target Thickness } \\
\text { Range } \\
\text { h } \\
\text { (in) } \\
\end{array}$ & $\begin{array}{c}\text { Areal Density } \\
\text { Range } \\
\mathbf{w} \\
\left(\mathbf{l b} / \mathbf{f t}^{2}\right) \\
\end{array}$ & $\begin{array}{c}\text { Obliquity } \\
\text { Range } \\
\theta \\
\text { (degrees) } \\
\end{array}$ & $\begin{array}{c}\text { Striking } \\
\text { Velocity Range } \\
\mathbf{V}_{s} \\
\text { (fps) } \\
\end{array}$ & $\begin{array}{c}\text { Fragment Size } \\
\text { Range } \\
\mathbf{w}_{s} \\
\text { (grains) } \\
\end{array}$ \\
\hline $\begin{array}{l}\text { Magnesium } \\
\text { Alloys }\end{array}$ & $0.05-3.00$ & $0.5-28$ & $0-80$ & $500-10500$ & $1.5 \times 10^{1}-2.40 \times 10^{2}$ \\
\hline $\begin{array}{l}\text { Aluminum } \\
(2024-T 3)\end{array}$ & $0.02-2.00$ & $0.3-29$ & $0-80$ & $1200-11000$ & $5.0 \times 10^{0}-2.40 \times 10^{2}$ \\
\hline Titanium Alloys & $0.04-1.20$ & $1.0-28$ & $0-80$ & $700-10400$ & $3.0 \times 10^{1}-2.40 \times 10^{2}$ \\
\hline Cast Iron & $0.19-0.56$ & $7.0-21$ & $0-45$ & $1099-6100$ & $1.5 \times 10^{1}-2.40 \times 10^{2}$ \\
\hline $\begin{array}{l}\text { Face-Hardened } \\
\text { Steel }\end{array}$ & $0.14-0.50$ & $5.0-20$ & $0-70$ & $2500-9800$ & $1.5 \times 10^{1}$ \\
\hline $\begin{array}{l}\text { Homogeneous } \\
\text { Steel }\end{array}$ & $0.03-1.00$ & $1.0-40$ & $0-70$ & $600-12000$ & $5.0 \times 10^{0}-8.25 \times 10^{2}$ \\
\hline Copper & $0.06-1.00$ & $3.0-46$ & $0-70$ & $1100-11400$ & $1.5 \times 10^{1}-2 . \overline{40} \times 10^{2}$ \\
\hline Lead & $0.07-1.00$ & $4.0-57$ & $0-70$ & $500-10400$ & $1.5 \times 10^{1}-2.40 \times 10^{2}$ \\
\hline Tuballoy & $0.10-0.20$ & $10-19$ & $0-60$ & $4500-10100$ & $3.0 \times 10^{1}-4.75 \times 10^{2}$ \\
\hline Unbonded Nylon & $0.02-3.0$ & $0.1-12.5$ & $0-70$ & $300-10000$ & $7.14 \times 10^{-4}-3.43 \times 10^{-2}$ \\
\hline Bonded Nylon & $0.43-2.0$ & $2.1-9.7$ & $0-70$ & $1000-12000$ & $7.14 \times 10^{-4}-1.18 \times 10^{-1}$ \\
\hline Lexan & $0.125-1.0$ & $0.8-6.2$ & $0-70$ & $1000-11500$ & $7.14 \times 10^{-4}-3.43 \times 10^{-2}$ \\
\hline Plexiglas as Cast & $0.20-1.1$ & $1.2-6.7$ & $0-70$ & $200-9500$ & $7.14 \times 10^{-4}-6.79 \times 10^{-2}$ \\
\hline $\begin{array}{l}\text { Stretched } \\
\text { Plexiglas } \\
\end{array}$ & $0.05-1.0$ & $0.3-6.4$ & $0-70$ & $500-11000$ & $7.14 \times 10^{-4}-6.79 \times 10^{-2}$ \\
\hline Doron & $0.05-1.5$ & $0.5-15.6$ & $0-70$ & $500-11000$ & $3.57 \times 10^{-4}-8.57 \times 10^{-2}$ \\
\hline $\begin{array}{l}\text { Bullet-Resistant } \\
\text { Glass }\end{array}$ & $0.20-1.65$ & $2.6-21.2$ & $0-70$ & $200-10000$ & $2.14 \times 10^{-3}-6.79 \times 10^{-2}$ \\
\hline
\end{tabular}




\section{Distribution:}

20 Southwest Research Institute

Attn.: $\quad$ K. A. Marchand

P. A. Cox

M. A. Polcyn

P.O. Drawer 28510

San Antonio, TX 78228-0510

1 MS0819 J. S. Peery, 1431

1 MS0327 R. F. LeBlanc, 2654

1 MS0327 $\quad$ W. W. Tarbell, 2654

1 MS0635 E. A. Disch, 12365

5 MS0635 G. A. Wymer, 12365

1 MS0636 R. M. Oelsner, 12367

1 MS0636 $\quad$ J. D. Huttenhow, 12367

5 MS0636 J. R. Kannolt, 12367

$5 \quad$ MS0636 $\quad$ K. W. Snyder, 12367

1 MS9018 Central Technical Files, 8523-2

5 MS0899 Technical Library, 13414

1 MS0619 Technical Publications, 12613

2 MS0100 Document Processing, 7613-2

For DOE/OSTI 